\title{
La evolución de los recintos urbanos amu- rallados castellano-leoneses a lo largo del siglo XII
}

\author{
The evolution of urban walls in Castilla-León troughout I 2th century
}

\author{
Antonio Malalana Ureña *
}

\begin{abstract}
RESUMEN
Tras la capitulación de Toledo (1085) los reyes castellano-leoneses impulsaron la construcción de murallas urbanas, principalmente en la Extremadura y en la Transierra. Durante el siglo XII varios enclaves fronterizos se transformaron en ciudades fortaleza. Uno de los principales promotores de esta política fue Alfonso VII, quien diseñó una estrategia para defender el reino frente a los almorávides. Esta idea tuvo su continuación, de manera separada, por Fernando II y Alfonso IX en León y por Alfonso VIII en Castilla. La tardanza en levantar los grandes perímetros amurallados significaría que las cercas se iniciasen como románicas y terminasen adaptándose al gótico o al mudéjar.
\end{abstract}

Palabras clave: Ciudades fortaleza. Murallas urbanas. Castilla. León. Siglo XII.

A lo largo de las siguientes páginas se pretende analizar el origen de las murallas urbanas castellano leonesas erigidas en uno de los momentos más delicados en la estabilidad política de estos reinos. En la misma línea se sitúa el estudio de los estilos arquitectónicos, así como las técnicas edilicias empleadas. Todo ello encaminado a establecer la siguiente hipótesis: existe un patrón, un mismo modelo, con el que se levantaron numerosos recintos urbanos, tanto en la Extremadura, como en la Transierra o en otros lugares al norte del Duero.

\begin{abstract}
After the capitulations of Toledo (1085) the kings of Castile and Leon stimulated the construction of urban walls, mainly in the Estremadura and in the Transierra. During the 12th century several frontier sites were transformed in fortified cities. One of the principal promoters of this politics was Alfonso VII, who designed a strategy to defend the kingdom against the Almoravids. This idea had his continuation, in a separated way, by Fernando II and Alfonso IX in León and Alfonso VIII in Castile. The lateness in raising the big walled perimeters would lead to the fences being initiated in Romanesque style and concluded in Gothic or Mudéjar style.
\end{abstract}

Key Words: Fortified towns. Urban walls. Castilla. León. 12th century.

El marco histórico se corresponde con una época muy convulsa. Durante largos años Castilla y León se enfrentan a una etapa política y territorial inestable, periodo que comienza inmediatamente después de la capitulación de Toledo (1085) y que se prolongará durante decenios hasta la victoria definitiva de las Navas (I2I2). El marco geográfico es tremendamente amplio. El espacio territorial se extiende a ambos lados del Sistema Central, ya que la política de construcción de murallas no estaría circunscrita sólo a la primera línea de

* Universidad CEU San Pablo 
frontera, sino que también incumbió a numerosos enclaves, algunos situados en el Duero. Esto es comprensible por la propia evolución política de León y Castilla, cuando Alfonso VII, al morir, dejaba una difícil herencia al repartir el reino entre sus hijos. Esta decisión introdujo una nueva variable en el complejo sistema político peninsular, ya que desde ese instante las fronteras se multiplican, al igual que los enfrentamientos militares.

Desde el año 1085 hasta la muerte de Alfonso VII, salvando el periodo protagonizado por doña Urraca y Alfonso I, el Batallador, la defensa del reino tiene una organización en ejes horizontales formados por el Tajo, el Sistema Central y el Duero. Esto quiere decir que la protección del territorio no descansa sobre la vanguardia que gira en torno a Toledo, sino que necesita de la participación de todo el reino, principalmente de aquellas ciudades repobladas a la sombra de la Sierra, como Salamanca, Ávila, Segovia, Sepúlveda, Ayllón, Soria, etc. En palabras de L.M. Villar García sería un sistema defensivo en profundidad (VILLAR GARCíA, 1986: p. 94). Con la muerte del emperador y la separación del reino cobran mayor importancia las fronteras verticales, líneas que recorren de norte a sur los territorios. Este hecho no es nuevo, pues, siempre se tuvo en cuenta las fronteras orientales con Navarra y Aragón, pero sí es determinante ya que tiene una notable influencia en Tierra de Campos, zona de litigio entre Castilla y León.

\section{I.CONQUISTA Y COLONIZACIÓN}

\section{I.I.El encuadre político}

Alfonso VI, en el año 1085, tras la capitulación de Toledo recibiría, de manera pactada, la taifa toledana, un vasto territorio cuya mayor parte se extendía entre el Sistema Central y el Tajo. Entre los enclaves entregados aparecen poblaciones de cierta relevancia, como Talavera, Maqueda, Santa Olalla, Alamín, Escalona, Madrid, Canales, Olmos, Talamanca, Uceda, Guadalajara, Hita, Buitrago, Calatalifa, Uclés, Berlanga, etc. (XIMENEZ DE RADA, 1985: pp. 85 y 136. PELAYO
DE OVIEDO, 19|3: p. 328). El control militar de todos los distritos del reino de Ibn Di-I-Nun entre Guadalajara y Talavera es inmediato (IBN AL-KARDABUS, 1993: pp. 108-1 12). A la incorporación de todo un extenso territorio al sur del Sistema Central habría que añadir el impacto psicológico que supuso la anexión de la ciudad de Toledo, capital del reino visigodo y uno de los centros urbanos, junto a Córdoba, Mérida - Zaragoza, más importantes de la España hispanomusulmana: ahora estaba en manos cristianas, un duro golpe para el Islam. Los imperios almorávides y almohades tendrán como objetivo recobrar Toledo.

A partir de ahora la frontera de los reinos cristianos se desplaza desde la Sierra hacia el Tajo, curso fluvial que, a priori, parece convertirse en una raya fronteriza que puede frenar a los musulmanes. Sin embargo, no podemos entender que esta línea fuese una frontera real, en todo caso se trataba de una línea de defensa natural, dentro de un complejo sistema, que concernía a un amplio territorio, la Extremadura y la Transierra. Así se entiende que muchos puntos, como por ejemplo Madrid, que aunque estaba enclavado a relativa distancia del Tajo, durante algo más de un siglo fue lugar de frontera (VALDEÓN BARUQUE, 1991: p. 78. 1993: p. 18). A este sustantivo Francisco García Fitz le ha añadido el calificativo "caliente", concepto por el que entiende la realidad fronteriza, "[...] una forma esencialmente marcada por la crudeza, gravedad y continuidad de la actividad bélica" (GARCÍA FITZ, 200 I: pp. 159-160). En definitiva una posición avanzada en ambiente hostil (MARTíNEZ SOPENA, 2002: p. 20).

No nos equivoquemos, la guerra no fue un enfrentamiento exclusivo entre cristianos y musulmanes. No debemos olvidarnos de la propia inercia fronteriza entre el reino castellano leonés con respecto a Navarra y Aragón. Estos episodios de luchas entre cristianos se intensificarían tras la muerte de Alfonso VII, quién al repartir el reino entre sus hijos, fijó una nueva frontera, línea que sería causa de continuos conflictos entre castellanos y leoneses hasta la definitiva reunificación con Fernando III, el Santo. 
Tras el encuentro de Zalaca, al norte de Badajoz, se crearían las condiciones que dominaron la política peninsular en los siguientes treinta años, en donde el objetivo principal seráToledo: los almorávides querían recobrar la ciudad, mientras que los cristianos debían conservar sus posiciones a toda costa (REILLY, 1992: p. 103). El sultán, Yūsuf b. Tāšufin, prepararía varias incursiones en territorio cristiano. Entre los años 1090 y 1 I 07, las más importantes tenían como objetivo, como ya se ha señalado, la recuperación de Toledo, aunque a lo largo de toda la frontera peninsular el enfrentamiento bélico y la estrategia política fueron constantes.

En la primera de las incursiones lanzada, en el verano de 1090, hacia el centro, Yūsuf sitiaría la ciudad, asolando toda la comarca de su contorno. Finalmente el cerco fue levantado. Años más tarde, en el verano de 1097, Yūsuf cruza el Estrecho por cuarta vez. Nuevamente el objetivo era la capital del reino toledano, aunque la expedición nunca llegaría hasta sus puertas. En I099, otra vez, Toledo fue sitiada y la comarca asolada. En el otoño del siguiente año, I l 00, ahora con los ejércitos comandados por Yahyà b. Abū Bakr, los almorávides volvieron a poner cerco a la ciudad, regresando a su punto de origen con un gran botín (GONZÁLEZ, 1975: t. l, pp. 86-94).

En I I08, Tamīm, hermano del nuevo sultán 'Alī b.Yūsuf, infligiría una severa derrota a Alfonso $\mathrm{Vl}$, el desastre de Uclés, provocando el desmoronamiento de la frontera. Entre las graves consecuencias, además de la muerte de Sancho Alfónzez, único hijo varón de Alfonso VI y el heredero al trono, se encuentra la evacuación de casi todas las plazas al sur del Tajo (MÍNGUEZ, 1994: p. 229. PÉREZ DETUDELA, 2005: p. 49); se había perdido toda la margen izquierda entre Aranjuez y Zorita, más la caída de Alcalá.

Tras la muerte de Alfonso VI, los almorávides atraviesan por enésima vez el Estrecho, iniciando una larga campaña que comienza en el verano de I 109. Se preparan para "[...] asaltar tanto la ciudad de Toledo, [...] como otras plazas fuertes y ciudades que estaban en la Transierra". Ante la fuerte resistencia presentada por los toledanos y con numerosas bajas, los ejércitos musulmanes abandonaron el sitio, no sin destruir todo lo que encontraron a su paso, asaltando ciudades y castillos.

"Entonces destruyó las murallas de Madrid, de Talavera, de Álamo, de Canales [...] e hizo gran número de prisioneros, matanzas y botines. Pero las torres más fortificadas de las ciudades mencionadas, que en nuestra lengua se llaman alcázares no fueron tomadas y en ellas permanecieron muchos cristianos supervivientes" (PÉREZ GONZÁLEZ, 1997: pp. 95-97).

Uno de los desastres de esta incursión fue la ocupación al asalto de Talavera (IBN 'IDARI AL-MARRAKUSI, 1963: pp. 122-124). Así mismo, si tomásemos en serio los textos de Ibn Abi Zar', también fueron ocupados otros castillos, como los de Madrid y Guadalajara (IBN ABI ZAR', 1964: pp. 3|3-3|4).

El imperio almorávide había obligado a leoneses y castellanos a replegarse a posiciones al norte del Tajo. La situación se agravaría con la muerte de Alfonso VI, desaparición que acarreó una grave crisis sucesoria. La toma del poder por doña Urraca, su matrimonio con Alfonso I, el Batallador, dio lugar a serios enfrentamientos civiles que debilitarían considerablemente el reino. Para León y Castilla llegaron malos tiempos, con luchas, despoblación y anarquía (GONZÁLEZ, 1974: p. 287).

El reino de Toledo "[...] quedó muy maltratado y desasistido" (GONZÁLEZ, 1974: t. I, pp. 97-102). Durante un largo periodo los almorávides conseguirían mantener una insoportable presión casi hasta I I 8. Por ejemplo, en I I I3, los musulmanes sitiaron Berlanga (GONZÁLEZ, 1974: p. 287). Estas campañas, entre otras consecuencias, provocaron que el asentamiento de los nuevos pobladores cristianos fuese lento e incluso que se abandonasen las tierras recientemente colonizadas.

Las continuas incursiones almorávides de mediados y finales de la década de los veinte sometieron a duros ataques toda la frontera, acciones que no se toparían con ninguna oposición de los "poderes centrales castellanoleoneses" (GARCíA FITZ, 2002, p. 80). En I I 26 los 
cristianos eran derrotados, otra vez, cerca de Uclés. Una nueva cabalgada se acercaba por tierras toledanas con la captura de su correspondiente botín (IBN 'IDARI AL-MARRAKUSI, 1963: pp. 169-170). Los ataques se repitieron en II 28 (IBN 'IDARI AL-MARRAKUSI, 1963: pp. 186-187) y en | | 30. En esta última incursión, comandada por Tāšufin b. 'Alī, futuro emir, el castillo de Aceca, que acaba de ser colonizado, fue destruido (PÉREZ GONZÁLEZ, 1997: pp. 99-100).

Así mismo, además de la exigencia por contener las envestidas que llegan desde el sur, Castilla y León, tras la muerte de Alfonso VI, entra en un periodo oscuro de enfrentamiento civil. En este instante emerge la figura de Alfonso I el Batallador, quién llega a controlar extensos territorios a lo largo de la frontera con Aragón, como en La Rioja y en tierras sorianas (LEMA PUEYO, 2008: pp. 302-304).

A principios de 1 126, y tras la muerte de la reina doña Urraca, Alfonso VII era entronizado en León. A partir de este instante se pone en marcha una nueva reorganización de fuerzas entre los reinos peninsulares. Las zonas calientes se centrarán en los territorios fronterizos castellanos con Aragón y Navarra y las zonas de vanguardia frente al Islam. Con respecto a los primeros los enclaves el Duero son especialmente sensibles. Lugares como Soria, San Esteban de Gormaz, Berlanga de Duero y Almazán están en poder de Alfonso I el Batallador, situación que quedaba revalidada tras la firma del Tratado de Támara en I 127. La repoblación de cada uno de estos puntos es obra del rey aragonés. Soria lo sería después de I | 19, y Almazán comienza a colonizase alrededor de | |28, data que también se considera para Berlanga. De hecho parece que Almazán podría haberse constituido como un punto estratégico para todo la región, status que se confirmaría con la noticia de la construcción de un cinturón fortificado para proteger la nueva población (LEMA PUEYO, 2008: p. 225). Sin embargo, con la muerte del Batallador, en I I34, de manera paulatina y a lo largo de I I 35 Alfonso VII conseguiría reintegrar casi la totalidad de los dominios que habían pertenecido a su abuelo Alfonso VI (RECUERO ASTRAY, 1979: p. 129).
Frente al Islam, a lo largo de los primeros años del reinado de Alfonso VII, pese al menor empuje almorávide, no se consigue dar estabilidad a la frontera, los choques continúan año tras año (PÉREZ GONZÁLEZ, 1997: pp. 137-140). Por ejemplo, en | |3 | una concentración de tropas musulmanes procedentes de varios puntos cayó sobre Alamín (PÉREZ GONZÁLEZ, 1997: p. 100).

En diciembre de I |34, Alfonso VII se proclama "imperator Hispaniorum", siendo coronado emperador al año siguiente, potestad que le permite, no solo consolidar su posición interior sino también fortalecer su situación frente a los almorávides que, aún debilitados, siguen hostigando la frontera del Tajo.

Entre | | 36- | | 37 le tocó el turno a Escalona, en donde Tasfín, encabezando una expedición, entró en la ciudad "[...] y no dejó vivo a ningún hombre". Según las crónicas árabes, las campanas de este enclave, junto al botín dieron lugar a un gran desfile en Córdoba, llevándose alrededor de 6.000 cautivos a Marruecos (IBN ABI ZAR', 1964: pp. 321-322). Si bien, los cronistas cristianos minimizan en parte lo sucedido: "Post annos vero aliquot, rex Azuel Cordubae et Abenzeta rex Sibiliae et coeteri reges et principes [...] rursus venerunt in civitatibus Toletanis et fecerunt multas strages et multa mala in Ascalona et in Alfamin et acceperunt castellum quod dicitur Mora" (PÉREZ GONZÁLEZ, 1997: p. 100-101. GONZÁLEZ, 1975: t. I, p. 139).

Pese a los contratiempos, con paso firme, Alfonso VII comienza el avance hacia el sur. En I | 39, recupera la vital posición de Oreja, hecho que le permitiría reconquistar los territorios ocupados por los almorávides en los valles del Henares y del Tajuña. En el año I |46, la línea había avanzado hasta Calatrava. La nueva situación coincide con el deterioro del poder almorávide y la llegada de las segundas taifas (MÍNGUEZ, 1994: pp. 27I-278). A partir de esta fecha entran los almohades en la Península.

A la muerte de Alfonso VII, en I|57, el reino castellano-leonés vuelve a dividirse: Fernando II hereda León y Sancho III Castilla. La repentina muerte de este último permitió el acceso al trono, en I I58, de Alfonso VIII. En 
I | 88, Alfonso IX sucedía a su padre como rey de León y Galicia.

La frontera entre León y Castilla fue fijada por Alfonso VII de una manera arbitraría, beneficiando claramente los intereses castellanos (GONZÁLEZ, 1960: t. l, p. 665). El pedazo más importante, el núcleo que rompería el equilibrio y que sería causa de litigios y guerras con León, se centra en Tierra de Campos. Esta arbitrariedad se nota incluso en la forma de trazar los límites. La divisoria, de Norte a Sur, se fija con el río Deva, los Picos de Europa y el cauce del Cea hasta un poco más allá de Sahagún. A partir de aquí, el rey traza una línea recta que llega hasta el Duero, cerca de Cubillas. En la Extremadura, hasta la Sierra, quedan para Castilla, Medina del Campo, Arévalo y Ávila. Desde el Sistema Central, tanto en la Transierra, como hasta los futuros territorios conquistados a los musulmanes, la calzada de la Guinea serviría como línea divisoria. Quedaran en el lado castellano lugares como: Saldaña, Carrión, Cea - Sahagún; en Tierra de Campos, Moral de la Reina,Tordehumos, Urueña y Cubillas (XIMÉNEZ DE RADA, 1985: pp. 153-154).

El reinado de Alfonso VIII es uno de los más determinantes, tanto para la historia de Castilla, como para la de España. En su trayectoria como gobernante, fue protagonista de dos sucesos capitales, ambos relacionados con la guerra, que marcan un antes y un después en el avance militar hacia el sur: estamos hablando de las batallas de Alarcos (1195) y de Las Navas de Tolosa (12 I2), encuentros de muy distinto signo, pero ciertamente transcendentales para toda una región que se extendía desde el Sistema Central hasta el Tajo.

En León, los reinados de Fernando II y Alfonso IX tendrían como fijación el litigio con Castilla porTierra de Campos, pero sobre todo, afianzar la Extremadura y seguir arrebatando tierras a los musulmanes.

La situación ni mucho menos era estable, ni tranquila para los habitantes de la frontera, de cualquier frontera. En otoño de I I 74, una expedición almohade conquista Alcántara y asedia Ciudad Rodrigo (IBN 'IDARI AL-MARRAKUSI, 1953: t. I, pp. 15-16); mientas que en Castilla intentan tomar infructuosamente Huete.

Habrá un periodo de cierta tranquilidad, en donde todos los reinos se centran en pacificar las contiendas con sus vecinos hermanos de religión. Las treguas de 1 I 73 y I I 74 permitieron a Alfonso VIII fortalecer sus fronteras. Para ello utilizaría las Órdenes Militares. Entre II 74 y 1176 distintos territorios pasaron a manos de los monjes guerreros: Uclés para la Orden de Santiago, un grupo de castillos y villas de Toledo a la de Alcántara, y otros lugares a la de Calatrava. Colocó a estos contingentes en aquellas zonas en donde eran necesarios, quizá en los puntos calientes de la frontera. Levantando una pantalla, una barrera, contra los musulmanes el reino estaría a resguardo (GARCÍA FITZ, 1998a: p. 194).

Tanta seguridad tenía en su reino, que el rey castellano se lanzó a la conquista de Cuenca. En I 177, cerca la ciudad. Como respuesta, los almohades se apresuran y contraatacan con cabalgadas sobre Toledo y Talavera, lo que obligaría a Alfonso VIII a levantar el cerco (IBN 'IDARI AL-MARRAKUSI, 1953:t. I, pp. 28-29. XIMÉNEZ DE RADA, 1985). La partida de ajedrez jugada entre todos los contendientes acaba de empezar.

Otra vez la tranquilidad se asienta en las fronteras con los reinos orientales y occidentales. En marzo de I| $8 \mid$ castellanos y leoneses habían firmado una nueva paz. Los cristianos fijarán su mirada en el vecino del sur. Aunque, la reacción de estos fue inmediata. En | | 82, los musulmanes respondían con una nueva cabalgada que tendría como objetivo Talavera (IBN 'IDARI AL-MARRAKUSI, 1953: t. I, pp. 49-5I).

Justo antes de Alarcos, Alfonso VIII habría conseguido un frente común entre castellanos, leoneses, navarros y aragoneses para combatir a los almohades. La paz entre los cristianos debería haber permitido derrotar a los musulmanes, pero una equivocada estrategia supuso un estrepitoso contratiempo. Además de la diplomacia, el rey intensifica el esfuerzo de las Ordenes Militares como soporte de su política bélica. Unos meses antes de la batalla, concedía a la Orden de Santiago la villa de Areños en la 
Pernía, justificando este hecho en la necesidad de levantar muros inexpugnables contras los pérfidos sarracenos (GONZÁLEZ, 1960: t. II, pp. 745-747).

La dura derrota de Alarcos significa un fuerte revés para la política monárquica de consolidación del territorio, pero sobre todo implica el derrumbamiento de la frontera castellana. La psicosis de peligro, de indefensión y de miedo se apoderó de todas las poblaciones al sur de la Sierra. Los pobladores se sintieron desprotegidos y muchos de ellos abandonarán sus nuevos hogares y las tierras recién ganadas. Más aún, dos de los aliados, el leones Alfonso IX y el navarro Sancho VII, aprovechado la coyuntura desfavorable para los castellanos, rompiendo la tregua e iniciando las hostilidades en Tierra de Campos y en las regiones sorianas y riojanas. Además, los leoneses, se coordinarán con el emir Abu Yusuf. Tan solo permanece fiel Pedro II de Aragón.

Alfonso VIII estaba consternado y desorientado, y se creía impotente ante el avance almohade. Bajo este estado de ánimo el rey buscó refugio "[...] en los confines de su país [a resguardo tras la Sierra de Gredos], gemía como gime el herido en el corazón, sin que terminasen sus lágrimas ni acabasen sus suspiros" (IBN IDARI AL-MARRAKUSI, 1953-1954: t. I, pp. 193-195). Sin embargo, los cronistas cristianos, utilizando también la propaganda, plantean una retirada táctica a la retaguardia; quizá para replantear una estrategia futura y defender mejor su reino ante el peligro exterior, tanto contra los musulmanes, como del leones Alfonso IX y los navarros (CABANES PECOURT, 1985: p. 28. XIMÉNEZ DE RADA, 1984: p. 17I).

Las Ordenes Militares seguían siendo una extraordinaria herramienta para defender aquellas zonas en donde el poder central no podía llegar, sobre todo en estos momentos de grave crisis del reino, pero fundamentalmente, no sólo por falta de recursos económicos, sino ante la falta de contingentes pobladores que ahora buscaban refugio más al norte, lejos de las zonas de fricción. En marzo de I195, concedía a la Orden de Trujillo, la villa y castillos de Albalat, "[...] situam in ripa Tagi [...]", Santa
Cruz, Cabañas y Zueruela, aportando para su sostenimiento la renta anual de 3.000 áureos de la greda de Magán, y lo hacía por la defensa de los cristianos, ya que los muros estaban indefensos "[...] contra saevitiam paganorum [...]" (GONZÁLEZ, 1960, t. III, pp. |39-14I). La sensación de una frontera desprotegida es real.

Ya fuese una circunstancia u otra, lo que sí es cierto es que los almohades desarrollaron grandes aceifas a partir de ese instante. En 1 196, el califa almohade, Abu Yusuf Ya'qub al-Mansur, partiendo de Sevilla y tomando la calzada de Mérida, comenzó la marcha con su ejército hacia tierras toledanas. Ante el avance, algunos lugares capitularon como Montánchez; otros fueron abandonados, como Trujillo; y otros asaltados y conquistados, como Plasencia; a su paso todo era arrasado, como la región talaverana, asolando Santa Olalla y Escalona (XIMËNEZ DE RADA, 1984: p. 171. HUICI MIRANDA, 1956: pp. 17I-174). Así se narra este episodio en los Anales Toledanos: "Prisio el rey de Marruecos à Montachez, Santa Cruz, è Trugiello, è Placencia, è vinieron porTalavera, è cortaron el Olivar, è Olmos, Santa Olalla, è Escalona, è lidiaron Maqueda è non prisieron, è vinieron cerca Toledo, è cortaron las viñas, è arboles, è duraron y $X$ dias en el mes de Junio, Era MCCXXXV" (PORRES MARTíNCLETO, 1993: p. (6I). Ibn Idari al Marrakusi, en su narración, transmite el terror, el pánico de las gentes: "[...] llegó el miedo a donde no llegaba lo negro de los sables y lo blanco de las espadas y les alcanzó el desarraigo y la emigración por la fuerza" (IBN IDARI AL-MARRAKUSI, 1953-1954: t. I, pp. 193-195). La frontera se venía abajo perdiéndose enclaves estratégicos y el riesgo de despoblación para toda la región era evidente.

En la primavera del año siguiente, en I I97, otra vez, los almohades realizarían una segunda incursión. Su ejército se dirigió nuevamente hacia las tierras toledanas, devastando todo a su paso, como los campos de Talavera, Maqueda y los alrededores de Toledo. En esta ocasión Alfonso VIII se encontraba en Madrid, acompañado de Pedro II, por lo que los norteafricanos se dirigieron hacia esa ciudad (CABANES PECOURT, 1985: p. 29. XIMÉNEZ DE RADA, 1984: p. 171. AL-HIMYARI, 1963, p. 19. PORRES MARTÍN-CLETO, 1993: pp. 163-164). Cuando Ilegó al-Mansur, el 
rey castellano ya no estaba en la ciudad, pues la había abandonado buscando refugio en la cercana sierra de Guadarrama y dejando el mando a Diego López de Haro apoyado por una guarnición de nobles y plebeyos (CABANES PECOURT, 1985: p. 29).

"Cuando llegaron los musulmanes al citado castillo, lo rodearon como rodea el halo a la luna llena y multiplicaron sus invasiones y alabanzas al Altisimo; casi se rompieron las entrañas de las rocas y se agitaron ante su resonancia los huesos de la gente de los sepulcros [...] cuando logró al-Mansur contra el castillo de Madrid más de lo que esperaba en sus designios y deshizo el golpe de sus pisadas los más duros corazones y destrozó a los fugitivos infieles en sus concentraciones de tropas regulares y conoció el infiel que no poseía una hilacha de su poder y que no lograría descubrir lo que Dios disponía que ocurriese, ni marchándose ni cambiando de lugar" (IBN IDARI AL-MARRAKUSI, 1953-1954: t. I, pp. 193-195).

Tras varios días de cerco, al-Mansur levantó a las tropas y siguió su camino hacia tierras conquenses, pasando por Alcalá y Guadalajara.

Tras estas expediciones, en 1 198, antes de regresar a Marruecos, al-Mansur, pactaría una tregua de diez años con Alfonso VIII, periodo aprovechado por el rey para preparar su venganza por la derrota de Alarcos y los sobresaltos ocasionados por los almohades durante tantos años (HUICI MIRANDA, 1956: pp. 181 y 227), pero también para conseguir la estabilidad con los reinos vecinos de León y Navarra, normalización que se alcanzaría entre los años 1206 y 1207.

Un año antes de espirar las treguas, en 1209, el rey castellano, en compañía de su hijo el infante Fernando, rompería las hostilidades. Ahora, las cosas se veían de otra manera. El Papa, Inocencio III, por bula de 22 de febrero de 1211 , encomendaba a los arzobispos de Toledo y a los obispos de Zamora, Tarazona y Coimbra a usar la amenaza divina contra los reyes vecinos de Castilla que hubiesen firmado treguas a no romperlas mientras aquella diri- mía sus disputas con los almohades (MANSILLA REOYO, 1955: pp. 472-473), quienes ya cruzaban el estrecho en mayo.

A pesar del cambio de rumbo, la situación seguía siendo compleja y el peligro se mantenía latente en toda la región. En septiembre de 121 , se perdería el enclave estratégico del castillo de Salvatierra (Ciudad Real); el rey, "[... ] resignado, se volvió a la sierra de San Vicente a Toledo, hallándose por Maqueda y Escalona el día 13 de septiembre, en que su enemigo fechaba regocijado el mensaje del triunfo" (PORRES MARTÍN-CLETO, 1992: p 170-171. GONZÁLEZ, 1960: t. I, p. 995).

Por fin, en julio de 1212 -cuya efemérides será tan importante como la capitulación de Toledo en 1085-,Alfonso VIII conseguía cambiar definitivamente el mapa político peninsular con la gran victoria de Las Navas de Tolosa; ahora se abrirían definitivamente las puertas hacia el sur del Guadiana, mientras que el reino toledano, incluidas las poblaciones de la ultrasierra pasarían a ser definitivamente territorio de interior, ni tan siquiera retaguardia. Es el momento de que los pobladores de estas tierras vivan en paz.

Paralelamente a los avatares y circunstancias bélicas los reyes castellano-leoneses procuraron consolidar las conquistas territoriales con la ocupación y organización del espacio. La capitulación de Toledo desencadena un efecto demográfico demoledor. Gran parte de la población musulmana, a pesar de los términos pactados, emigraría hacia el sur buscando tierra amiga lo que derivaría en el abandono de las ciudades, pero sobre todo de los espacios rurales. Alfonso VI se vería obligado a buscar pobladores que sustituyeran el vacío dejado. Junto a este proceso se inicia en paralelo otro de la misma envergadura, colonizar la Extremadura.

\subsection{La colonización de los territorios. La consolidación de los espacios con- quistados.}

Los cristianos acudieron en oleadas a colonizar todos estos territorios. Entre el Duero y la Sierra, poblaron tierras deshabitadas. Mien- 
tras que entre la Sierra y el Tajo, parece clara la emigración de los musulmanes de manera inmediata a la capitulación, siendo lugares como Madrid y Toledo un fiel reflejo de este abandono masivo (GONZÁLEZ, 1975: II, 26. MIGUEL RODRÍGUEZ, 1989: 18-24; 1990: 312-313. DEDIEU, 1992: p. 47). Entre las causas, según Jean-Pierre Molénat, estarían las exigencias del Corán a los creyentes de no permanecer en territorio infiel (MOLÉNAT, 1998). De hecho, los cristianos llegarán como pobladores de reemplazo, y lo hacen para ocupar tierras y casas vacías (MOXÓ, 1979: p. 221).

Sin embargo, la demografía tendrá sus limitaciones. Junto a los cristianos del norte, buena parte de los contingentes estarían formados por pequeñas comunidades judías que huían de la España musulmana. Después de la expulsión decretada por los almorávides, otros tantos se refugiaron en la Castilla de Alfonso VII. Los almohades, también perseguirín a esta minoría con nuevos decretos de expulsión. El arraigo de los judíos a mediados del siglo Xll era un hecho. Con Alfonso VIII creció la sensación de cobijo, llegando más contingentes, no solo de tierras musulmanas, también de Aragón, Cataluña y Francia. La protección real de los judíos era notable, entre otros aspectos, por el emplazamiento de las juderías dentro de los castillos o junto a una fortaleza, fundamentalmente por necesidades de seguridad y protección (GONZÁLEZ, 1960; t. I, pp. 125-126.). Muchos son los ejemplos, como Toledo ', Cuenca ${ }^{2}$, Madrid $^{3}$, Zorita de los Canes, Burgos, etc. Incluso, en ocasiones, se les cedía la responsabilidad en la defensa común de las ciudades, al custodiar determinados accesos, como ocurrió en Toledo con la puerta del Cambrón.

La utilización de la Iglesia y las Ordenes Militares sigue esta estela. Los monarcas caste- \|lano leoneses cederán bastas regiones a estas instituciones para que las colonicen, pero sobre todo, para que las defiendan.

La Transierra, en donde existía una organización del espacio bien definida, va a ser modificada profundamente. Una de las secuelas inmediatas es el abandono definitivo de ciertas poblaciones musulmanes, como Albalat o Miknasa (MOLÉNAT, 1988. BERNAL ESTÉVEZ, 1998: p. 23). Dentro de las transformaciones debemos incluir el cambio de jerarquía de ciertos enclaves, ya que ante la nueva estrategia territorial, lugares como Madrid, Alcalá o Sigüenza dejarán de ser meros puntos fortificados para transformarse en centros urbanos de importancia (GAUTIERCALCHÉ, 1988: p. 205).

En definitiva, a partir 1085 surgen pequeños, medianos y grandes territorios concejiles; comunidades que evolucionaran, hasta 1212 , marcadas e influenciadas por los vaivenes militares de la frontera: "[...] los cristianos ponen en práctica una nueva forma expansiva brillante, con la ocupación de territorios densa y permanentemente habitados y con la expugnación de ciudades vivas e incluso populosas" (MOXÓ, 1979: p. 20I).

Ante el reducido volumen de los contingente, junto a la inseguridad de la frontera, la población va a encastillarse (VILLAR GARCíA, 1986: p. I 17. MARTíN VISO, 2000; 2001; 2002). Pocos serán los núcleos que absorban a los nuevos colonos, refugiados tras las murallas. Aquí, en la Transierra, sustituir la populosa ocupación de las zonas rurales alejadas de los castillos, de momento, no será posible.

En las tierras extremaduranas, bajo unas circunstancias parecidas, el proceso poblador también sería lento. Aquí la ocupación se hace

\footnotetext{
I La primera referencia documentada al castillo de los judíos toledanos es de febrero de I I63, cuando el caíd, don Pelayo Petrez, prestaba al judío Isaac ben Abiysef I 70 mizcales de oro. Como garantía, Abiysef empeñó varias propiedades, entre las que se encontraba media casa que poseía pro-indiviso con su hermano David, "[... en el castillo del los judíos, sobre el río Tajo". AHN, Clero, perg., carp. 3036, nº 5 (LEÓN TELLO, 1979: t. II, p. 10).

2 Tras la toma de Cuenca, en I I77, por Alfonso VIII, entre otros contingentes, los judíos encontraron su sitio en el mismo alcázar (ÁLVAREZ DELGADO y LÓPEZ REQUENA, 2002: p. 20)

3 En Madrid varios documentos nombran el Castillo de los Judíos, cuya ubicación podría localizarse dentro de la Almudena o del
} albacar. 
ex novo o sobre pequeños núcleos de población, marginales y ajenos a cualquier poder superior, enquistados durante largos años en antiguos enclaves tardorromanos, visigodos e, incluso, andalusíes. La existencia de "castillos" en Soria, Ávila, Segovia y Sepúlveda, servirán de protección para organizar la colonización y como embrión de la nueva traza de la ciudad (GONZÁLEZ, 1974, pp. 350-352).

Pese a que algunos de los puntos estratégicos, como Sepúlveda, que recibió su fuero, concedido por Alfonso VI, en 1076, y que en San Esteban de Gormaz una de sus iglesias románicas, la de San Miguel, fuese erigida en 108I, la mayor parte de la Extremadura, tardará algunos decenios más en ser poblada eficazmente. Ese momento no llegaría hasta la capitulación de Toledo, en 1085, que por fin, encadenaría otros procesos en las provincias de Soria, Ávila, Segovia y Salamanca ${ }^{4}$. Ahora, con la seguridad de ver a los musulmanes más allá del Tajo, junto a la necesidad de consolidar estos territorios como requisito indiscutible para poder afianzar la anexión de la Transierra y el cauce del Tajo, Alfonso VI se decide a impulsar su colonización. Por mandato del rey, Raimundo de Borgoña, en I088, puebla Segovia y, en I I02, hace lo mismo con Ávila y Salamanca.

Raimundo de Borgoña, con la población de Salamanca, tenía que poner en marcha toda una línea defensiva apoyándose en el curso natural del Tormes, con enclaves como Alba, Ribas, Ledesma y la propia Salamanca, aunque solo pudo consolidar esta última y Alba (GONZÁLEZ, 1943: p. 204). En esta zona, resulta interesante la aparición de Ciudad Rodrigo, lugar fundado por Fernando II, rey de León. Se incentivó además Ledesma, ambos como punto de apoyo frente a Portugal. La fecha fue | | 61, y muy pronto se amuralló Ciudad Rodrigo, cuya dirección recaería en Juan de Cabrera (GONZÁLEZ, 1943: p. 228).

No cabe ninguna duda, de que enclaves como Ávila y Segovia, fueron puntos estratégicos, ya que se colonizaron por razones militares: son ciudades de frontera que tienen encomendada la defensa del territorio (LACARRA, 1963. VILLAR GARCÍA, 1983: p. 94. VALDEÓN BARUQUE, 1993: p. 18). Ávila, protege los puertos del Pico y Arrebatacapas, dos accesos fáciles en la Sierra de Gredos. Segovia, hace lo mismo con la Fuenfría, y Sepúlveda, sobre Somosierra, ambos en la Sierra de Guadarrama. Salamanca, respalda a Coria ante cualquier intento musulmán de flanquear el Sistema Central por la izquierda. Además, Coria junto a Plasencia, se convirtieron en núcleos de distribución y canalización de los colonos que ocuparán Extremadura (CLEMENTE RAMOS Y MONTAÑA CONCHIÑA, 1994: p. 97. MONTAÑA CONCHIÑ̃A, 1997: p. 24). Después, cuando León y Castilla estén separados, Plasencia tendría una doble función, defender esta región tanto de los musulmanes, como de los leoneses. En definitiva, Salamanca, Ávila, Segovia y Sepúlveda, sin dejar fuera a Soria, forman una línea defensiva por detrás de la Sierra, que debería proteger las tierras del Duero; siempre con la circunstancia hipotética de que Toledo volviese a caer en manos musulmanas y la nueva situación restituyese las posiciones anteriores a 1085. Esta fase se inserta como un momento decisivo en el proceso expansivo del reino de León (MÍNGUEZ, 2000, p. 68).

Una de las iniciativas regias para fijar en los nuevos territorios a los colonos fue la concesión de privilegios, principalmente los tributarios, pero sobre todo, textos, los fueros, que pondrían orden a una vida en común dentro de un territorio hostil. Junto a las prerrogativas, las familias necesitaba sentirse a salvo en una frontera convulsa: los nuevos pobladores, ante un peligro latente, residirían en lugares seguros, protegidos por altos y gruesos muros, fundamentalmente dentro de grandes recintos urbanos amurallados.

Para lograrlo, la monarquía inicia, si se puede denominar así, un programa, ejecutado a ambos lados del Sistema Central, que compaginaría la reconstrucción de las viejas murallas, junto a la construcción de nuevos recintos murados;

4 El obispo Pelayo enumera los castillos y ciudades pobladas por Alfonso VI en la Extremadura: Salamanca, Ávila, Coca, Arévalo, Olmedo, Medina, Segovia, Iscar y Cuellar. (PELAYO, 1924: p. 8I). 
igualmente se puso en marcha una reorganización del territorio, fundamentalmente el sistema de defensa, estructura que también incluiría castillos y torres. Lógicamente, en cada sitio, la iniciativa y la puesta en marcha de las obras estaba en manos de los gobiernos locales. Fueron ellos quienes edificaron los recintos, aunque ante ciertas características, por ciertos rasgos comunes, es factible pensar que todos perseguían el mismo objetivo.

\section{EL MODELO DE MURALLA URBA- NA EN LA DEFENSA DE LA FRON- TERA FRENTE A LAS INVASIONES MAGREBÍES}

\section{I.Sistemas de defensa en la fron- tera}

En todo momento estamos manejando el término frontera como un calificativo, no solo para esta etapa histórica, acaso también para un territorio y para aquellas sociedades, la cristiana o la musulmana, que estuvieron sometidas a los avatares de una política de conquista. La propia existencia de la frontera, con un sistema, más o menos, jerarquizado de fortificaciones, junto a su relación con el entorno físico: sierras, puertos, cauces fluviales, vados, red viaria, puentes, etc., nos hace percibir que sí debió existir una estructura. Aunque ésta, en demasiadas ocasiones, no respondiese con eficacia ante las incursiones enemigas (NOVOA y VILLALBA, 2000).

Las ciudades amuralladas, o ciudades fortaleza como las prefieren denominar Leopoldo Torres Balbás ( 1987: p. 100) o el hispanista galo Gautier Dalché (1979: p. 105) se desarrollan siguiendo un patrón, y si esto es así, es porque existe una política de defensa, de crear un sistema que proteja los reinos. La idea de establecer patrones comunes era algo habitual en el gobierno de Alfonso VII. Otra visión interesante es el empuje que daría a la colonización de regiones sensibles en la organización territorial del reino. A este rey se debe el impulso de nuevas villas como Maqueda, Santa Olalla, Escalona, Sigüenza, Mora, Illescas, Ocaña, etc. (IZQUIERDO et al., 2006: p. 270).
Quizá, el mejor ejemplo que demuestra la existencia de sistemas defensivos lo encontramos en el diseñado por Fernando II, aunque es Alfonso IX quien lo ejecuta, a lo largo de la frontera oriental como respuesta a la demarcación fijada por Alfonso VII para separar León y Castilla en dos reinos independientes, y así hacer frente a los reyes castellanos. J. Avelino Gutiérrez ha estudiado en profundidad el sistema defensivo leonés:

"[...] el sistema defensivo que se levanta por uno y otro lado no se reduce a una sola línea de fortificaciones ante la imprecisa divisoria, sino que se fortifica un gran número de lugares de "retaguardia", más retrasados, creando una defensa en profundidad; las construcciones militares que los leoneses levantan entre los montes cantábricos y el Duero se alinean de norte a sur, desde las cabeceras de los ríos Esla y Cea, siguiendo su curso medio, integrando también el curso del Valderaduey en Tierra de Campos, para proseguir por los Montes de Torozos hasta Toro, ya en el Duero".

Asimismo, Alba de Aliste, Castrotorafe, Zamora, Sanabria y otros lugares integran a su vez la defensa de la frontera con Portugal (GUTIÉRREZ GONZÁLEZ, 1988: pp. 182-183. 1989: pp. 165-169. 1995: pp. 149 y 165). Toro y Zamora, asentadas sobre el Duero, aparecen como dos baluartes, tanto hacia oriente, como frente al sur.

El esfuerzo por crear un sistema de fortificaciones en la frontera, llevó a los monarcas leoneses a impulsar la repoblación interior, tarea que perseguía varios objetivos: frenar los intereses castellanos, crear nuevas pueblas de realengo para reorganizar el poblamiento, consolidar el poder real dentro de los territorios y equilibrar una zona dominada por señoríos eclesiásticos y nobiliarios. (MARTÍNEZ SOPENA, 1989: p. I | 8). Un buen ejemplo es el poblamiento de Benavente, cuyo fuero fue otorgado por Fernando || en I 64 (GONZÁLEZ, 1942: pp. 424-426; GONZÁLEZ RODRÍGUEZ, I997a: pp. 105-138).

Toda la cuestión radica en que comprendamos que tipo de frontera existía entre cristianos y musulmanes en aquellos tiempos. J.M $\mathrm{M}^{\mathrm{a}}$. 
Monsalvo Antón tiene una interesante forma de explicarlo:

"Este fue el tipo de frontera que se configuró entonces, una frontera que no era una línea, un limes -como la frontera entre los reinos cristianos, por ejemplo-, sino una tierra abierta, de superficies cambiantes y espacios amplios, precariamente organizada, en peligro crónico, de dominio inestable, en suma, un espacio elástico para colonizar y defender paulatina y progresivamente en un contexto de guerra intermitente. Podríamos llamar a este tipo de espacio de contacto «frontera pionera», para distinguirlo de otros tipos de frontera" (MONSALVO ANTÓN, 2003: p. 57).

Tampoco le va mal el calificativo de «frontera caliente» dado por Francisco García Fitz, (200 I: pp. 159-160). No es una frontera rígida, ni estable, en donde las posiciones, tanto cristianas como musulmanas pueden cambiar de manos en cualquier momento (CLEMENTE RAMOS y MONTAÑA CONCHIÑA, 1994: p. 83). Las gentes de estas regiones tenían muy claro tres conceptos: guerra, frontera y territorio (PALACIOS ONTALVA, 2005: p. 68).

Con la caída de la taifa toledana, Alfonso VI hereda una organización del espacio que se fue fraguando desde el Emirato. Un sistema de estructura compleja diseñado para defender AlAndalus de las incursiones del norte. Igualmente creado para apoyar cualquier iniciativa de conquista o castigo más allá del Sistema Central, hasta los límites marcados por el Duero. Las tres grandes Marcas, que giran en la defensa inmediata de Mérida, Toledo y Zaragoza, se estructuran en atalayas, torres, puentes fortificados, castillos y ciudades amuralladas; y todo se organiza en torno al paisaje, cauces fluviales y sistemas montañosos, o las principales vías de comunicación -de primer orden o secundarias-, que a su vez también se articulan en función de los accidentes geográficos. Asimismo, vemos que dicha estructura se distribuye principalmente de norte a sur, poniendo, por supuesto, su horizonte de vigilancia hacia el Norte; pero también de Oeste a Este, pues el Sistema Central es el gran determinante de las fronteras. En conjun- to podemos comprobar la existencia de una densa trama de enclaves (SÁEZ LARA, MARTíNEZ LILLO y MALALANA UREÑA, 1999). Además, como bien apunta Eduardo Manzano, aparte de las fronteras externas, existen las internas, es decir aquellas estructuras creadas para controlar los movimientos en contra del poder central cordobés (MANZANO MORENO, 1991). Lógicamente, esta configuración, a lo largo de las primeras taifas, cambiaría ligeramente. Tras la anexión cristiana esta estructura se alterará radicalmente.

El cambio más notable es la orientación de la frontera, antes miraba al norte cuyo horizonte quedaba marcado en las cumbres de la Sierra, ahora lo hará hacia el sur, oteando el Tajo. En ambos casos el centro sigue siendo el mismo: la protección de la ciudad de Toledo. Lo que antes fue la retaguardia, todas aquellas fortalezas que están a lo largo del cauce, ahora es la primera línea de defensa. Por el contrario, otros lugares, como Madrid, que fueron la vanguardia frente a los reinos cristianos, ahora serán la retaguardia. Sin embargo, ninguno de los puntos fortificados de la Transierra perderá su valor estratégico, pues de una u otra manera forman parte del sistema. El ejemplo más claro es Alcalá de Henares, situada a las espaldas de Toledo, que durante algunos años fue pieza vital en el hostigamiento magrebí sobre los territorios cristianos. Otro ejemplo era Talavera, ciudad situada sobre el Tajo, que permitió a los musulmanes controlar el flanco izquierdo.

Un cambio notable es la creación de una nueva línea al norte del Sistema Central, son los enclaves resurgidos de antiguos asentamientos como Salamanca, Ávila, Segovia, Sepúlveda, Ayllón, etc.; y todos están alineados a lo largo de una vieja ruta de origen romano que transita en paralelo a la Sierra.

Una trasformación más se observa entre Toledo y los Montes de Toledo; región que fue concebida, desde época de Alfonso VII, como un cinturón de fortalezas para defender la capital, que por sus características y su importancia estratégica, puede ser incluida dentro de esta zona intermedia de la vanguardia fronteriza (RODRÍGUEZ-PICAVEA, 1999: p. 36). 
Nuestra fijación por la frontera castellana no es casual, nos guiamos por razones estratégicas. Tanto los almorávides, como lo almohades, centraron la actividad militar, por cuestiones políticas, ideológicas y de propaganda, en recuperar la ciudad de Toledo. De ahí, que la frontera leonesa fuese más estable que la manchega, entre otras cosas, por el propio Tajo, que para esta región actúa con una barrera de mayor eficacia (CLEMENTE RAMOS y MONTAÑA CONCHIÑA, 1994: p. 83-84).

En definitiva, entre 1085 y 1212 , durante casi ciento treinta años, los extensos territorios de la Extremadura y la Transierra se conformaron como un gran tablero en la estrategia político militar entre cristianos y musulmanes. Una prioridad de las monarquías era integrar todos los territorios que estaban bajo su corona en un sistema encaminado a resistir los envites, fundamentalmente, frente a los musulmanes y trasladar la sensación de protección y confianza hacia los nuevos pobladores. Pero no solo contra el Islam hubo lucha, los litigios entre cristianos también tendrán una influencia decisiva en la configuración de las fronteras, sobre todo frente a Navarra, Aragón y Portugal. Una de las etapas clave para castellanos y leoneses llegará con las querellas tras la separación del reino entre los hijos de Alfonso VII. La fijación de la frontera entre León y Castilla tras la división del reino, en II57, a favor de Fernando II y Sancho III implicaría el reforzamiento de numerosos enclaves, política que se intensificaría después con Alfonso IX y Alfonso VIII. Por todo ello, se entiende la importancia de Galisteo y Plasencia, dos enclaves enfrentados. En el otro extremo, Castilla, en la frontera con Navarra y Aragón, lugares como Soria y Almazán serán piezas vitales para los castellanos (DIAGO HERNANDO, 1992).

Los grandes enclaves urbanos van a ser los puntos de referencia, tanto para la organización de la defensa, como para el asentamiento y distribución de los pobladores. En palabras de Julio Valdeón existe cierta obsesión por la seguridad (1991: pp. 69 y 83-85). Las ciudades se transforman en elementos defensivos, símbolos de protección. Los aspectos visibles de la existencia de un programa lo vamos a poder observar, precisamente, en la reconstrucción o edificación de murallas urbanas.

Aquí, en este momento, es necesario introducir un comentario, el extraordinario papel jugado por la concesión de los fueros; ya que se incluyeron epígrafes destinados a favorecer los mecanismos que posibilitasen la construcción de recios muros.

Es muy probable que Alfonso VII, rey de Castilla y León, fuese quién pusiese en marcha esta iniciativa; la coincidencia cronología entre las técnicas constructivas empleadas, el origen de ciertos epígrafes en numerosos fueros, junto a otros datos, convergen en su reinado. Por ejemplo, la curia regia, en I I 35, había elaborado leyes generales para todo el ámbito del imperio (RECUERO ASTRAY, 1979: p. 142).

Posteriormente, con la división del reino, los monarcas castellanos y leoneses, cada uno por su lado, no solo finalizaron las obras ya iniciadas, sino que las mejoraran e incluso pondrán en marcha otras nuevas. En León, tanto Fernando II, como Alfonso IX, en su afán de afianzar y avanzar en la repoblación de la Extremadura leonesa colonizaron varios enclaves estratégicos.

Sin embargo, es Alfonso VIII el continuador natural de la política de Alfonso VIl; de hecho, prácticamente cierra todo un largo periodo de construcciones, quizá la más interesante, faceta que sería rematada por Fernando III, sobre todo en tierras manchegas.

El rey castellano, tras el revés de Alarcos, desconcertado por la dolorosa derrota, comprendió la fragilidad de una frontera en fase de colonización. Un contratiempo más era el de no contar con un gran ejército. Por todo ello, se volcaría en la tarea de proteger los territorios; impulsó la mejora de las defensas en ciudades y castillos con más murallas o aplicó novedosas técnicas arquitectónicas (GONZÁLEZ, 1960: t. I, p. 97I). Él impulsó las obras, pero fueron las entidades locales las responsables últimas de cumplir el programa. 


\subsection{Los nuevos recintos amuralla- dos}

A lo largo y ancho del territorio elegido para el estudio, vamos a tener dos tipos de ciudades amuralladas, modelos que se estructuran en función de su origen, su ubicación geográfica o geopolítica y por su posterior desarrollo (fig. I).

Por un lado, están los emplazamientos de la Transierra. Estos enclaves son de origen hispanomusulmán, ciudades o castillos ya diseñados, configurados y en buen uso.

Por otro, tenemos las ciudades fundadas en la Extremadura. En estos lugares, aunque se construyen recintos de nueva planta, reutilizarían antiguos emplazamientos tardorromanos e incluso sobre construcciones visigodas o andalusíes mantenidos por poblaciones residuales.

En ambos casos y en los primeros años, la evolución viene a ser la misma: reparar, restaurar o reconstruir. Lógicamente, esta tarea es emprendida durante el reinado de Alfonso VI. Hoy en día, contamos con algunos ejemplos vivos, como Salamanca, Ávila o Toledo. El objetivo es el mismo, dar cobertura y protección a los contingentes que se atreven a poblar los territorios de frontera.

Alfonso VII, el Emperador, cambiaría la tendencia. Ahora las necesidades son otras y tiene que abrir la puerta a sus ambiciones territoriales. Se pone en marcha una política bien distinta, a partir de los recintos ya existentes, se construyen otros nuevos con el objetivo de aumentar el espacio urbano para dar cabida a más pobladores. Salvo Toledo, aquellos enclaves enumerados por las crónicas de la Reconquista como lugares conquistados y repoblados coinciden con la construcción de grandes perímetros amurallados. Para la densidad de población de la época serán enormes. Salamanca es un buen ejemplo de ello (MONSALVO ANTÓN, 2002: p. 127) "Los dos flancos de la ciudad, oriental y occidental, se repoblaron al menos en sentido urbano durante los últimos años del XIl y más aún en el primer cuarto del siglo XIII, acaso para rellenar el casco señalado por la muralla" (GONZÁLEZ, 1943: p. 22I).
Otro de los ejemplos descomunales para la población que tenía en ese momento es Soria (ASENJO GONZÁLEZ, 1999).

El arquitecto P. Feduchi ha realizado un cálculo del tiempo necesario para la construcción de las murallas de Ávila: setenta y dos años. Teniendo en cuenta otra de sus características, que no se levantaron todos los flancos al mismo tiempo, sino que la obra iba avanzando según la disponibilidad de recursos, significa que los abulenses no vieron sus murallas totalmente cerradas hasta finales del siglo XII, durante el reinado de Alfonso VIII.

Ante lo dilatado de la obra se comprende una de las primeras particularidades: la construcción de estos grandes perímetros solo fue posible por la existencia de otras fortalezas que diesen la protección necesaria a los vecinos mientras se levantaban los nuevos espacios fortificados.

Como toda obra pública, es necesario disponer de los recursos económicos suficientes para sufragar el coste de los materiales y de la mano de obra, concluyendo en los plazos previstos los trabajos encomendados a las cuadrillas. Precisamente, a través de concesiones otorgadas por Alfonso VII, Alfonso VIII y Alfonso IX a varios concejos podemos entender la importancia del impulso dado por los monarcas para crear una frontera impermeable, constituida por puntos fuertemente defendidos.

Cuadrar las cronologías es una tarea extraordinaria. Un buen punto de partida podría ser las descripciones que aporta el geógrafo AlIdrisi ( I 099- I | 64), cuyas referencias habría que centrarlas en la primera mitad del siglo XII. Si tenemos en cuenta los comentarios sobre Ávila, "que no es más que un conjunto de aldeas", de Segovia, "que tampoco es una ciudad, sino muchas aldeas próximas unas a otras hasta tocarse sus edificios" (AL-IDRISI, I88I: p. 8I), de Santarém, "villa edificada sobre una montaña muy alta... [que] no tiene murallas" (AL-IDRISI, 190I: p: 23), de Burgos "ciudad grande" partida en dos por un río, cada una con su muralla y una de ellas dominada por los judíos (AL-IDRISI, I88I: p. 8I) o de Madrid, "pequeña villa bien poblada y castillo fuerte: del tiempo del islamismo" (AL-IDRISI, 190I: p 27), 
parece difícil entender que los grandes recintos de la Extremadura o la Transierra ya estuviesen levantados antes de I I 50; salvo Zamora, "ciudad importante, una de las capitales de los cristianos", que sí cuenta "con solidas murallas de piedra" (AL-IDRISI, I88I: p. 80).

Si además añadiésemos otras informaciones, datos procedentes de numerosos fueros, la mayoría otorgados durante los reinados de Alfonso VII y Alfonso VIII, las dudas se acrecientan. El fuero de Salamanca es uno de los mejores ejemplos, pues sus Alcaldes darían la orden, "quando el Emperador fue a Almeria [1 147]", para construir la nueva muralla. El de Madrid, cuenta con algunos epígrafes, que formarían parte de primitivo fuero otorgado por este mismo monarca, destinados a facilitar la fábrica de su segundo recinto. Un dato, al margen de estos textos, disponemos de una inscripción de Almazán, Soria, que recoge la noticia de que la muralla fue obra de Alfonso VII. A partir de aquí, otros textos forales, aunque ahora concedidos en tiempos de Alfonso VIII, como los de Cuenca, Plasencia, Bejar, demuestran la larga evolución de la construcción de las murallas urbanas. Edificaciones que concluirían en muchos lugares, como Ávila, a lo largo de este reinado, pues, al margen de los fueros, sería necesario conceder ciertos privilegios para conseguir cerrar definitivamente las murallas urbanas.

\subsection{La construcción de las murallas a través de los fueros y otros pri- vilegios}

Un buen número de los fueros otorgados a las ciudades de frontera incluyen normas particulares para regular la defensa de cada una de ellas y entre los epígrafes aparecen disposiciones para levantar o reparar murallas y otras fortificaciones (CASTRILLO LLAMAS, 1995: pp. 39-66). Los fueros marcan tres prioridades, a la vez que identifican las dificultades que tienen que resolver los gobiernos locales para llevar a cabo una construcción tan monumental como son las murallas. A saber: la mano de obra que ejecute el proyecto, los distintos materiales de obra (canteras, madera, yacimientos de yeso, etc.) y los recursos económicos necesarios para sufragar todo lo anterior. Se quiere forjar un símbolo, un icono de paz interior y de poder exterior frente a su propio territorio, hacia las ciudades y villas vecinas, pero principalmente, hacia al Islam.

A partir de aquí, disponemos, entre otros, de los fueros, de Briviesca (Burgos), Salamanca, Zamora, Madrid, el de Miranda (de Ebro), el de Benavente, inspirado en el de León, los de Mayorga, Laguna y Puebla de Sanabria, el de Tuy, los de Cuenca, Plasencia y Béjar, etc.

Con posterioridad, y de manera complementaria, los monarcas concedieron a los concejos ciertos privilegios parciales, a veces temporales, encaminados a recaudar por otros medios recursos económicos extraordinarios. La nueva recaudación serviría, en algunos casos, para finalizar las obras iniciadas años antes $y$, en otros, bien para ampliar las defensas programadas, o bien para introducir nuevas técnicas o estilos edilicios.

En todos los casos, el inventario de noticias nos aportan datos muy relevantes para conocer algunos de los detalles de la ejecución de la obra pública; pero sobre todo, podremos aventurar en qué momento se estaban emprendiendo dichas construcciones, por lo que la información es muy útil para intentar cuadrar las cronologías.

Cifrar el número de trabajadores necesarios para levantar una muralla no es faena sencilla. Lo que sí parece cierto es la especialización de las tareas, siendo las más significativas la de carpinteros y canteros, todos trabajando in situ; de hecho, en Madrid, contamos con algunos restos que atestiguan el trabajo de los canteros a pie de obra.

Volviendo a los fueros, en algunos de los epígrafes se redactaron varias fórmulas para liberar y reclutar la mano de obra necesaria. Algunos de los textos llegarán a contradecir el espíritu de los enclaves fronterizos. Ahora no existen privilegios, cuando se trata de la construcción de la muralla la situación cambia, la seguridad es prioritaria. 
Gracias a los fueros, los gobiernos locales tenían la potestad de reclutar a los trabajadores para cualquier actividad constructiva. El Fuero de León, dado por Alfonso $V$ y doña Elvira, su mujer, el 30 de julio de 1017, es un buen antecedente pues obliga a todos los habitantes, tanto los de la villa, como del resto del territorio, a colaborar, en tiempo de guerra, en la reparación de las murallas. Como contraprestación, los pobladores quedaban exentos del pago del portazgo sobre los productos introducidos en la ciudad para ser vendidos en el mercado local (RODRÍGUEZ FERNÁNDEZ, 1981: p. 21). A partir de a aquí era frecuente el castellaje, la castellería y las facenderas, es decir la obligación de la prestación del trabajo personal de todos los vecinos y moradores del término a trabajar en el bien común, que en aquellos tiempos, podrían ser los muros de las cercas - los puentes. Al mismo tiempo se preveía la liberación de estos trabajos a ciertos grupos sociales o ciertas compensaciones tributarias a cambio del trabajo (ALVARADO PLANAS, 1995).

Alguno de los ejemplos más ilustrativos lo tenemos en los fueros de Cuenca, Plasencia, Béjar, Benavente, Salamanca y Mayorga de Campos. A finales del siglo Xll y por iniciativa de Alfonso VIII se redacta el texto conquense, documento que serviría de matriz para otros tantos códigos locales. En él, en una de sus primeras leyes, se establece que los nuevos pobladores que llegasen a la ciudad, y para fomentar el arraigo, estarían exentos de cualquier pecho. Sin embargo, se hacía una salvedad, el castellaje, la obligación de participar en las obras de la muralla de la ciudad, así como para la construcción de torres dentro de su término (UREÑA Y SMENJAUD, 1935: pp. 118-119). De esta obligación quedaban excluidos aquellos caballeros que poseyeran una montura valorada en más de 50 mencales. En otros dos fueros, el de Plasencia, de I 196 (BENAVIDES CHECA, 200 I: p. 41; POSTIGO ALDEAMIL, 1984: p. 180) y el de Béjar, de 1208, también concedidos por el rey castellano, cuentan con las mismas leyes y una redacción similar (GUTIÉRREZ CUADRADO, 1975: p. 44).

En || $|8|$, Fernando II, en el mismo documento por el que extendía los términos de Benavente, obliga a los habitantes a contribuir con las facenderas o prestación de trabajo comunal. También, en otra disposición, se exime a los vecinos del pago del portazgo. Esta exención es equiparada por Rafael González con uno de los preceptos del Fuero de León: aquellos que, viviendo en las aldeas acudieses a vender sus mercancía al mercados loca, se les excusaría del pago del portazgo a cambio de trabajar en las obras de reparación de la muralla (GONZÁLEZ RODRÍGUEZ, 1997b: pp. 15I184). En ese mismo año, el rey leonés concedía fuero a Mayorga de Campos, manteniendo la misma línea trazada desde León a Benavente. Esta misma fórmula también se encuentra en los fueros de Laguna y Puebla de Sanabria (MARTÍNEZ SOPENA, 1989: p. 128). La idea, aunque con otros términos, también se trasladaría a Tuy, enclave costero gallego. En la carta de fundación de esta villa, Fernando II se refiere expresamente a la construcción de la muralla: "[...] ut vos ibidem civitatem construatis et eandem per circuitum amplissimis fossis et muris nec non et turribus muniatis qui siquidem loco et civitati tali de novo concedimus vocabulum scilicet Bonam Venturam" (GAUTIER DALCHÉ, 1979: p. 133).

Pascual Martínez Sopena, apoyándose en algunos documentos referentes a Mansilla, y aunque tardíos, plantea un modelo de reparto de las facenderas. La muralla se organizaba en tramos y estos se repartían entre las aldeas que integraban el alfoz. Cada uno de los sectores estaba perfectamente delimitado, por ejemplo por las torres, e incluía muro, almenas y cárcava. La responsabilidad no acaba con la construcción, sino que continuaba de manera permanente con la obligación de mantener la muralla en buen estado, reparando si era preciso los desperfectos, y procurar que el foso estuviera siempre limpio (MARTíNEZ SOPENA, 1989: p. 132).

En Salamanca, cuyo fuero es una fusión de varios textos que abarcan un espacio cronológico muy concreto, entre principios del siglo XII y mediados del XIII, con varias paternidades, como Alfonso VII, Fernando II, Alfonso IX y Alfonso $X$, las noticias demuestran el reclutamiento de trabajadores con la implantación de ciertas cargas, como la castellería (GONZÁLEZ 
GARCíA, 1988: p. 42). El epígrafe 172, uno de los capítulos que pertenecen a la redacción de Alfonso VII, se otorgó a los alcaldes, mientras se construyera la cerca, la potestad para reclutar a los hombres necesarios. Fernando II, en I I 8 I, en una disposición dirigida al concejo de Benavente, exige a los vecinos a contribuir a la facenderas: "Hoc totum do in perpetuum uobis populatores de Beneuento, pro alfoz uestro et termino, ut supra diximus; quod in omnibus foris uestris, faciendariis ac regiis nocibus, homines de his terminis uobiscum respondeant et satisfaciant" (MARTíNEZ SOPENA, AGUADO SEISDEDOS y GONZÁLEZ RODRÍGUEZ, 1996: doc. 2; GONZÁLEZ RODRÍGUEZ, 1997b: pp. 15 I - 184).

Cómo con el reclutamiento forzoso, junto a la más que posible contratación de peonadas y cuadrillas, no se disponía de la mano de obra necesaria, se estipularon otras formulas complementarias. En algún que otro ejemplo, como el de Madrid, ciertos delitos se redimen mediante trabajos forzados en las obras de la cerca. Precisamente, sobre las cuadrillas, el Fuero de Cuenca estipula alguna normativa muy interesante, que nos ilustra un poco en lo relativo al ritmo del trabajo, en concreto en el cumplimiento de los plazos de entrega de la obra: Cap. XLII: "Si el maestro alguna obra començare commo torre, o iglesia, o libro, o puente, o casa, o molino, o vinna, o qualquier otra obra, acabela según el pleito oviere puesto; si non peche el aver que eviere rreçebido doblado [...]" (UREÑA Y SMENJAUD, 1935: p 793).

La segunda dificultad a la hora de edificar las cercas, tal y como ya se señaló anteriormente, es la consecución de los materiales de obra. Esta circunstancia no es un problema menor, todo lo contrario. Por ejemplo, en Salamanca, a pesar de haberse empleado la primitiva muralla romana como cantera, a partir de 1 I47, se acentúa la necesidad por localizar los materiales (GONZÁLEZ GARCíA, 1988: p. 42). A partir de este momento es vital la búsqueda en las cercanías de las materias primas. La proximidad de estos depósitos naturales abarata los costes y reduce los tiempos de ejecución. Dos ejemplos contrapuestos demuestran con claridad esta circunstancia.
Mientras, en Zamora, por la propia composición del suelo rocoso sobre el que se asienta la ciudad, es posible extraer los sillares al pie de obra, incluso parte de las piezas son recicladas del material arrancado de las fosas de cimentación (GUTIÉRREZ GONZÁLEZ, 1990: p. 18). $\bigcirc$ en Ávila, en donde los mampuestos provienen del espolio sobre edificaciones anteriores o se obtienen en el entorno próximo (GUTIERREZ ROBLEDO, 2000: 484. 2002: 69. 2007: 125). En Madrid, por tratarse de un suelo de arenas y arcillas, los constructores se vieron obligados a desplazarse bastantes kilómetros para encontrar las canteras. Hacia el norte, en la Sierra, las pedreras a cielo abierto podrían estar localizadas en Rascafría, Guadarrama y Valdemaqueda. En Vallecas, Vicálvaro, Rivas y Vaciamadrid se hallarían los depósitos de piedra caliza con la que se elabora la cal y el yeso (NIETO, 2006: pp. 49-50).

Elisa Carolina de Santos, aunque en el fuero de Plasencia no se hace una mención expresa, entiende que el control que los concejos ejercen sobre las canteras y otros depósitos naturales, como las yeseras, lo es para asegurarse su utilización en la construcción de las cercas. Ítem más, aquellos particulares que en sus heredades tuviesen estos recursos estaban obligados a ofrecerlos al concejo. Estos epígrafes también se incluyen en los textos forales de Cuenca y Béjar (UREÑA Y SMENJAUD, 1935: pp. 220-221. BENAVIDES CHECA, 200I: p. 173. POSTIGO ALDEAMIL, 1985: p. 207. GUTIERREZ CUADRADO, 1975: p. 66. SANTOS CANALEJO. 1986: p. 129).

Por último, la tercera dificultad, como consecuencia de la aplicación de las dos anteriores, será la disponibilidad de recursos económicos para hacer frente con suficiencia a los altos costes. Los portazgos, en palabras de Jean Gautier Dalché, recaudados en núcleos fortificados tendrían como destino contribuir a la construcción y sostenimiento de las fortificaciones de cada lugar. De hecho, cree que el portazgo fue creado para satisfacer parte de las necesidades presupuestarias (GUATIER DALCHÉ, 1981: p. 75). Fuese como fuere, la procedencia del dinero necesario es muy diversa, como el reparto de algunas penas aplicadas a distintos 
delitos, la explotación de determinados bienes comunales, la aplicación de un impuesto sobre la "herencia" de los vecinos, etc.

Aquí va una muestra de las distintas maneras de buscar recursos económicos. En el fuero de Briviesca (Burgos), dado en II23, ya se destinan penas por homicidio a la financiación del castellum (SAGREDO FERNÁNDEZ, 1979: pp. 24024I). En el texto foral de Calatalifa, concedido el 21 de febrero de $1|4|$ por el Emperador, se permiten ciertas ventajas tributarias, con la exención del portazgo y otras contribuciones cuyo destino sería la construcción de las murallas y de las iglesias (GROSS, 1987: p. 126). En el de Mayorga de Campos está el gravamen a la viuda que contrajese matrimonio antes de un año o el tributo impuesto a los habitantes de abadengo. En el de Béjar se establece que la cuarta parte de las caloñas se destinasen a la cerca (GUTIÉRREZ CUADRADO, 1975: p. 94).

En el de Zamora, concedido por Alfonso IX y confirmado por el mismo en 1208, en el epígrafe 15 , se regula destinar parte de penas económicas a las defensas de la ciudad (MAJADA NEILA, 1983: p. 23. FERNÁNDEZ DURO, I883: vol. III). O los de Salamanca, Alba de Tormes y Mayorga de Campos, en donde se establece cierto impuesto sobre el derecho de transmisiones patrimoniales de los difuntos:

Salamanca. Cap. 182: "Del mortorio, quanto den al Castiello. "Todo omne que morier e oviere valia de XX moravedis, de uno por su alma al muro; e de $X$ medio; e si negar iure; de $X X$ maravedí con II vecinos e de $X$ con uno; e si firma ovier del clerigo e de los iurados délo; e los de la villa firmen con el clerigo e con II vecinos" (CASTRO y ONIS, 1916: p. 185, MARTíN y COCA, 1987: p. 88).

Alba de Tormes: I 29. Fuero de muerto. "Todo omne que en Alba o muler, o en su termino moriere, sus parientes metan en el lecho I. tapet e una colcha e .Il. savanas e .II. plumazos e .I. manto o .l. cobertor e $l^{a}$ cocedra; el que mas y metiere, peche VI moravedis, medios al castiello e medios allos alcaldes". (CASTRO y ONIS, 19|6: p. 334).
Mayorga de Campos: Cap. 49: "Todo ome que habidare en Mayorga o en su alfoz, si oviere valor de $X$ maravedis quando muriere de un maravedi al castiello si fuere de edat".

En Ledesma, cuyo fuero fue otorgado en la segunda mitad del siglo XII, cuenta con un buen número de preceptos, penas, que se invierten en las obras de los muros y del puente (CASTRO y ONIS, 1916: pp. 244, 249, 263, 282-283). Y Alba, enclave que sigue la estela de Ledesma, igualmente destina algunas caloñas para la cerca (CASTRO y ONIS, 1916; p. 33I). El fuero de Miranda, concedido por Alfonso VIII, en II 77, dedica uno de sus epígrafes a cubrir con multas la fábrica de los puentes y muros de la villa (LLORENTE, |806-1808: vol. 3, pp. 472-485).

En el fuero de Madrid, existen varios preceptos destinados a facilitar la realización de las obras necesarias en sus murallas. Recursos que fueron canalizados para financiar la construcción durante el reinado de Alfonso VII, como para terminar los trabajos con Alfonso VIII. En concreto son determinadas rentas, junto a ciertas penas pecuniarias impuestas por la comisión de algunos delitos graves o faltas leves, entre los que se encontraba el homicidio ${ }^{5}$.

Al margen, de los epígrafes de los fueros, en algunos lugares, no fueron suficientes para terminar unas costosísimas obras, trabajos que se alargaban año tras año. Para sufragar las reparaciones de las torres y puertas de León, Alfonso IX, llegaría a aportar dinero propio (GONZÁLEZ, 1944:t. I, p. 475). Tanto en León como en Castilla, se habilitaron sistemas complementarios para la financiación, casi todos privilegios extraordinarios y temporales otorgados por Fernando III, Alfonso IX y Alfonso VIII.

Por ejemplo, en I I 80, Fernando II concedería una exención temporal de impuestos a los vecinos de Melgar de Arriba. Durante diez años no pagarían nada a cambio de edificar el castillo y defender la villa (MARTíNEZ SOPENA: 1985 p. 130; 1989: p. 132). En 1214, gracias a la mediación de Alfonso IX, el concejo de Villacet recibiría

5 Son los epígrafes IX, XIV, LXX, LXXI, XCVIII, CX o Carta de Otorgamiento (n 7, 9, I I y I3), CIX y CXI. 
durante 17 años un tercio de los diezmos del monasterio de Sahagún, cobrados en la propia villa, para destinarlos a la fábrica de la cerca (GONZÁLEZ, 1943: II, pp. 4l0-4I I).

En Castilla, el 20 de abril de | 191, el cabildo y el concejo de Palencia, llegaron a un acuerdo para cumplir un mandato real, por el cual debían contribuir, junto al resto de los palentinos, en la ampliación del muro y de los fosos de la ciudad, en función de los recursos disponibles, en un plazo de diez años.

\begin{abstract}
"Quod, scilicet, singuli excusati canonicorum Palencie, quos de more antiquo habent canonici heredes in villa Palencie, et alii excusati de refectorio, operantur cun aliis Palentinis conciuibus in opere murorum de Palencia et carcauis per decem annos, unusquisque por modo facultatum suarum, secundum mensuram qua alii operabantur conciues per se et per sumptus pecunie, sue, set ab omni alio pacto et facendera sint exucati, liberi et inmunes" (GONZÁLEZ, 1960: t. III, pp. I5-17. RIU, 1992: p. 214).
\end{abstract}

El 12 de abril de 1192, dispondría que los judíos y mudéjares palentinos también pechasen para colaborar en la edificación de la muralla (GONZÁLEZ, 1960: t. III, pp. 49-50).

El 5 de marzo de I 193, el rey, aprovechando el reconocimiento por escrito de los términos territoriales de Ávila, eximió, temporalmente, a los caballeros del pago del quinto del botín a cambio de que utilizaran dichos recursos para la muralla y las "turres fortissime" que debían defender a los abulenses de las incursiones de los enemigos:

"Et insuper dono sibi perheniter et concedo quod illi milliti qui civitatem islam ex manu patrie regie tenuerit, in Christianorum exercitu, nisi ipsa preseas in expedicione cum eis fuerit, quintam sibi sedere non congantur, ea namque fiducia fundatur opida et turres fortissime ut, cum ad sumum palidez et consumaciones gloriam Deo dante pervenerint, ab inimicorum incursibus ipsorum presidio laboris participes defendantur [...]" (GONZÁLEZ, 1960: t. III, pp. 87-90).
En 1205, cuando Alfonso VIII vuelve a marcar los límites territoriales abulenses ya no se incluye el anterior privilegio, es muy probable que la obra ya estuviese concluida (GONZÁLEZ, 1960: t. III, pp. 359-36I).

Para Toledo, el 29 de marzo I196, Alfonso VIII concedió 200 maravedíes anuales de la renta del portazgo de la Puerta de Bisagra para la fábrica o el reparo de muros y torres:

"[...] dono et concedo vobis concilio Toletano
presenti et futuro ducentos morabetinos
annuatim im perpetuum percipiendos de
portatico deporte Bebsagra quos expedan-
tis in fabrica et reparatione murorum et
turrium ville vestreetin ceteris structuris ville
vestre neccessariis". (GONZÁLEZ, 1960: t. III,
pp. 155-156).

Algunos años más tarde, en 1203, añadiría la parte sobrante de la renta del mesón del trigo para que "[...] lo espendades en la obra del refaçimiento de los muros de Toledo" (IZQUIERDO BENITO, 1991: pp. 108-109).

\section{LAS MURALLAS ROMÁNICAS Y SU EVOLUCIÓN HASTA PRINCI- PIOS DEL SIGLO XIII}

Con los datos documentales en la mano todo parece concluir que la edificación de los grandes recintos amurallados castellanos leoneses supondría un enorme esfuerzo en recursos humanos y económicos. Tanto es así, que una de las principales consecuencias fue la excesiva dilatación en la construcción de los enormes perímetros, más de medio siglo y tres largos reinados. Pese a la tardanza en las obras, las cercas mantendrían cierta homogeneidad estética, aunque casi todas ellas demuestran que a lo largo de su edificación asimilaron, tanto los avances en las técnicas de defensa, como en los estilos arquitectónicos. Igualmente, se observan ciertos cambios en los modelos de los paramentos. Las intervenciones de Alfonso VI, Alfonso VII, Fernando II, Alfonso VIII y Alfonso IX han dejado una clara huella en la arquitectura urbana castellano leonesa, actividades que también tendrían su reflejo con el 
levantamiento de otros grandes edificios, como las catedrales y las iglesias (LACARRA, 1963: p. 220. VALDEÓN BARUQUE, 1991: p. 79).

Son muchos los ejemplos de recintos urbanos fortificados, algunos muy próximos entre sí, y otros más distantes. No obstante, la mayoría manifiestan y desarrollan los mismos patrones edilicios. El modelo de ciudad amurallada se extendería de oeste a este, tanto al norte como al sur de la Sierra, en la línea fronteriza o en la retaguardia; aunque la mayoría de los ejemplos están en la Extremadura, Soria y en la Transierra, pero también al norte del Duero. Entre los ejemplos más característicos tenemos Zamora, Salamanca, Plasencia, Ávila, Segovia, Madrid, Toledo, Sigüenza, Berlanga de Duero, Calatañazor, Soria, Almazán y algunas otras más (fig. 2). El modelo seguido no es nuevo, pues se tomará como prototipo las cercanas murallas tardorromanas de Astorga o León, recintos que también serían reparados a lo largo de ésta etapa, sobre todo sus torres (fig. 3).

\section{I. Los ejemplos de ciudades amu- ralladas}

Teniendo en cuenta que defendemos la hipótesis de la existencia de sistemas defensivos bien definidos veamos cómo se conforman algunos de los ejemplos, no todos, pero sí los mas ilustrativos. Para hacer frente a la amenaza almohade, las ciudades fortalezas se articularan a lo largo de ejes horizontales que toman como referencia los grandes accidentes geográficos, como el Tajo, la Sierra o el Duero, y otros menores, como los ríos Jerte, Alberche, Henares, Adaja, Eresma, Duratón, Tormes, etc. Igualmente, se establecen ciertas diferencias entre las ciudades fronterizas, la primera y la más acusada, su origen, unas fueron conquistadas a los musulmanes, las ubicadas en la Transierra, y otras serían fundadas, las de la Extremadura. Una segunda característica diferenciadora será el tamaño, los conjuntos situados al norte de la Sierra tendrán perímetros, en ocasiones, exagerados para la demografía de la época, frente a las ubicadas al sur, cuyos recintos tendrán, por lo general, dimensiones más acordes con las necesidades de la época (GAUTIER DALCHÉ, 1979: p. 121).
Tras la incorporación de los extensos territorios al sur de la Sierra, teniendo en cuenta la propia estructura del territorio castellano leonés, las ciudades fortificadas tienden a organizarse. En la Transierra, en donde las ciudades ya estaban configuradas, observamos un primer cambio. Algunos de los enclaves, aquellos que en alguna medida habían conseguido cierta autonomía administrativa con respecto a la capital taifa, como Talavera, Madrid o Guadalajara, adquirirán mayor protagonismo a partir de Alfonso VI (GAUTIER DALCHÉ, 1979: p. I I 5). Otros lugares, como Sigüenza, Calatañazor, Almazán - Berlanga, se unirán a esta lista de nuevas ciudades amuralladas.

Si miramos la frontera desde el sur, desde las posiciones almohades, comprobamos como a partir del siglo $\mathrm{Xl}$, pero sobre todo durante todo el siglo XII, se organizaría la resistencia cristiana frente al Islam. Salvando la inestabilidad de la raya fronteriza, difícilmente definible, Toledo es punto de referencia, tanto para cristianos como para los musulmanes. Es el bastión a defender $\mathrm{o}$ a conquistar.

Estamos ante una de las ciudades de mayor rango, con antecedentes romanos y visigodos, que cuenta con un complejo sistema fortificado heredado de todas estas culturas. Algunas de las reformas y remodelaciones, como respuesta al periodo de hostilidades que se abre a finales del siglo $\mathrm{XI}$, son prácticamente inmediatas a la capitulación (1085). Intentar resumir los cambios ejecutados para ampliar o mejorar los recintos pre-cristianos es compleja, aunque sí es plausible delinear a grandes rasgos cuáles son sus particularidades (fig. 2d).

Según los Anales Toledanos, Alfonso VI, en | I0 |, "[...] mando facer el muro de Toledo desde la Taxada que va al Rio de yuso la puent de piedra hasta la otra Taxada, que va al Rio en derecho de San Estevan" (PORRES MARTíN-CLETO, 1993: p. 75). Es decir, entre el puente de Alcántara y la coracha de San Esteban junto al Baño de la Cava. Incluso sobre la coracha surgen ciertas dudas con respecto a su cronología, pues bien podría haber sido levantada en este momento con el fin de proteger una pasarela sobre barcas, antecedente del mudéjar (MALALANA UREÑA, 
1990: pp. 216-217). Tampoco debemos poner en duda, aunque no se mencionen en los textos, las acciones de Alfonso VII, también como respuesta a otros momentos de incertidumbre frente a los almorávides. La actividad se acrecentaría posteriormente con Alfonso VIII, remodelaciones que fueron intensificadas y aceleradas tras la derrota sufrida en la batalla de Alarcos. Este rey impulsó una profunda reforma de todo el recinto, pero sobre todo entre las puertas del Vado y más allá de la de Bisagra Vieja.

Éste sector es mejorado considerablemente, al menos en dos fases ejecutadas a lo largo de los siglos XI y principios del XII (RUIZTABOADA, 2004: p. 267. 2005: p. 243), aunque creemos que debería alargase hasta los primeros años del XIII. Estas actividades constructivas se reflejan en el reforzamiento de los muros con el levantamiento de torres semicirculares, otras cuadrangulares, más los nuevos perfiles de las puertas del Vado, Bisagra Nueva y Bisagra Vieja. También debemos de tomar como iniciativa de Alfonso VIII la reparación o mejora de determinados puntos, como en el Torreón de los Abades (PONCE DE LEON y CARROBLES SANTOS, 2004: p. 189).

Aguas abajo, apoyando el inmediato flanco izquierdo aparece Talavera, ciudad fuertemente amurallada desde los gobiernos andalusíes. Reconquistada temporalmente por los musulmanes, volvería a estar definitivamente en manos castellano-leonesas. Con el fin de aumentar su potencial defensivo, los poderes cristianos reforzarían las murallas con la construcción de algo más de una quincena de enormes torres albarranas dispuestas en serie (figs. 2e y 27)). Aunque este tipo de torres no es una novedad, pues los musulmanes ya había hecho uso de ellas ahora, tanto en Castilla como en León, se generalizan con numerosos ejemplos a ambos lados del Sistema Central.

Aguas arriba, sin embargo, el modelo de ciudades fortaleza no llega a implantarse, aquí, la defensa se desarrolla mediante complejos sistemas de fortificaciones, como el de Oreja, o se mantienen los ya configurados por los musulmanes, como Zorita.
En una segunda línea, entre el Tajo y la Sierra aparece un buen grupo de ciudades fortaleza, todas asentadas a la orilla de afluentes del propio Tajo y controlan un vado o un puente estratégico, e incluso se posicionan como cerrojos en los posibles accesos a los puertos de montaña. En el entorno directo de Toledo encontramos a Escalona, Madrid, Alcalá - Guadalajara, ubicadas en puntos clave de los ríos Alberche, Manzanares y Henares.

El ejemplo de Madrid quizá sea el más desconocido, pues apenas quedan restos visibles y no tiene el impacto visual que ofrecen las ciudades anteriormente citadas. Sin embargo, gracias a las numerosas intervenciones arqueológicas de los últimos veinte años, es la que más datos aporta sobre el modelo constructivo (fig. 2f). Si nos fijamos en su fuero, las obras del segundo recinto habrían comenzado antes de I 145 y concluido alrededor de 1202 (GROSS, 1987: pp. |36-137).

El perímetro cercado pudo tener más de setenta torres, aunque no todas tenían la misma planta, variación que responde a su funcionalidad; las dispuestas en serie vendrían a tener un diámetro aproximado de 5 a 6 metros, mientras que las de las puertas aumentarían hasta los 6. Las torres forman una estructura única con los lienzos a los que se une. Asimismo, como todo el perímetro se levantó en el borde de los barrancos, las torres tienen una segunda función, sirven de contrafuertes a toda la estructura. Para asentar fuertemente se abre, en caja, una profunda fosa de cimentación, que puede alcanzar los $2 \mathrm{~m}$. de profundidad, ya que se adapta al terreno, hasta tal punto, que en algunas zonas es escalonada; los lienzos pueden llegar a tener hasta los 2'5 m. de ancho y una altura que ronda los $1 \mathrm{l}-15 \mathrm{~m}$.

A finales del siglo XII o principio del XIII evoluciona la técnica constructiva. Se abandona el románico y se adopta el mudéjar, al menos, en algunas de las puertas. La de Guadalajara es la única documentada, aunque en otras, como las de Valnadú, de Moros y Cerrada, también habrían sido reformadas siguiendo el modelo de puertas toledanas. No es posible saber si 
las torres albarranas, como las levantadas en el tramo de los Torrejones, fueron erigidas en este momento.

Lejos de Toledo, en el lado occidental de la Transierra, al resguardo del río Jerte, aparece Plasencia (fig. 2g). La ubicación estratégica del enclave es incuestionable, asentada sobre la calzada de la Guinea, tiene que proteger Salamanca. Su desarrollo e impulso definitivo se debe a la preocupación personal de Alfonso VIII, interesado por consolidar la defensa del reino, no solo frente al Islam, sino también frente a los leoneses; además de potenciar la colonización de las tierras del Tajo. Tenemos dos fechas clave: I |86, año en el que la población, supuestamente, fue fundada por el monarca castellano; y I196, doloroso momento, pues como consecuencia de una de las aceifas almohades, Plasencia fue ocupada temporalmente por los musulmanes (PALACIOS MARTíN, 1989 y 1992).

Si seguimos las propuestas de Francisco Sayáns, en Plasencia se habrían construido dos cercas. La primera cerraría un primer asentamiento, levantándose su estructura entre I I 72 y I | 82. Mientras que la segunda lo sería inmediatamente después de la incursión almohade, entre II 97 y II 99 (SAYÁNS, 2005: p. 269).

Las características generales de la segunda cerca, siempre en palabras de F. Sayáns, serían las siguientes: la altura de la muralla es de 9-10 metros, aunque confiesa desconocer si cuenta o no con cimentación. En su perímetro, de unos tres mil metros, se alzan setenta torres, casi todas semicirculares, aunque algunas referencias apuntan hasta las ochenta. Las puertas eran de vano simple flanqueado por dos torres semicirculares (SAYÁNS, 2005: p. 27I-274).

En la zona oriental de la Transierra, la región se ensancha, rebasando claramente el Tajo. Aquí nos encontramos en tierras sorianas, guadalajareñas y conquenses. Puntos como Sigüenza, lugar estratégico en la cabecera del Henares,
Almazán y Berlanga, sobre el Duero, o Cuenca deben cerrar cualquier iniciativa envolvente que permita a almorávides y almohades atacar las tierras del Duero por los pasos sorianos. La colonización de la provincia soriana es de las más tardías, del primer tercio del siglo XII, obra de Alfonso el Batallador, quién puebla Soria ( I 199), Berlanga y Almazán (GAUITIER DALCHÉ, 1979: p. 104. ASENJO GONZÁLEZ, 1999: p. 42. LEMA PUEYO, 2008: pp. 224-225).

En Berlanga de Duero, nos centramos en el primero de los recintos, el que protegía la villa vieja, cuyo emplazamiento primitivo se situaría en el cerro (fig.4). Según Fernando Cobos y Javier Castro fue Alfonso el Batallador quien impulsó la obra. Su factura es similar a que tienen los recintos de Soria, Calatañazor y Almazán. Como una de las características reconocibles es la larga línea de cubos semicirculares de flanqueo dispuestos en serie, se conservan alrededor de una veintena, que protegen el único flanco intacto. La puerta, de acceso directo, estaba defendida por otros dos cubos de flanqueo (COBOS GUERRA y CASTRO FERNÁNDEZ, 1994: p. 224).

Almazán, si tenemos en cuenta las palabras de José Ángel Márquez Muñoz, ya contaba con una fortificación anterior, indicando que aquí intervinieron Alfonso VI, Alfonso el Batallador y Alfonso VII. De hecho, es el Batallador quien repuebla definitivamente el enclave. Toda esta zona estuvo sometida a fuertes presiones por parte de los almorávides, de hecho, Berlanga fue asediada en I I 3 (MÁRQUEZ MUÑOZ, 1087: p. 27). En 1896, se registra un expediente en la Real Academia de la Historia. El texto trata de una inscripción que se hallaba sobre la clave del arco de la Puerta del Mercado, cuyo contenido, al parecer, recoge la noticia de que la fortificación de la villa fue obra de Alfonso VII ${ }^{6}$. Márquez apuesta por una cronología comprendida entre la segunda mitad del siglo XII y principios del XIII, para un recinto que dispone de siete accesos, cuatro puertas: de la Villa, de Herreros (fig. I7), del Mercado y de Berlanga, y tres pos-

6 Real Academia de la Historia, CASO/9/7973/34. 
tigos, de Santa María, San Miguel y San Vicente. Las primeras estaban protegidas por torres de flanqueo y "[...] sobre estas torres volaba un arco con matacán". El acceso más paradigmático era la Puerta del Mercado, ya que las torres que la protegían tenían planta prismática.

El grosor de los muros es de unos dos metros, aunque en algún punto, por su debilidad, al parecer esta anchura se amplía hasta los cuatro. El aparejo es de sillarejo más escuadrado y mampostería regularizada, en donde "[...] se labra una cara, que era la que aparecía en el exterior, se colocaban estos sillares cara-vista en ambos lados, rellenando el espacio intermedio con un fuerte hormigón de mortero, guijarros y sillarejo". Salvo las de las puertas, el resto del perímetro carece de torres (MÁRQUEZ MUÑOZ, 1087: pp. 42-43).

Entre la Sierra y el Duero se constituye una nueva línea de defensa con ciudades cabeceras de extensos territorios extremaduranos como los de Salamanca, Ávila, Segovia y Sepúlveda, además de Soria. Curiosamente estos son los ejemplos de murallas que cercan los espacios de mayor tamaño y todos, salvo Sepúlveda, son enclaves fundados sobre tierras no conquistadas. Sin embargo, debemos añadir otro lugar, de menor peso, pero con un valor estratégico incalculable. Salamanca, situada demasiado al norte del Sistema Central, necesitaría del apoyo de Béjar. Por lo tanto, la verdadera línea de estaría constituida por Béjar, Ávila, Segovia, Sepúlveda, Ayllón, Calatañazor y Soria. Todos estos puntos se sitúan a lo largo de una antigua ruta romana, que ponía en comunicación la calzada de la Guinéa, trazando una línea paralela a la Sierra, con Soria. Además, por su ubicación eran una segunda opción de bloqueo de los pasos serranos que otras ciudades fortaleza debían procurar en la vertiente sur. Así, Béjar protege la retaguardia de Coria y Plasencia; Ávila, tanto a Talavera, como a Escalona, para los puertos de Tornavacas, El Pico, Mengamuñoz y Arrebatacapas; Segovia a Madrid para los puertos de la Fuenfría y Navacerrada; y Sepúlveda, también a Madrid, pero sobre el de Somosierra. Por último, Calatañazon y Soria salvaguardan las espaldas de Berlanga y Almazán. Toda esta estructura tiene una clara finalidad, en caso de que los almohades reconquistasen Toledo y rebasasen los puertos del Sistema Central, proteger las tierras del Duero.

La Salamanca cristiana es heredera de un emplazamiento romano antiguo (fig.2b). En I 147, en época de Alfonso VII, tal y como lo señala el fuero salmantino, se daría la orden de levantar una segunda muralla (MARTíN y COCA, 1987: pp. 16 y 186. MUÑOZ, 1954: p. 30). La cerca nueva se construye como consecuencia de la necesidad de ampliar, en la segunda mitad del siglo XII, el reducido espacio protegido por la Cerca Vieja (GONZÁLEZ GARCÍA, 1988: p. 42). La antigua barrera pertenecía al trazado romano y encerraba las partes esenciales, como las residencias del tenente y del obispo, catedral, mercados, plazas, etc. La nueva, se levantó para proteger las pueblas y naturas emergentes (GONZÁLEZ, 1943: p. 225). La obra llevaba un ritmo poco satisfactorio. Tanto es así, que años después Alfonso IX, en I206, se vería obligado a reactivar y acelerar los trabajos. Para ello, el monarca leonés ordenaba a los vasallos foreros de la iglesia de Salamanca y a los de las Órdenes del obispado para que pagasen por San Martín medio o un maravedí, eximiendo a aquellos "[...] qui solent laborare in aliqua cerca civitate auto aliquo çerto castello den al laborem ipsius Castelli" (VILLAR GARCÍA, 1986: p. 300). El nuevo recinto cercaría un espacio de I 10 H. Si bien su trazado irregular se adaptaba a la perfección al accidentado terreno, para los puntos vulnerables fue necesaria la excavación de un foso o cava.

Además, y aunque apenas quedan testimonios, y como afirman adecuadamente Luis Serrano-Piedecasas y Miguel Ángel Muñoz, quienes se apoyan en la vista de la ciudad dibujada por Wyngaerde y por alguno de los restos que han sobrevivido, la nueva muralla estaría protegida por cubos semicirculares. Una de las huellas la tendríamos en los accesos. De las numerosas puertas con las que contó, al menos la de Villamayor sigue el patrón establecido para las murallas románicas: acceso directo protegida por dos torres de flanqueo (fig. I6) (VARGAS AGUILAR, 1974: p 14). 
Por otro lado, la fábrica general es de mampostería concertada en hiladas formadas con piezas irregulares regularizadas con ripio, técnica muy similar a la empleada en Plasencia (SERRANO-PIEDECASAS y MUÑOZ GARCÍA, 2000: 409-4I0).

Ávila, ciudad poblada tras la capitulación de Toledo, heredará una fortificación levantada durante el periodo romano y reparada por visigodos y andalusíes (figs. 2c y 5) (CATEDRA y TAPIA, 1997: pp. I58-159. MARTÍNEZ LILLO y MURILLO FRAGERO, 2003: p. 287). Esta circunstancia supone que los pobladores disponían a finales del siglo XI de una fortificación que, a pesar de que ofrecía ciertas garantías de defensa, fue mejorada sensiblemente con otras obras. Gracias a unas intervenciones arqueológicas recientes podemos establecer algunas referencias cronológicas. Las torres cuadrangulares de la puerta de San Vicente y del Alcázar, por ejemplo, fueron levantados en la primera década del siglo XII. Éstas posteriormente quedaron embutidas en otras semicirculares. Ahora, las nuevas obras se desarrollarán por iniciativa de Alfonso VII y Alfonso VIII (MARTíNEZ LILLO y MURILLO FRAGERO, 2003: pp. 287-289).

A estos datos se añade la hipótesis de Pedro Feduchi, quién afirma, que en el frente oriental, pero ceñido al espacio próximo a la puerta de San Vicente, se notan dos construcciones distintas (fig. I4). Eliminando las torres ultrasemicirculares, tanto las de la puerta, como aquellas que miran al templo de San Vicente, todo este lienzo ha sido construido con una fábrica muy particular: hiladas de grandes sillares, reutilizados de la necrópolis romana, regularizadas con pequeños mampuestos, colocados muchos a tizón, y ripio para conseguir una superficie horizontal sobre la que asentar la siguiente hilada de sillares. A cierta altura, el aparejo cambia para seguir el mismo esquema que el utilizado en las torres utrasemicirculares, manteniendo la misma disposición los sillares son sustituidos por mampuestos. Interpreta acertadamente Feduchi que estos dos aparejos estarían determinando dos fases. La más baja sería contemporánea a la primitiva puerta de San Vicente, protegida mediante torres cuadrangulares (FEDUCHI. 2003: pp. 82-83 y 86 ).
El frente meridional, el comprendido entre las torres de la Malaventura y de la Espina, presenta una imagen radicalmente distinta. La primera de las diferencias significativas está en la planta de las torres, semicircular, de menor tamaño y adosado directamente a las cortinas de la muralla. El segundo de los contrastes lo tenemos en la fábrica, que aunque sigue el mismo esquema general, su aspecto es menos cuidado. La última, variación la encontramos en las puertas, que para este sector, son tres: la de la Malaventura, la de la Santa y la del Rastro, estas dos últimas entre dos torres cuadrangulares de flanqueo. Posteriormente, se abrieron tres portillos: Malaventura, los Dávila y Episcopal. Para Feduchi este lateral tendría la cronología más tardía de todo el recinto, pues habría sido construido en una última fase.

Las distintas fases constructivas planteadas, junto a su cronología, son las siguientes: sobre la fortificación levantada por los primeros pobladores, a principios del siglo XII, se iniciaría la obra de la muralla nueva, comenzando su edificación por el lado este, actividad que seguiría en dirección al río. Todo el proceso se habría prolongado a lo largo de setenta años, durante los reinados de Alfonso VII y Alfonso VIII (FEDUCHI, 2003: pp. 96-103). Sin embargo, alguna de las fechas hasta ahora apuntadas es puesta en duda por J.L. Gutiérrez Robledo, quien afirma que la construcción es posterior a I I 46 y que su construcción debió alargarse hasta finales del XII (GUTIERREZ ROBLEDO, 2000: 505; 2003: 86; 2007: 143).

La ciudad de Segovia está ubicada en una posición privilegiada, excelentemente protegida por los cortados formados por los ríos Eresma y Clamores. Pese a que contamos con alguna publicación centrada en la Baja Edad Media segoviana (ASENJO, 1986), no disponemos de trabajos documentados o estudios arqueológicos de conjunto para las murallas. No obstante, a primera vista podemos expresar algunas ideas con respecto a la cerca.

En una primera observación podemos intuir la gran superficie que encierra el perímetro amurallado, peculiaridad de las ciudades fortaleza de la Extremadura, mucho más extensas 
que las de la Transierra. La segunda apreciación se centra en el propio perfil de la muralla, que alterna tramos de torres semicirculares con otros de planta cuadrangular. Sin embargo, en algunos puntos los cubos se asientan sobre los restos de torres cuadrangulares; nos referimos a espacio comprendido a lo largo de la calle Leopoldo Moreno hasta llegar a la puerta de San Andrés. Precisamente aquí, podemos comprobar algunas de las fábricas. Coincidiendo tanto en los restos de las torres cuadrangulares, como en la base de los lienzos existe cierta homogeneidad constructiva: el paramento está edificado con grandes sillares, algunos reutilizados de construcciones romanas, sillarejo y mampuesto escuadrado.

En el resto del desarrollo vertical de los paños se aplica una doble técnica, el hormigón y el mampuesto colocado a espejo; ésta última es muy similar a la empleada en Ávila y Sigüenza. En los cubos, aunque es ciertamente complejo establece un patrón, pues están muy retocados, es fácil comprobar cómo siguen un patrón similar a los muros. Sin embargo, en algún otro caso el paramento se asemeja bastante al usado en las zonas bajas de la cerca (fig.6).

Todos estos datos demuestran la complejidad del análisis del recinto segoviano. Aunque es muy probable que existan etapas constructivas similares a las desarrolladas en otras ciudades, como Ávila o Sigüenza, con fases que podrían adscribirse a los reinados de Alfonso $\mathrm{VI}$, Alfonso VII y Alfonso VIII. Aunque, para las bases cuadrangulares, Juan Zozaya las equipara con las zarpas emirales (2004: 54). En definitiva, sería conveniente diseñar un programa encaminado a estudiar el perímetro amurallado en su totalidad.

Sepúlveda pasa definitivamente a manos cristiana en 10 I0, gracias a Sancho García. Pero será Alfonso VI quién pueble y fortifique la villa en 1076. Lógicamente, el emplazamiento sepulvedano es un conjunto de varias etapas defensivas, entre las que tendríamos, al menos tres fases. Una fase hispanomusulmana fechada en el siglo $X$, que emplea sillares grandes, muchos de ellos reutilizados de otras construcciones, como lápidas funerarias romanas, etc. A lo largo del tramo se conservan varias torres de flanqueo cuadrangulares. Otra la correspondiente a Sancho García, con un estilo constructivo que parece tomar como referencia el anterior y que podría ser una reconstrucción de las defensas andalusíes. La datación ha sido posible gracias a la pervivencia de una inscripción ubicada en uno de los cubos, texto que indica que la torre fue edificada en el año 1063.

Las obras de Alfonso VI se llevaron a cabo a partir de 1076, ahora se utiliza para la fábrica del muro piedra de tamaño medio, bien colocada en hiladas horizontales y regulares. Para los autores citados, los tramos conservados serían las torres semicirculares del castillo, los muros situados bajo la Puerta del Vado y algún otro lienzo más (MARTíN AYMERICH, TARDÍO DOVAO y ZAMORA CANELLADA, 1990: pp. 131 - 140. 1992: pp. 425-432).

La cerca de Soria tiene un largo perímetro, aunque prácticamente ha desaparecido. Los datos aportados por Leopoldo Torres Balbás nos permiten extraer interesantes ideas. Al parecer su construcción muestra un paramento de "[...] cal y canto labrada en cajones, como si fuera tapial". Además, alguno de los lienzos se protegía con pequeñas torres semicirculares. Tan solo se han conservado unos metros en el paseo de la ermita del Mirón, en el Descenso hacia el Duero, en el Postiguillo y en las calles de la Alberca y de las Puertas de Pro. El aparejo es mixto, encofrado y sillarejo en las partes altas, lo que viene a demostrar que existen, al menos, dos fases edilicias (fig.7). La cronología que este erudito aporta establece una fecha para la construcción de la cerca nunca anterior al bienio | 195- | | 96, estando la obra concluida antes de 1290 (TORRES BALBÁS, 1952: pp. 25-26. 1987: p. 103).

Por fin, el cauce del Duero parece haberse convertido en una zona segura. Sin embargo, existen fuertes recelos. Zamora, bien emplazada a orillas del río, cuenta con una primera referencia documental de sus murallas hacia 1082. Sin embargo, el trazado y fábrica, hoy visibles, se deben a la iniciativa de Fernando I, quien organizaría la puebla y la dotaría de fuero. Aunque, sería Alfonso VI quien completase, sobre todo de la mano de su yerno, Raimundo de Borgo- 
ña, la obra. Por lo que la construcción de este primer recinto debió erigirse, según Gutiérrez González, entre 1063 y 1082 (fig. 2a). En los tramos originales se comprueba la defensa de los paños mediante cubos semicirculares, se conservan dieciocho, dispuestos en serie (fig. 8); la construcción queda fuertemente anclada al terreno rocoso mediante una cimentación con zarpa excavada en caja (fig. 9), que en ocasiones, dispone de orificios de desagüe; el adarve comunica todo el sistema, incluyendo cubos y puertas; la fábrica se compone de mampostería careada, a hilada, con grandes juntas (GUTIÉRREZ GONZÁLEZ, 1990: pp. 17-20 y 45-46. 1994: pp. 245-246).

La mayoría de las puertas están documentadas desde los siglos XI y XII, aunque casi todas fueron restauradas con posterioridad: son la Puerta de Olivares, la de Santa Coloma y la de Zambranos o de doña Urraca (fig. I3). La de Olivares fue concluida por iniciativa y con fondos del propio Alfonso IX, en 1230 (GONZÁLEZ, 1944: t. I, pp. 474-474). De todas las puertas la de doña Urraca resume las características que debieron de tener las restantes: acceso directo, rastrillo, bien protegidas mediante cubos de flanqueo, también semicirculares, y arco volado semicircular muy similar a las abulenses (GUTIÉRREZ GONZÁLEZ, 1990: p. 18. 1994: p. 246).

No lejos de Zamora tenemos Valladolid. En esta ciudad, en la calle Angustias, se recuperó un pequeño tramo de la muralla que incluye la cimentación de una torre semicircular de 4'20 m. de diámetro. Técnicamente, cubo y muralla, en la cimentación aparecen como dos elementos individuales. A priori, todo parece indicar que debe incluirse dentro de la "cerca vieja". A pesar del hallazgo, no fue posible establecer una cronología exacta. A continuación, en la misma calle, fue documentada una gran estructura de planta trapezoidal, de cuatro metros de lado, que pertenecía a la cimentación de una torre, con una cronología aportada por los arqueólogos de principios del XII. Esta fecha, ayuda a determinar que la torre semicircular y el tramo de cerca encontrado serían, al menos, posteriores a principios de ese mismo siglo (VILLANUEVA ZUBIZARRETA, SEQUERO MARTÍN y SERRANO GUTIÉRREZ, 1991: pp. (89-214).
Contrariamente a este dato, Adeline Rucquoi indica que existió una cerca primitiva de tapial, levantada en la segunda mitad del siglo XI, pero que pudo ser reconstruida durante el reinado de Alfonso VIII por otra más solida de piedra (RUCQUOI, 1997: p. 84). Dentro de esta misma hipótesis, y reinterpretando los resultados arqueológicos recabados del tramo excavado en la calle Angustias, la cerca vieja debe incluirse en el marco establecido por el rey castellano de reforzamiento de la frontera con León (ESCRIBANO VELASCO y SAN MIGUEL MATÉ, 2002: p. 292).

Más al norte se sitúa Burgos. Nazario González, Gonzalo Martínez Díez y José Ortega Valcárcel advierten que, por los datos aportados en ciertos documentos, habría existido otra cerca levantada, según cada uno de estos autores, en el siglo $X$, entre el XI-XII o en el XII respectivamente (GONZÁLEZ, 1958: pp. 86-87. MARTINEZ DÍEZ, 1994: pp. 92 y 96-100. CRESPO REDONDO, 2007: p. 392). Sin embargo, para los restos visibles, que incluyen las puertas de San Martín y San Esteban, el lienzo que enlaza ésta última puerta con el castillo y el tramo conservado en la Avenida de los Cubos, los historiadores apuestan por conceder la iniciativa de su construcción a Alfonso X (MONSALVO ANTÓN, 2002: p. 123). Si hacemos caso a Jesús Crespo Redondo, dicha obra se habría extendido entre el último cuarto del siglo XIII y la primera mitad del XIV (CRESPO REDONDO, 207: p. 394). Frente a esta afirmación tan categórica, que otorga la misma cronología a todo la muralla burgalesa, debemos indicar, que como en casi todos los ejemplos existen procesos y evoluciones. La propia existencia de las puertas mudéjares de San Martín y San Esteban es el mejor argumento. Asimismo, junto a éste último acceso, tenemos todo un largo lienzo constituido por tres torres cuadrangulares, con sus correspondientes lienzos: toda la obra es unitaria y su cronología es de finales del siglo XII. Más aún, la puerta de San Martín se construyó entre dos cubos ultrasemicirculares, torres que podrían pertenecer a un recinto anterior. De hecho, J. Ortega Valcárcel habla de una cerca, para el siglo XII, que se extendería desde la puerta vieja de San Esteban hasta el borde del camino francés y que continuaba a lo largo de dicha 
vía hasta la puerta vieja de San Pedro o de San Martín (CRESPO REDONDO, 207: p. 392).

A lo largo de este recorrido hemos dejado otros tantos ejemplos, de momento este estudio se ciñe a las ciudades fortaleza descritas. Espero en próximos trabajos avanzar en el análisis.

\subsection{El modelo de muralla urbana de repoblación}

Los ejemplos anteriormente citados son algunas de las cercas construidas aplicando un mismo patrón y todas se erigieron en momentos de crisis. Hoy en día, es extremadamente complejo saber cuál de todas ellas serviría de modelo o patrón de referencia a las demás. Sin embargo, fuese la que fuere, se situó como un eslabón entre éstas y las murallas tardorromanas de Lugo, Astorga o León. Quizá Zamora podría situarse como el primer modelo medieval.

Los lugares elegidos para emplazar las nuevas ciudades fortaleza persiguen el aislamiento total, a priori conseguido gracias a la topografía del terreno. Salvo algunos de los núcleos heredados tras la conquista, como Toledo y Talavera, el resto surgen en mesetas cortadas por uno o dos cauces fluviales. Otros, como Madrid, para su segundo recinto, se adaptan a las distintas elevaciones forjadas por cursos de arroyos estacionales. En cualquier caso, cuando la naturaleza no aísla el asentamiento se excavaran profundos fosos o cárcavas, como las de Madrid o Palencia. Pero además, los lugares elegidos contienen otras ventajas, controlan y protegen pasos estratégicos, como vados o puentes en rutas de vital importancia para los reinos de León y Castilla. Las ventajas no se acaban aquí, pues en su entorno inmediato y en el territorio que gobiernan, las posibilidades de desarrollo económico, fundamentalmente agrícola y ganadero, es patente. En definitiva, se dan las circunstancias objetivas para impulsar la edificación de grandes recintos amurallados.

Desde que Alfonso $\mathrm{VI}$ anexionara Toledo al reino de Castilla y León, a grandes rasgos, podemos establecer cuatro etapas evoluti- vas en la construcción de murallas o cercas urbanas. Todas ellas están condicionadas por los avatares políticos peninsulares y asimilan los estilos arquitectónicos de cada época. En todos los casos, la construcción de perímetros urbanos evoluciona a partir de núcleos bien diferenciados. En la Transierra, región conquistada a los musulmanes, la actividad constructiva estuvo encaminada a reparar o consolidar las defensas heredadas. Mientras que en la Extremadura, cuyos territorios fueron colonizados sistemáticamente alrededor del año I I00, el trabajo será más concienzudo. Los enclaves elegidos como cabeza de territorio, Salamanca, Ávila o Segovia, aunque no eran lugares abandonados, ni despoblados, sus poblaciones pueden considerarse como residuales. Los tres ejemplos, son centros heredados de culturas anteriores, hispanorromana y visigoda. A partir de los restos conservados se articulará la nueva población, en este caso, la reconstrucción es un hecho, incluso en algún caso podemos hablar de reconstrucciones integrales. En todos ellos aún pueden documentarse restos de varias fases culturales. Cronológicamente, este momento se alargaría entre finales del siglo Xl y primera mitad del XII.

Los muros se construyen, en la mayoría de los casos, reutilizando material de edificaciones anteriores. Es sencillo comprobar, como estelas de las necrópolis tardorromanas ahora se convierten en piezas para componer los paramentos regulares, cuyas hiladas son niveladas mediante engatillados o con ripios de pequeño tamaño. Las torres de flanqueo son cuadrangulares y las puertas, de acceso directo, protegidas con torres laterales de flanqueo. No son muchos los ejemplos, Ávila, Salamanca o Sepúlveda.

La segunda etapa se corresponde con el periodo central de levantamiento de recintos amurallados. Impulsada por Alfonso VII, se inicia una ambiciosa política de construcción de murallas. Prácticamente, la mayoría de los perfiles de las ciudades extremaduranas, sorianas y de la Transierra se configuran a lo largo del segundo tercio del siglo XII. El modelo es muy similar, todos los nuevos recintos nacen de los "castillos" ya construidos. Ahora, no existen diferencias, amplían el espacio habitado intra- 
muros, da igual que tengan un origen hispano musulmán o que fuesen levantados durante el reinado de Alfonso VI. Los nuevos espacios cercados serán enormes, tanto que algunas de las hectáreas estarán desocupadas durante decenios. Durante largos años no se dispondría del número de colonos suficiente como para poblar las ciudades ampliadas. En parte, este lento proceso de ocupación tiene una causa. Algunos de los perímetros diseñados tardarán en cerrarse más de cincuenta años.

La planta de la ciudad se adapta al terreno buscando la protección de defensas naturales; en la mayoría de los ejemplos se trata de mesetas elevadas, cuyas paredes, casi siempre verticales, han sido formados por cauces fluviales, sobre los que tienen un dominio estratégico al controlar un vado o puente. Cuando en alguno de sus lados carece del aislamiento se excavan fosos o cárcavas.

Todo el perímetro se levanta, precisamente, en los bordes de las mesetas con el fin de aumentar verticalmente la imagen de inexpugnabilidad. Esto es, la ciudad cuenta con altos muros difíciles de escalar. En los lados en donde se abren fosos, la muralla también se ubica en el borde de las cavas.

Lógicamente, como consecuencia de lo expuesto en el párrafo anterior, todas las murallas deben estar perfectamente asentadas, más bien ancladas al terreno, con el fin de evitar su rotura o desplazamientos hacia los barrancos. La solución propuesta, como era de prever, es la preparación de una buena cimentación. En aquellos ejemplos en los que ha habido aplicación de metodología arqueológica se demuestra la existencia fosas de cimentación. Y ésta variará en función del suelo. A priori, todas tienen que adaptarse a la topografía, por lo que veremos desniveles y escalonamientos a lo largo de todos los perímetros. Dicha técnica la podemos comprobar en dos ejemplo, en Ávila, las torres de flanqueo de la Puerta del Río no están al mismo nivel; en Madrid, en el frente del manzanares, el sector del primitivo albacar, vemos como un lienzo de la muralla está escalonado.
Volvamos al suelo. En aquellos lugares en donde las murallas se asientan sobre la roca, como en Zamora, la fosa excavada en caja, no es muy profunda (fig.9). Sin embargo, cuando el terreno es blando, de arenisca 0 arcillas, como en Madrid, las fosas pueden alcanzar profundidades superiores a los dos metros (fig. I0). Es este último caso se busca un buen asentamiento de la estructura, por lo que se sobrepasan los niveles blandos e inestables, como los depósitos antrópicos.

Para las torres, el fundamento es más complejo, pues al desarrollarse perpendicularmente a los muros, tienen que adaptarse al desnivel del terreno, nivelación que se consigue mediante la utilización de zarpas escalonadas. En cualquier caso, la cimentación de lienzos y torres suelen forman un solo cuerpo.

Una vez colmatada la fosa se levantarán los lienzos. Casi todos los ejemplos demuestran la existencia de zarpas o zócalos, de una o varias hiladas escalonadas, como basamento, técnica que ayuda a sujetar mejor la verticalidad del resto de la obra.

La fábrica de los muros es ejecutada por varias cuadrillas que trabajan coordinadamente, pero en distintos lugares hasta que terminan por confluir en un mismo punto, por lo que es muy fácil descubrir en los lienzos, y raramente en las torres, las líneas o cremalleras de unión de dos de ellas. Igualmente, la talla de las piezas pétreas por los canteros se realiza in situ.

La siguiente cualidad es la forma de construcción de la muralla, ya en su alzado. Su fábrica es horizontal, es decir se levanta hiladas de manera progresiva. Aunque no existen huellas al respecto, es muy posible que se prepare un encofrado de madera para sujetar, tanto los sillares como el mampuesto concertado o regularizado de las caras vistas. A continuación se rellenaba el núcleo de la muralla con hormigón compuesto por una argamasa de cal y tierra con piezas de pequeño y mediano tamaño. La prioridad es dar a toda la estructura consistencia y dureza. 
En cuando a la fábrica de las murallas, no existe un modelo único, aunque sí podemos establecer tres tipos de paramentos que emplean el granito o la caliza. En Zamora y Salamanca, todo el perímetro está construido con sillares regulares bien trabajados y colocados. En Ávila, se utiliza la disposición en «espejo», piezas dispuestas verticalmente, aunque existen diferencias dependiendo de los sectores. En el frente de San Vicente, se certifica la reutilización de materiales ${ }^{7}$, lo que les da una fisonomía más cuidada y antigua, pues hay bastantes piezas regulares; sin embargo, para el resto de los frentes, se utiliza el mampuesto de hiladas en espejo, que son niveladas con ripio. Esta misma técnica la tenemos en Sigüenza y Segovia. Para el resto de los ejemplos se emplea el mampuesto concertado. La altura que pueden alcanzar los lienzos varía en función de los lugares, pero por término medio, vienen a desarrollar entre los 12 y los 15 metros incluida la línea de almenas. Por otro lado, el espesor de los muros casi siempre superan los dos metros de ancho, por lo que tenemos estructuras de aspecto pesado y robusto.

Para defender los lienzos se disponen numerosas torres de flanqueo dispuestas en serie, Ávila cuenta con 88, Plasencia con 73 y Madrid alrededor de 80. En otros casos, como en Béjar, la presencia de cubos se reduce a proteger los ángulos o se erige una sola torre en un punto central de los frentes.

Las torres, aunque tampoco son homogéneas, presentan dos tipos de plantas, las semicirculares y las ultrasemicirculares. El empleo de una u otra está determinando por un cambio constructivo y, por lo tanto, son dos fases cronológicas bien distintas. Las primeras son las más comunes y en alguno de los caso, como Zamora, pueden llegar a ser cónicas. Las segundas casi son únicas y se emplearon en Ávila y Plasencia. Recordemos, que la villa cacereña fue impulsada por Alfonso VIII a partir de I I97. En Ávila, uno de los frentes, el menos monumental, cuenta con torres semicirculares, mientras que los otros tres son ultrasemicirculares. El mismo rey castellano, mediante un privilegio del 5 de marzo de I193, por el que concedía términos a la ciudad, eximió temporalmente a los caballeros abulenses de la entrega del quinto del botín para que pudiesen revertir en la cimentación y en las "turres fortissime" (GONZÁLEZ, 1960:t. III, pp. 87-90). Además, en la parte alta de las torres se va a introducir un motivo decorativo mudéjar: una cenefa de ladrillo. Uno y otro dato, nos permiten interpretar que a principios de la década de los noventa se estaban construyendo las ultrasemicirculares.

Para finalizar esta parte de la exposición nos centraremos en los lugares neurálgicos de los perímetros: los accesos. Habitualmente, existía uno por flanco o lado, aunque, no todas las puertas estaban abiertas. Incluso en determinados circunstancias llegaban a tapiarse, sobre todo durante las crisis bélicas o epidemias.

Las puertas regularizan el tránsito de personas, animales y mercancías entre el exterior y el interior de las ciudades. Al tratarse de una apertura en la muralla, son puntos débiles para la defensa conjunta de los perímetros amurallados. De ahí que los accesos sean los lugares con mejor protección. Su perfil irá evolucionando hasta convertirse en verdaderas fortalezas independientes. Los accesos de mediados del siglo XII desarrollan un mismo patrón y sus constructores vuelven a tomar como referencia las puertas tardías romanas, como las de Veleia, Contrebia, Lucus, Asturica o Caesaraugusta: son un solo vano y están flanqueadas por dos torres semicirculares (figs. I I a- | 2) (FERNÁNDEZ OCHOA y MORILLO, 2006: p. 269).

La comunicación entre el exterior y el interior de las ciudades se hace a lo largo de un pasillo de manera franca y directa, bajo un arco de medio punto y bóveda de medio cañón (fig. l l b y c). Las puertas, que se alinean con los lienzos de la muralla, están protegidas

7 Asistencia Técnica de Patrimonio, S.L.: Informe Técnico de los trabajos de investigación arqueológica. Proyecto de restauración integral de la muralla de Ávila y su entorno; diciembre 1998-mayo 1999 (FEDUCHI, 2003: 82). 
con dos torres macizas de flaqueo de planta semicirculares, salvo en Ávila y Plasencia que son ultrasemicirculares (figs. I3- 17). En algunos de los ejemplos estos cubos están ataludados. Igualmente, en numerosos casos estas torres suelen tener un mayor tamaño que aquellas que protegen los lienzos.

El arco de acceso se cierra mediante dos hojas de madera que se desplazan de dentroafuera girando con gorroneras inferiores $y$ superiores. Inmediatamente después, un rastrillo que se desliza entre dos arcos paralelos de medio punto, aísla el acceso principal, del interior de la ciudad. En algún caso, aunque no podemos confirmar si se trata de la misma época, un matacán interior protege el espacio entre ambas puertas. El acceso a la parte superior de la puerta, lugar desde donde es manejado el mecanismo del rastrillo, se hace desde un acceso abierto en la cara interna de la muralla, en donde nace una empinada y estrecha escalera.

\subsection{La evolución de las ciudades amuralladas tras la muerte de Alfon- so VII}

Tras la muerte de Alfonso VII, el reino castellano leonés se reparte entre sus hijos Sancho III, que hereda Castilla, y Fernando II, que recibe León. A la guerra fronteriza contra los musulmanes se añade ahora un nuevo conflicto. Las regiones cercanas a la raya dibujada por el Emperador para separar los reinos van a ser fuertemente fortificada, sobre todo en el lado leonés. A partir de aquí los recintos murados desarrollan una tercera fase, etapa que debemos desglosar en dos, pues cada reino ejecuta su propio programa de fortificaciones.

Aquí vamos a analizar con una mayor profundidad el ejemplo castellano, pues entre otras características, introduce el estilo mudéjar como una excelente respuesta a las necesidades militares a las que tienen que hacer frente.

En León, durante los reinados sucesivos de Fernando II y Alfonso IX, aunque mucho más con este último, la iniciativa constructiva fue muy fuerte (MAÑARES PÉREZ, VALBUENA Y ALONSO PONGA 1980a y 1980b). Con respecto al segundo de los monarcas, y dejando a un lado la actividad en los edificios y conjuntos religiosos, se trabajó intensamente en la restauración y en la construcción de nuevas cercas. El obispo Nuño repara las de Astorga y doña Berenguela las torres de León. Alfonso IX aportaría los recursos necesarios de su propio pecuniario, contribución que permitiría a un canónigo, en 1214 , reconstruir algunas partes; en 1217 , para otra zona cercana a la calle de la Canónica; o en la puerta de la Platería, concluida en 1220 (GONZÁLEZ, 1944: t. I, pp. 474-475). Sendas inscripciones colocadas en la propia muralla leonesa documentan las iniciativas. La primera de las inscripciones se encontraba en el interior de uno de los cubos y dice lo siguiente:

\section{"Ego Guterius Didaci Sedis Legionensis Eccle- siae Canonicus hoc opus feci di pecunia Ade- fonsi Regis Legionensis sub era MCCLV [...]". En la segunda, que estaba en el arco, se lee: "Ego Guterius Didaci Canonicus Legionensis Eclessiae hoc opus feci de pecunia Adefonsi Regis Leginonensis sub era MCCLVIII [...]" (RISCO, 1792: p. 70).}

En 1230, ahora en Zamora, se terminaría la Puerta de Olivares (GONZÁLEZ, 1960: t. I, pp. 474-475). Para hacer frente a las nuevas construcciones se abandona el aparejo regular y el de mampostería concertada y se adopta el encofrado de cal y canto para levantar tapias de hormigón. En las puertas el estilo comienza a ser el gótico, con entradas bajo arcos ojivales.

Muchas fueron las pueblas emprendidas, tanto a lo largo de la frontera con Castilla, como contra los musulmanes. Los ejemplos más destacados son Toro, Mansilla, Ciudad Rodrigo, Villalpando, etc.; las dos últimas pobladas por Fernando II. Villalpando, en la primera línea frente a Castilla, es uno de los modelos de villa fortificada, levantada con planta rectangular, aunque lo más habitual es la planta ovalada, con castillo en uno de sus ángulos. En la fábrica de los muros se ha empleado la técnica constructiva de tapias de encofrado de hormigón de cal y canto (SERRANO-PIEDECASAS 
y MUÑOZ GARCíA, 1994 y 1996). Por lo general, para las puertas, al menos hay dos tipos: en forma de callejón perpendicular a los lienzos - se abren bajo torres de sillería, con arco apuntado, de acceso directo y cierre de quicios dobles (GUTIÉRREZ GONZÁLEZ, 1995: pp. I52-153 y 174. MARTÍNEZ SOPENA, 1989: p. 128). Un ejemplo de este último es Ciudad Rodrigo (LARRÉN IZQUIERDO Y GUTIÉRREZ GONZÁLEZ, 1999, pp. 502503 y 505. MUÑOZ GARCÍA y SERRANO-PIEDECASAS, 2000: p. 384). Cuando existen torres de flaqueo, pueden ser "meros engrosamiento rectangulares y macizos de los muros", o sólidas de sillería. Aparte de la actividad en la frontera, la ciudad de León, a pesar de estar en el interior, tiene que reparar sus muros y utiliza para ello esta técnica de encofrado de cal y canto, el mismo arte que será empleado en levantamiento del segundo recinto, el del Burgo Nuevo.

Las murallas de sillar, sillarejo o mampostería concertada, que trasmiten al ojo del viandante una imagen de mayor monumentalidad. También son más costosas, pues tanto los materiales, como los operarios especializados exigen un mayor presupuesto. Además, la actividad constructiva se prolonga demasiado en el tiempo. Frente a este tipo de fábrica aparece el encofrado, más barato, que no necesita operarios tan cualificados y acorta considerablemente los tiempos en la ejecución de la obra. En cuanto a la resistencia frente a los asedios y asaltos, prácticamente, es la misma. La gran diferencia, además de la visual o la estética, llegará con el paso del tiempo o la climatología, que terminarán por dañar más a la tapia que a la piedra.

En frente, Castilla, con un buen número de enclaves, como Medina del Campo, Navas del Rey, etc., también tienen murallas de este tipo (GUTIÉRREZ GONZÁLEZ, 1995: pp. 173-174.). Da la impresión de que maestros y peones trabajasen a ambos lados de la frontera. También, es muy frecuente la utilización de tapias de hormigón de cal y canto en la Transierra, como en el castillo de Escalona (Toledo), la muralla de Buitrago, datada por Fernando Sáez Lara a lo largo del siglo XII (1993: p. I43), y en Alarcos, que pertenece al intento de Alfonso VIII por reconstruir sus muros durante los días previos a la batalla (I 195) (CABALLERO KLINK y MENA
MUÑOZ, 1986. JUAN GARCÍA, CABALLERO KLINK y FERNÁNDEZ RODRÍGUEZ, 1995: p. 52). Las transformaciones en las defensas castellanas no se circunscribirían exclusivamente en las fronteras. Las retaguardias inmediatas tampoco se desprotegen (CADIÑANOS BARDECI, 2002).

Alfonso VIII tendría que cubrir varios frentes, el navarro, el leonés y el almohade; aunque será este último el que obligue al castellano a desarrollar una intensa política de defensa de la frontera frente a los almohades. La situación militar se complica por la presión de los norteafricanos como consecuencia de la debacle de Castilla en Alarcos. Todo parece indicar que se introducen importantes mejoras durante el reinado de este monarca. Aunque ahora se constata un cambio de estilo arquitectónico, ya que se abandona el románico y se evoluciona hacia el gótico o el mudéjar.

Ahora se edifican puertas y se levantan torres aplicando el "aparejo toledano", estilo que tiene su origen en el siglo $X$ en la ciudad de Toledo y cuya referencia es la mezquita del Cristo de la Luz, erigida entre diciembre del 999 y enero del 1000. Este estilo emplea la mampostería irregular formando cajones entre verdugadas de ladrillos o de pequeñas lajas de piedra, protegidos por machones también de ladrillo (ROJAS RODRÍGUEZ-MALO y VILLA GONZÁLEZ, 1999: pp. 583-585. FRAILE DELAGO, 2005: cap. 5, p. 10). Uno de las introducciones novedosas, precisamente, es la utilización del ladrillo como un material de obra fundamental, duro, resistente, fácilmente trabajable, bastante más barato que la piedra y accesible. Tanto la mampostería como el ladrillo no necesitan trabajadores tan cualificados como los canteros.

Aparte del cambio de estilo arquitectónico aparecen nuevos elementos que deben mejorar la capacidad de defensa de las ciudades. En primer lugar, se transforman las puertas, tanto en planta, como en alzado. El segundo lugar, se recupera la torre de planta cuadrangular desechando la semicircular.Y, tercero, inspirándose en otras fortificaciones hispanomusulmanas, se incorpora la torre albarrana. En definitiva, se abandonan los modelos norteños, para adquirir técnicas desarrolladas por los musulmanes. 


\subsection{Las puertas de tradición his- panomusulmana}

Para conocer mejor esta fase tendremos que otear varias ciudades, la mayoría ubicadas en la Transierra y en la línea del Tajo. Los ejemplos a tener en cuenta son las puertas de El Vado, Bisagra Nueva y Bisagra Vieja en Toledo, la puerta de la villa en Maqueda (Toledo), la Torre del Reloj en Buitrago y la de Guadalajara en Madrid. A éstas, a priori, deberíamos añadir otras dos, ambas erigidas en Burgos, las de San Esteban y San Martín (figs. I 8-22).

Los accesos que van a servir de referencia, pues han sido datados tras sendas intervenciones arqueológicas, son los de la ciudad de Toledo. Los cambios en las dos puertas se incluyen dentro de una reforma más profunda que incluye también algunos tramos de la muralla, con el levantamiento de varias torres cuadrangulares (RUIZ TABOADA, 2005: p. 235).

La puerta Vieja de Bisagra (fig. I 8) destaca por su dualidad constructiva, la parte inferior edificada con grandes bloques de gneis y la superior con mampostería concertada. El acceso es directo mediante un arco de herradura, cuya dovela está formada íntegramente por material pétreo. La defensa se complica con la presencia de buhedera y buharda, rastrillo y un postigo lateral.Verticalmente, la puerta se organiza en tres niveles: la planta baja con el pasillo de acceso, en donde también se abre un puerta adintelada desde donde arranca una estrecha escalera con varios tramos, que permite subir a los niveles superiores; la primera planta 0 buharda, en donde reside el cuerpo de guardia y se controla el rastrillo; la planta superior, abierta, completada con una crujía exterior, que desempeña una inestimable labor de atalaya. El conjunto se completa con una torre de flanqueo situada a su derecha, que si miramos desde extramuros está en una posición muy adelantada en relación con la puerta (VALDÉS FERNÁNDEZ, 1987: pp. 282-285. 2004: p. 60).

Esta puerta, en opinión de Fernando Valdés, fue edificada durante el reinado de Alfonso VIII, entre finales del siglo XII y principios del XIII (1987: p. 293. 2004: p. 65); es decir, entre la derrota de Alarcos y la victoria de Las Navas (VALDÉS FERNÁNDEZ, 2006: p. 42I). Mas o menos, ésta cronología se ha visto confirmada con la reciente intervención arqueológica ejecutada en la toledana puerta del Vado (RUIZ DETABOADA y CARROBLES, 2006: p. 40I).

La Puerta del Vado muestra numerosas semejanzas con la Vieja de Bisagra. Tiene planta cuadrangular, rompe la línea de la muralla, tanto en el interior como en el exterior; emplea la combinación de paramentos, el pétreo y la mampostería concertada; el acceso se realiza atravesando un arco de herradura y cuenta con un rastrillo (PONCE DE LEON, 2004: pp. 27I-272. RUIZ DETABOADA y CARROBLES, 2006: pp. 394-395). Las dos puertas en sí mismas pueden convertirse en fortalezas independientes (PONCE DE LEON, 2004: p. 272).

Este sistema de defensa autónomo tiene uno de sus puntos fuertes en la estructura vertical, distribuida en varias plantas. La baja, como es lógico es la del acceso a la ciudad, con una puerta exterior, zaguán abovedado, rastrillo, zaguán abovedado y puerta interior (fig.23). En la planta primera, o estancia abovedada, se cobija el cuerpo de guardia y es desde donde se manipula el rastrillo. La segunda planta "[...] se configura en su crujía exterior como una galería techada y abovedada, ciega hacia el interior y con huecos para la defensa exterior", pero protegida con un almenado en su perímetro. "Esta planta es la que queda a pie llano respecto al adarve de la muralla en que se ubica la puerta". En el espacio interior entre puertas, se abre una poterna, que mediante una empinada escalera, permite acceder a los pisos superiores (PONCE DE LEON, 2004: p. 272-274).

En Buitrago nos debemos fijar en la Torre del Reloj, otro complejo acceso (fig. 19). Cronológicamente, tenemos una primera fase constituida por un arco de herradura doble de ladrillo sobre jambas de piedra, que podría estar protegida y flanqueada por dos torres cuadrangulares de mampostería encintada. Según Fernando Sáez esta fase sería contemporánea a las torres colindantes. Posteriormente, la puerta complicó su acceso construyéndose un bastión pentagonal, que se abre en su lateral mediante 
un arco ojival. El resto hasta desembocar en la puerta primitiva, forma un acceso en recodo. Esta última fase se erigirá al mismo tiempo que el refuerzo del muro y la barbacana, aproximadamente del siglo XIV (SÁEZ LARA, 1993: pp. |38-139 y |43).

Sin embargo, para la primera de las fases contamos con alguna opinión no coincidente en la cronología. Para Basilio Pavón Maldonado, el paramento, al utilizar piezas individuales de mampostería enmarcadas con ladrillos, indica que estaríamos es una modalidad toledana propia de los siglos XI o XII (PAVÓN MALDONADO, 1988: pp. 48-49). Por el abanico de fechas propuesto significaría que la Puerta del Reloj sería una de las construcciones erigidas en los primeros años de la Repoblación. En la misma línea crítica se sitúa Alonso Zamora, no solo para el acceso, sino también para otros puntos de la muralla (| 993: pp. | |4- | | 5). La búsqueda de paralelos, ha llevado a Zamora a localizar ejemplos de paramentos similares a lo largo de los cauces del Duratón y Riza en Segovia, como en Sepúlveda, Fuentidueña, Ayllón, Saldaña de Ayllón y Fresno de Cantespino. Todos estos enclaves militares tienen una directa relación con la defensa del los pasos de la Sierra, fundamentalmente Somosierra. La cronología apuntada se centra en el siglo XI (ZAMORA CANELLADA, 1994 y 2008. ZAMORA CANELLADA y VELA COSSíO. 2005). Por los datos arqueológicos, algunos tomados de otras fortificaciones, como Peñafora (Guadalaraja), Talamanca (Madrid) o Maqueda (Toledo), estaríamos ante un nuevo intento por mejorar el sistema defensivo en torno a Toledo, bien en los últimos años de Califato o durante la taifa toledana. Este hecho supone que la frontera no estaría en las cumbres de Guadarrama, sino en la vertiente norte. La fecha límite para la configuración de este enésimo sistema sería 1076, momento de la repoblación definitiva de Sepúlveda.

En cuanto a la planta y al desarrollo vertical, a diferencia con las puertas toledanas, en donde el ingreso a las plantas superiores se hacía desde el pasillo entre puertas, a pie de calle, aquí se consigue mediante un acceso en altura localizado en la fachada intramuros, en un nivel por encima del alfiz del arco.
El recorrido por los ejemplos a los que hemos recurrido para encontrar paralelos, continúa en la población de Maqueda. La puerta de la villa, hoy una de las entradas a la iglesia parroquial, es el resultado de una larga evolución constructiva desarrollada en cuatro fases: las tres primeras de tradición hispanomusulmana y la última enteramente cristiana. Lógicamente nos vamos a fijar en una de las tres primeras actuaciones, ya que ha sido comparada y asociada a la Puerta del Reloj de Buitrago (PAVÓN MALDONADO, 1999: p. 478. ZAMORA CANELLADA, 1993: p. 116).

La cronología de ésta puerta es confusa, pues según quien proponga una fecha, podría estar a caballo entre los siglos X y XIII. Para Basilio Pavón Maldonado estaríamos frente a una puerta de acceso directo flanqueada por torres cuadrangulares, al que se añadiría, ya en época cristiana, el arco de la buhedera exterior. En definitiva para la puerta hispanomusulmana da la segunda mitad del siglo $X$, es decir, califal, mientras que para la reforma mudéjar propone los siglos XII-XIII. Sin embargo, observamos cierta confusión, pues para la de Buitrago, tratándose de una arquitectura gemelar, adelanta un siglo la fecha de la fábrica (PAVÓN MALDONADO, 1999: pp. 28, 438, 478 y 48I).

Lo verdaderamente probable para estos dos últimos ejemplos, es que ambos pueden suponer el modelo precursor y el antecedente de las de Toledo, Madrid o Burgos, y cuya cronología debería situarse a lo largo de la primera mitad del siglo $X \mid$.

La obra resultante para la de Guadalajara en Madrid supuso una reforma extraordinariamente profunda (fig.20). A pesar de que se mantienen los cubos semicirculares de flanqueo, la nueva planta rompe el alineamiento con la muralla, aunque su desarrollo se traslada hacia el interior de la Villa. Asimismo, el arco original sería sustituido por otro de forma muy distinta. Agustín Gómez Iglesias, a partir de las medidas aportadas por los documentos consultados, ha "[...] trazado un arco de herradura con las proporciones califales" (GÓMEZ IGLESIAS, I95I: p. 328). Este último detalle, implica que el estilo de toda la nueva fábrica es el mudéjar. En cuanto 
a los distintos paramentos, tan solo podemos enumerar los materiales, como cal, piedra, ladrillo, reconociéndose también el empleo de sillares. Si tomamos como ejemplo las puertas de Toledo, predominaría la mampostería encintada con verdugada simple de ladrillo, también denominado aparejo toledano. Ya en su momento, el propio Gómez Iglesias observaría que el aspecto de la Puerta de Guadalajara era muy similar a la Vieja de Bisagra (195 I: p. 329). No obstante, persiste la duda sobre la rosca del arco, pues podría estar formada, tanto por dovelas de ladrillo, como por sillares; mientras que las jambas sí estarían formadas por grandes bloques de piedra.

Continuando con las semejanzas entre las distintas puertas comparadas, la de Madrid, también tiene un desarrollo vertical en tres niveles:

- En la planta baja, siguiendo el esquema toledano, como elementos claros, tendríamos uno de los arcos de entrada, el rastrillo, el pasillo hasta el arco de salida y una pequeña puerta adintelada desde donde arranca la escalera que conduce a las estancias superiores.

- La primera planta o buharda era la residencia del cuerpo de guardia y desde donde se controlaba el rastrillo.

- La segunda planta, abierta al exterior, es la azotea y sirve como atalaya. Por la existencia de una serie de arquillos, es muy probable que la de Guadalajara, igualmente, contara con una crujía.

Lejos del Reino de Toledo, al norte de Castilla, también podemos encontrar algún ejemplo de este modelo de puerta. En la ciudad de Burgos la actividad de los maestros mudéjares fue muy dinámica gracias al impulso personal de Alfonso VIII. Durante su reinado, el centro religioso ubicado extramuros, el Real Monasterio de Las Huelgas tuvo varias intervenciones (OSABA Y RUIZ DE ERECHÚN, 1976: p. 79. CONCEJO DÍAZ, 2003: p. 361). En el conjunto monástico el muro y el acceso primitivo de la capilla de la Asunción hay que situarlo entre 1 187, fecha en la que se empezó a construir Las Huelgas, y 1212 (CONCEjO DíAZ, 2003: p. 34). Empecemos por la de San Esteban (fig.2I), identificada en un documento de 1253, emitido por Alfonso $X$, como la "puerta mayor de la villa" (BALLESTEROS BERETA, 1943: p. 4). Ma Luisa Concejo ha datado la puerta en la primera mitad del siglo $X I I I$, con reformas a finales del XIV, a principios del $X V$ y con otros destalles bajo el reinado de los Reyes Católicos. No obstante, el intento de aportar una cronología aproximada no parece tarea fácil. La participación en alguna reforma del maestro mudéjar Mohamad, en los primeros años del siglo $X V$, parece orientar la opinión de varios historiadores, entre ellos Torres Balbás (1949: p. 342). José Luis Monteverde ha propuesto una evolución en la edificación de dos fases. El cuerpo bajo de la puerta dataría de finales del XII o principios del XIII. Esta afirmación la hace apoyándose en las obras que Alfonso VIII realizó en el palacio que donó para la fundación del Las Huelgas. La segunda fase, que se corresponde con el cuerpo alto, que la data en la segunda mitad del XV (MONTEVERDE, 1949: pp. 31-32). Finalmente, Concejo Díaz, es partidaria de las dos fases, pero piensa que la primera de ellas se construyó durante el reinado de Fernando III (1217-1252), mientras que la segunda lo hace con el arzobispado de Pedro Tenorio (13751399) (CONCEJO DÍAZ, 2003: pp. 376 y 379).

Una descripción detallada de la puerta modificará la cronología, al menos en su primera fase. La construcción se parece mucho a las puertas del Vado y Bisagra Vieja. Las características generales son las mismas. El acceso está protegido por dos torres; aunque, al exterior mantiene la alineación con la muralla, al interior se rompe. El pasillo cuenta con tres arcos de herradura y dos estancias con bóveda de medio cañón. El arco intermedio es un doble arco por el que se desliza el rastrillo. En la pared derecha, entre el rastrillo y arco que desemboca en la ciudad, se abre una poterna adintelada por la que se asciende al primer piso o buharda, en donde reside el cuerpo de guardia y se controla el mecanismo del rastrillo (figs.24-25).

La segunda de las puertas burgalesas es la de San Martín (fig.22), aunque es más sencilla que la de San Esteban, sigue el mismo patrón, pero cuenta con algunas diferencias muy marcadas: 
aparentemente, carece de cuerpo superior, y el acceso no se protege con torres cuadrangulares, sino con torres de medio punto. El pasillo es similar, pero los tres arcos de herradura son de mayor tamaño. Ubicada en el llamado Paseo de los Cubos estuvo siempre ligada al Camino de Santiago y, según la tradición, era por donde entraban las comitivas reales en la ciudad. La mayoría de los historiadores apuestan por darle una data en la segunda mitad del siglo XIV, relacionándola con el reinado de Enrique || (|369-1379), pues se parte de una inscripción de 1372 colocada en el muro de dicho paseo y que recoge la finalización de la construcción de la muralla burgalesa (OSABA Y RUIZ DE ERECHUN, 1976: p. 82. CONCEJO DÍAZ, 2003: pp. 381-382). Aunque hay quien opine de manera distinta y lleve su edificación al siglo XII (M. DE V., 1883: p. 182).

Observando la puerta in situ, podemos decir que tiene ciertas similitudes con la Puerta de Guadalajara de Madrid. El punto de coincidencia es la sustitución del acceso de estilo románico por el mudéjar. Manteniendo los dos gruesos y robustos cubos semicirculares como torres de flanqueo. La puerta en sí, tendría un primer arco de herradura que da paso a una estancia abovedada con medio cañón, otro doble arco, también de herradura para el rastrillo, una nueva estancia abovedada y un nuevo arco de herradura que desemboca en el interior de la ciudad. Tanto las fachadas extra como intramuros muestra un doble aparejo, irregular para el grueso de la puerta y el ladrillo para la rosca del arco. La existencia de rastrillo implica, aunque ha desaparecido, la existencia de un segundo cuerpo, primera planta o buharda, en donde residiría el cuerpo de guardia y se controlaría el rastrillo. El acceso a esta primera planta se hacía desde el interior de la ciudad, a través de una pequeña puerta abierta a la izquierda del conjunto.

Este tipo de puerta supone un punto estratégico en cada una de las ciudades, pues pueden constituirse en enclaves, pequeños castillos, independientes dentro de los perímetros. Tenemos documentos, aunque tardíos, de finales de la Edad Media, que recogen el nombre de aquellos individuos, personajes de gran relevancia dentro de las sociedades locales, que custodiaban las puertas comandando una pequeña guarnición. Eso ocurre en Madrid, en la crisis del final del reinado de Juan $I$, este ordenaría a Ruy Sánchez Zapata la entrega de la torre de la puerta a Don Gabriel Manrique, Comendador Mayor de Castilla ${ }^{8}$. En el mismo documento, la orden se extendía a todas las torres y puertas, aunque se insiste con la de Guadalajara ante la reiterada negativa de Ruy. Años después, en otro momento de crisis, ahora con Enrique IV, se vuelve a demostrar su interés estratégico. En una carta del monarca, remitida al Concejo de Madrid en 1465, se ordenaba que esta puerta fuese el único acceso abierto de la Villa, pues todas las demás debían estar tapiadas según el mismo había ordenado ${ }^{9}$. Durante la guerra civil entre Isabel I y la Beltraneja estuvo en posesión de Diego López Pacheco, Marqués de Villena, líder del bando que defendía los intereses de doña Juana (GÓMEZ IGLESIAS, 1963: p. 33), y en cuyo conflicto sufrió graves daños.

Esta independencia se potencia, tanto a nivel de calle, como en el adarve, pues, se interrumpe el transito a lo largo de la muralla y lo controla en ambos sentidos. Además, al tener una mayor elevación, actúa de torre obteniéndose una posición de dominio sobre el mismo adarve. En el caso de la puerta de San Esteban, en Burgos, Bisagra Vieja y el Vado, en Toledo, Guadalajara, en Madrid, al contar también con hojas de puertas dobles en el interior de la ciudad, el aislamiento es completo, ya que el acceso a las plantas superiores se hace desde una poterna abierta en uno de los laterales del pasillo o, como ocurre en Buitrago, en altura. Este tipo de puerta servía tanto para resistir asaltos y asedios, como para repeler algaradas o revueltas de la población. Por último, al estar ubicadas en lugares sensibles de las murallas, por

\footnotetext{
8 AVM, Archivo de Secretaría, 2/I58/27.

9 AVM, Archivo de Secretaría, 2/31 I/22.
} 
su altura, actúan como atalayas que otean todo su entorno; y como ocurre en Toledo, además se complementa con un contacto visual entre las puertas y las torres intermedias, como la de la Reina.

La puerta tiene tanto un desarrollo horizontal, como vertical. El conjunto traslada al ojo del transeúnte la imagen de un pequeño castillo de planta cuadrangular o rectangular que se extiende, tanto intra o extramuros, rompiendo la línea dibujada por la muralla. Habitualmente sobresale por igual en ambos espacios, salvo el caso de la puerta de Bisagra Vieja, que aparenta un mayor desarrollo hacia el interior, en una falsa apariencia provocada por el quiebro que aquí hace el perímetro del segundo recinto toledano.

El acceso es recto, directo entre el exterior y la ciudad, pero protegido por un complejo sistema de defensa. En los ejemplos bien conservados tenemos tres tipos de fachadas: la puerta de Bisagra Vieja, cuenta con una única torre de flanqueo; las que tienen dos torres semicirculares, reutilizadas del anterior recinto, como las de San Martín (Burgos) y de Guadalajara (Madrid); y las que tienen dos torres cuadrangulares, como la de San Esteban (Burgos).

El tránsito entre el exterior y el interior se hace a lo largo de un pasillo o corredor con tres puertas sucesivas. La principal, la que da entrada a la ciudad, es de arco de herradura, las jambas son de sillería, mientras que la rosca del arco es de ladrillo. Las hojas de las puertas son dobles, de madera, forradas con chapas claveteadas al exterior, abatibles dentro-afuera al girar sobre dos gorroneras - una en el suelo y otra en la parte superior-. A continuación tenemos una puerta intermedia, ésta de rastrillo, cuyo movimiento o deslizamiento vertical queda articulada entre dos arcos de herradura con jambas de sillería y rosca de ladrillo. Entre estas dos puertas se forma un habitáculo independiente y aislado. La tercera de las puertas permite que los transeúntes desemboquen en la ciudad y su compostura es similar a la que permite la entrada: arco de herradura con jambas de sillares y rosca de ladrillo, dos hojas de madera, forradas con chapas claveteadas al exterior, abatibles dentro-afuera al girar sobre dos gorroneras, una en el suelo y otra en la parte superior (fig.23). Sin embargo, para las puertas del Vado, Bisagra Vieja y San Esteban, en este último espacio se abre, en su lado derecho en el sentido de entrada, muy pegado a la fachada exterior, una poterna desde donde arranca las empinadas escaleras que permite acceder a las plantas superiores del conjunto. Esta pequeña apertura solía quedar oculta tras una de las hojas abatibles de la puerta. De esta manera, el control sobre el acceso y el aislamiento con respecto a su entorno era absoluto.

En otros dos casos, sin embargo este acceso se realizaba desde el exterior, pero en la fachada interior de la ciudad. En Buitrago, una puerta en altura, permitía aislar a la guarnición. Esta característica puede interpretarse como una fase primitiva en el desarrollo de este tipo de puertas. El otro ejemplo lo encontramos en Burgos, pero en la puerta de San Martín, el portillo se abre a nivel de calle, en la fachada interior, en un lateral de la puerta. La autoprotección de la guarnición y el aislamiento de la puerta es menor frente al asalto que llegase desde el interior de la ciudad.

La fábrica interna del corredor es interesante. Todas tienen un zócalo de sillería, que alcanza la misma altura que los zócalos de las fachadas interior y exterior. A partir de aquí, la construcción es de aparejo toledano, en su tipo $\mathrm{Al}$, hiladas simples de mampuestos irregulares con piedras pequeñas o medianas nivelando los tramos en la parte superior de la hilada, separadas por verdugadas simples de ladrillo (figs.2425). Este mismo aparejo aparece en los muros del claustro denominado Las Claustrillas y en otras estancias contiguas en el Real Monasterio de las Huelgas en Burgos, institución fundada por Alfonso VIII en I I87. Sólo encontramos dos diferencias, ambas edificadas con el mismo aparejo: hiladas de mampuestos irregulares con piedras medianas enmarcados por ladrillos. Este tipo acentúa aun más la antigüedad de dichas puertas, las de Maqueda y Buitrago. Finalmente, la bóveda que cubre todos los corredores es de medio punto, completamente de ladrillo. 
Verticalmente, las prestaciones como castillo independiente mejoran considerablemente. La puerta de Bisagra Vieja es la que aporta más variantes, pero todas tienen un mismo patrón. Contamos con tres niveles, el de calle, que ya ha sido explicado. Desde el portillo interno o poterna, una estrecha y empinada escalera permite a la guarnición circular entre todas las estancias. Esta escalera puede bloquearse mediante portillos en todas las plantas. El segundo de los niveles es una estancia abovedada desde donde se controla el manejo del rastrillo, siendo además el hábitat del cuerpo de guardia. El tercer nivel, es una crujía exterior con una galería techada y abovedada, ciega hacia el interior y con huecos para la defensa exterior. El resto de la planta es una terraza abierta hacia la ciudad, pero protegida por un parapeto o almenado. El último nivel es el adarve $\mathrm{o}$ atalaya (PONCE DE LEÓN, 2004: p. 273). Al menos esto es así para la puerta de Bisagra y la del Vado, más o menos en la de Guadalajara y Buitrago. Sin embargo, en Burgos tenemos ciertos problemas para comprobarlo, pues la de San Martín ha perdido las estancias superiores. Y, aunque, la de San Esteban desarrolla el mismo esquema, cuenta con una diferencia notable, la secuencia de pequeñas ventanas de arquillos de medio punto no se abren al exterior, sino hacia el interior, ha sido sustituida por pequeñas aspilleras. Tampoco sabemos, la influencia que han podido tener las intervenciones posteriores, algunas documentadas en los siglos XIV y XV (TORRES BALBÁS, 1949: p 342. MONTEVERDE, 1949: pp. 31-32. CONCEJO DÍAZ, 2003: pp. 370-372).

La fábrica de todo el conjunto es muy similar. Todas tienen un basamento de sillares, con piezas de distintas dimensiones según los ejemplos, que suele coincidir con el nivel de las jambas. Este basamento se comprueba, tanto en el exterior, como en el interior, así como en las torres cuadrangulares de flanqueo. La rosca de los arcos, salvo la de Bisagra, es de ladrillo. También habitualmente, el arco suele estar enmarcado con un alfiz de ladrillo. El resto de la obra, exceptuando las bóvedas del corredor, es de aparejo toledano, tipo AI, salvo, como ya hemos indicado anteriormente Buitrago y Maqueda.
Con respecto a la puerta de Buitrago queremos plantear una pequeña reflexión. Aunque cuentan con patrones similares a las otras puertas descritas, recalquemos que existen dos claras diferencias: el aparejo y que el acceso a las plantas superiores se realiza mediante una pequeña puerta en altura.

La fábrica, mampuesto enmarcado entre ladrillos, también se utiliza en flanco de la muralla que se extiende entre dicha puerta y el río Lozolla, incluso el basamento constituido por varias zarpas escalonadas, emplea el mismo estilo edilicio. Hasta ahora, el recinto murado de Buitrago se había fechado como posterior a 1085. Sin embargo, creemos que debería modificarse esta cronología.

\subsubsection{Las torres}

Además de las puertas, otro de los cambios notables en el diseño para las murallas es la recuperación de la planta cuadrangular para las torres. En Toledo en el espacio comprendido entre la Puerta del Vado y el postigo de la Granja, a la secuencia de torres hispanomusulmanas y a las semicirculares cristianas, se añadieran nuevos cubos: los de la Reina, la que está ubicada justo antes de la puerta vieja de Bisagra Vieja, que domina un ángulo del perímetro, y su torre de flanqueo (fig.26). Las tres puertas, Vado, Nueva y Vieja de Bisagra, y las torres se conectan visualmente (RUIZ DE TABOADA, 2004: p. 248).

En Burgos, en el frente de la puerta de San Esteban, junto a la construcción de la puerta se reformó todo su lateral derecho, obra que incluiría tres torres de flanqueo cuadrangulares. Todo este espacio puerta y torres fue construido al unísono.

En Maqueda, donde tenemos otras de las puertas utilizadas como ejemplo, también se construyeron torres cuadrangulares siguiendo el esquema del aparejo toledano.

En conjunto, las plantas de las torres varían en forma y tamaño, tendríamos desde las cuadradas a las rectangulares, de pequeñas como 
las de Buitrago o las de gran tamaño en Burgos, Toledo y Maqueda. Todas tienen basamento de sillares, pero después se desarrollan con el aparejo tolerando, aunque en Burgos las hiladas de mampuestos no se separan mediante verdugadas de ladrillo.

La última innovación, más bien incorporación a la iconografía de las fortificaciones cristianas es la torre albarrana. Basilio Pavón Maldonado entiende que la aparición de este tipo de torres en las ciudades castellanas del centro peninsular está directamente relacionada con el peligro almohade. Defiende que los recintos murados que surgen en este momento incluyan en sus defensas torres albarranas y cita las de Talavera, las de los arrabales de Toledo y las de Benjaque y Alvar Fáñez en Guadalajara. Curiosamente, también encuadra en este grupo las de las Vistillas en Madrid y las de los castillos de Montalbán, Santorcaz y Escalona (PAVÓN MALDONADO, 1992: pp. 56 y 82. 1988: p. 292). Michel Terrassa se atreve, incluso, a dar una secuencia evolutiva para las cristianas. El eslabón entre éstas y las islámicas de Badajoz y Uclés, serían las de Escalona, mientras que las talaveranas aparecerían con la conclusión de este tipo de torre. Entre medias se ubicarían las de Montalbán y las Madrigal de las Altas Torres (Ávila) (TERRASSE, 1970: p. 88).

Entre las más cercanas geográficamente, tenemos los ejemplos de Alcalá la Vieja, datada entre el siglo XII y XIII, y la torre de la Antequera de Toledo, ésta de XIII. Sin embargo, la cronología de ésta última ha sido corregida por Arturo Ruiz Taboada, retrasando su construcción hasta el XIV por el parecido que tiene esta planta y la Puerta del Sol en la propia Toledo, y cuya edificación fue impulsada por el arzobispo Pedro Tenorio (RUIZ DE TABOADA, 2004: p. 243).

En Talavera, en donde a lo largo de todo su recinto se levantan, en serie, más de una quincena de grandes albarranas (fig.27), que se construyeron como una prolongación de las torres cuadrangulares del recinto andalusí. Estas murallas protegían una de las ciudades más extensas de la región, incluso algunos escritores la consideran como la mayor, la más segura y alta. En cuanto a la fábrica de dichas torres, según que historiador se consulte, tendría cronologías dispares. M ${ }^{\mathrm{a}}$ J. Suárez Álvarez apuesta por un fecha muy amplia, siglos XIIXIII (SUARÉZ ÁlVAREZ, 1982: p. 38). Por su parte, Basilio Pavón Maldonado, serían del siglo XIII (PAVÓN MADONADO, 1988: pp. 46, 82 y 47); idea que es compartida por Leopoldo Torres Balbás. Sin embargo, tras las sucesivas intervenciones arqueológicas realizadas en el yacimiento de Entretorres, el equipo de arqueólogos ha planteado dos fases. Aquí han sido documentadas, entre otras estructuras, dos albarranas y una barbacana. Una de ellas, por su paramento, realizado en mampostería encintada, pudo ser construida en época de Alfonso VI. La segunda, junto al antemuro, se correspondería con obras ejecutadas en época de Alfonso VII o Alfonso VIII, de la misma manera que ocurre en otros lugares de Castilla (MORALEDA OLIVARES, MARTíNEZ LILLO y SÁNCHEZ SANZ, 1999-2000, p. 66. MORALEDA OLIVARES, SÁNCHEZ SANZ Y MARTÍNEZ LILLO, 2004: pp. 4I 4-4 I5. MARTíNEZ LILLO, MORALEDA OLIVARES Y SÁNCHEZ SANZ, 2005: pp. 136-137). La analogía se encuentra en el tipo de fábrica, el mampuesto regularizado, empleado en los paramentos de las albarranas de Talavera, así como en algunos lienzos y torres de Plasencia (puerta de Berrozama), Ávila y Montalbán (MARTíNEZ LILLO, 1998: p. 205).

Las ocho torres del castillo de Escalona (fig.28), tradicionalmente, han sido asociadas a la iniciativa constructiva del Infante Don Juan Manuel, señor de aquellas tierras a principios del siglo XIV (COOPER, 1980-1981: 713-7|5. MALALANA UREÑA, 1987: pp. 69-7I). Sin embargo, habría que corregir ligeramente la cronología, aunque la tarea no es sencilla, pues se observan numerosas intervenciones restauradoras, algunas realizadas durante los siglos medievales, aunque la que puede llegar a confundir a los estudiosos fueron las realizadas en la década de los setenta del pasado siglo. Técnicamente hablando, las albarranas no están en el origen del castillo, sino que fueron erigidas en una segunda fase e incluso podrían asociarse a una tercera. Los lienzos primitivos, si nos fijamos en la fábrica de algunos de los paramentos, fueron construidos mediante tapias de encofrado de hormigón, muy similar al empleado en las murallas de Buitrago. 
En el lado norte de castillo, quizá tengamos las zonas menos afectadas por las reparaciones. Una de las principales características, siguiendo el patrón de otros modelos, es que la albarrana se adosa a las torres cuadrangulares de flanqueo preexistentes, algunas levantadas en tiempos inmediatamente anteriores. La fábrica de los muros exteriores muestra un paramento compuesto por cajones de mampuestos irregulares. Para nivelar esta irregularidad se cubren los huecos con pequeñas piedras, o bien se añade una hilada de material pétreo de menor tamaño. En ambas ocasiones los cajones se separan entre sí con una verdugada simple de ladrillos. Son los denominados tipos AI y B del aparejo toledano, cuya cronología abarca los siglos XII y XIII (ROJAS RODRÍGUEZ-MALO y VILLA GONZÁLEZ: 1999: pp. 584-588).

\section{CONCLUSIONES}

Las ciudades fortaleza castellano leonesas son la suma de circunstancias políticas, sociales, económicas, demográficas, artísticas, etc.; pero, sobre todo, es la imagen aquellos pobladores inmersos en una dura época de enfrentamientos entre culturas, pero también, entre reinos hermanos.

Surgieron para dar cobijo a los colonos que quisieron establecerse en regiones de frontera. Y pese a que vivan en un territorio hostil, deseaban emprender una nueva andadura.

En la Extremadura, en un primer momento reconstruyeron antiguos reductos, que si bien estaban descuidados, aún permanecían activos por la presencia de comunidades residuales. En la Transierra, sustituirían a los musulmanes que de manera masiva, habiendo renunciado a permanecer en sus propiedades, emigraron al sur en busca refugio. En este instante, la verdadera intención de los cristianos fue consolidary rehabilitar las defensas heredadas. Ahora, tanto en la Extremadura como en la Transierra los pobladores se encastillan, fenómeno que no se abandonaría hasta después de la victoria de Las Navas (1212).

Dentro de esta idea de vivir dentro de recios muros va a sufrir una transformación radical a mediados del siglo XII. Alfonso VII impulsara, apoyándose en los poderes locales la configuración de un sistema para la defensa del reino, de una gran frontera conformada entre el Duero y el Tajo y cuyo núcleo principal serán las ciudades fortaleza.

Así, en las ciudades extremaduranas, como Salamanca, Ávila y Segovia, junto a Soria, se comenzarán a levantar enormes perímetros murados, extraordinariamente extensos para la población que pueden albergar en ese momento. Mientras en la Transierra, al margen de Toledo o Talavera, lugares como Madrid, Sigüenza, Plasencia, etc., se levanta otros perímetros, pero con un tamaño más acorde con las necesidades, cuyo espacio intramuros tampoco podrá colmatarse. Aún, en el siglo XIII, el vacio de las ciudades persiste, situación que preocupaba a Alfonso $X$, quién intentaría revertir el proceso con la concesión, a partir de 1256, de privilegios orientados a fijar a los pobladores locales (O'CALLAGHAN, 1996: p. 129. ASENJO y MONSALVO ANTÓN, 2006: p. 26I).

Estas ciudades, no solo ofrecen seguridad a los vecinos, sino que permitirán articular todo un vasto territorio, sus jurisdicciones, de una manera paulatina. En esta articulación también se inserta un extraordinario desarrollo social y económico, en numerosos casos apoyado en la ganadería.

Precisamente, para la construcción de las murallas no solo fue necesario el desarrollo económico, también era preciso el demográfico. Aquí, desempeña un papel primordial los fueros; su concesión incluye, entre otras normativas, epígrafes que facilitarán el reclutamiento de mano de obra, de la recaudación de recursos económicos y la reserva de los materiales de obra. La terminación, el cierre de los recintos, fue tan complicada que algunos de los reyes tuvieron que invertir dinero propio o conceder privilegios extraordinarios y temporales. La prolongación de la obra, alrededor de cincuenta años, tendría distintas consecuencias.

La separación del reino tras la muerte de Alfonso VII incorporaría otros aspectos en la evolución de las murallas. Si bien, tanto en León 
como en Castilla, los reyes continuaron la política emprendida por el Emperador, añadirán sus propias peculiaridades. Por ejemplo, una nueva frontera y, por lo tanto, los esfuerzos militares se dispersan. Ahora a ambos lados de la difusa línea que divide los dos reinos se levantan nuevos sistemas defensivos. Es lógico pensar que surjan o renazcan más ciudades amuralladas y aparezca otros estilos arquitectónicos.

Tras la capitulación de Toledo, los colonos construyeron o reconstruyeron las cercas aplicando el estilo románico. Por los restos conservados en algunos lugares, como Ávila, las torres eran cuadrangulares, dos de ellas flanqueaban las puertas. Posteriormente, con Alfonso VII, sino antes, los grandes perímetros se levantarán tomando como modelo las murallas tardorromanas de Astorga o León, que utilizan torres semicirculares en serie para los frentes $y$ dos torres, igualmente semicirculares protegiendo las puertas. Los accesos simples y directos también aplicarán modelos tardorromanos. Como hipótesis, Zamora podría ser el primer ejemplo castellano leonés.

Años después los gobernantes se suceden y los estilos cambian. Aparece el gótico y emergen otros aparejos. Alfonso VIII no solo adopta e introduce el mudéjar, sino que incorpora mejoras sustanciales en la protección de las ciudades, sobre todo en las puertas, ahora más complejas pero con mayores prestaciones. Asimismo, se recupera la torre cuadrada como alternativa a las semicirculares. Además, en un momento indeterminado se implanta la torre albarrana.

En el primer cuarto del siglo XIII, León y Castilla, cuentan con una "red" de ciudades fortaleza; enclaves que se extienden a ambos lados del Sistema Central y al norte del Duero que conseguirán organizar los territorios. No son perímetros sencillos, todo lo contrario, su monumentalidad habla por sí sola. Basta mirar los ejemplos vivos de Zamora, Ávila, Segovia, Berlanga de Duero, etc.

Decenios más tarde, aún conservaban su valor militar, los conflictos internos demuestran que las murallas urbanas siguen cumpliendo el principal objetivo con el que fueron construidas: proteger las poblaciones. Tanto es así, que para los vecinos terminarían por convertirse en un símbolo de poder frente a su entorno.

\section{BIBLIOGRAFÍA}

AL-IDRISI, Muhammad b. Muhammad al-Sarif (|88I): Geografía de España del Idrisi. Eduardo Saavedra (ed.). Madrid, Imprenta Fortanet.

AL-IDRISI, Muhammad b. Muhammad al-Sarif (190I): Descripción de España. Madrid, Depósito de la Guerra.

AL-HIMYARI (1963): Kitab ar-Rawd al-Mi'tar fi habar alaktar. Valencia, Gráficas Bautista.

ALVARADO PLANAS, Javier (1995): "La castellaría en la edad media castellana: análisis histórico-jurídico", Boletín de la Facultad de Derecho. №. 8-9. Madrid, pp. I5-30.

ÁLVAREZ DELGADO, Yasmina y LÓPEZ REQUENA, Jesús (2002): "La ciudad de Cuenca: recinto amurallado, muralla natural", Ciudades amuralladas. Cuadernos de Patrimonio Histórico. No I. Cuenca, pp. 13-33.

ASENJO GONZÁLEZ, María (1986): Segovia. La ciudad y su tierra a fines del Medievo. Segovia, [s.n.].

ASENJO GONZÁLEZ, María (1999): Espacio y sociedad en la Soria medieval. Siglos XIII-XV. Soria, Diputación Provincial.

ASENJO GONZÁLEZ, María; MONSALVO ANTÓN, José María (2006): "Dos visiones de las villas de la Extremadura: sectores occidental y oriental de la cuenca meridional del Duero (siglos XI-final XV)". En Pascual Martínez Sopena y Metxe Urteaga: Las villas nuevas medievales del suroeste europeo. De la fundación medieval al siglo XXI. Análisis histórico y lectura contemporánea. Actas de las Jornadas Interregionales de Hondarribia (I6-18 noviembre 2005). Boletín Arkeolan, I4. Irún, pp. 239-266.

BALLESTEROS BERETTA, Antonio (1943): "Datos para la topografía del Burgos medieval", Boletín de la Comisión Provincial de Monumentos Históricos y Artísticos de Burgos. Vol. XXI, No. 78. Burgos, pp. I-9.

BARRAGÁN RAMOS, Rafael Fernando (2007): "Recuperación de la memoria arqueológica de Plasencia. Noticias del Alcázar medieval desaparecido", Revista de Estudios Extremeños. Vol. 63, No I. Badajoz, pp. 37-7I

BARRIOS GARCÍA, Ángel (1983-1984): Estructuras agrarias y de poder en Castilla. El ejemplo de Ávila (I0851320). Avila, Universidad de Salamanca, Institución Gran Duque de Alba.

BARRIOS GARCÍA, Ángel (2000): "Repoblación y colonización: la dinámica de creación de paisajes y el crecimiento económico". En Ángel Barrios García (coord.): Historia de Ávila. II. Edad Media (siglos VIII-XIII). Ávila, Institución Gran Duque de Alba, Diputación Provincial, Caja de Ahorros de Avila, pp. 27|-335. 
BENAVIDES CHECA, José (200I): El Fuero de Plasencia. Plasencia.

BENITO RUANO, Eloy (1978): "Las murallas y cercas de la ciudad de León durante la Edad Media". En León medieval. Doce estudios. Ponencias y comunicaciones presentadas al coloquio El reino de León en la Edad Media. León, Universidad de León, pp. 25-40.

BERNAL ESTÉVEZ, Ángel (1998): Poblamiento, transformación y organización social del espacio extremeño (siglos XIII al XV). Cáceres, Junta de Extremadura, Editora Regional de Extremadura.

CABALLERO KLINK, Alfonso y MENA MUÑOZ, Pilar (1986): "La muralla medieval del Cerro de Alarcos (Ciudad Real). En Actas del I Congreso de Arqueología Medieval Española. Tomo V. Cristiano. [Zaragoza], Diputación General de Aragón, pp. 193-207.

CABANES PECOURT, Ma Desamparados (ed.) (1985): Crónica latina de los Reyes de Castilla. Zaragoza, Anubar.

CADIÑANOS BARDECI, Inocencio (2002): "Fortificaciones y castillos de los siglos románicos". En Pedro Huerta Huerta (ed.): Palencia en los siglos del románico. Palencia, Fundación Santa María La Real, Centro de Estudios del Románico, pp. 169-199.

CASTRILLO LLAMAS, Ma Concepción (1995): "Fortificaciones, elementos defensivos y organización militar en los fueros castellanos y leoneses de la Edad Media (siglos XI-XIII)", Anuario de Estudios Medievales. No 25, fasc. I. Barcelona, pp. 39-66.

CASTRO, Américo y ONÍS, Federico de (1916): Fueros leoneses de Zamora, Salamanca, Ledesma y Alba de Tormes, I. Madrid.

CÁTEDRA, María y TAPIA, Serafín de (1997): “Imágenes metodológicas e históricas del tiempo y del espacio: las murallas de Ávila", Política y Sociedad. Nº 25. Madrid, pp. | 5 | - I84.

CLEMENTE RAMOS, Julián y MONTAÑA CONCHINA, Juan Luis de la (1994): "La Extremadura cristiana (1 | 42-1230). Ocupación del espacio y transformaciones socioeconómicas", Historia. Instituciones. Documentos. N ${ }^{0}$ 21. Sevilla, pp. 83-124.

COBOS GUERRA, Fernando; CASTRO FERNÁNDEZ, Javier de (1994): "Análisis de las estructuras urbanas y defensivas de la Villa de Berlanga de Duero (Soria)". En Rafael Azuar y Javier Martó Oltra (coords.): Sociedades en Transición. IV Congreso de Arqueología Medieval Española. Alicante, Asociación Española de Arqueología Medieval, Diputación de Alicante, vol. II, pp. 223-233.

CONCEJO DÍAZ, Ma Luisa [2003]: El arte mudéjar en Burgos y su provincia. Madrid, Universidad Complutense de Madrid, Servicio de Publicaciones.

COOPER, Eduard (1980-198|): Castillos señoriales de Castilla, s. XV y XVI. Madrid, Fundación Universitaria Española.

CRESPO REDONDO, Jesús (2007): La evolución del espacio urbano de Burgos durante la Edad Media. Burgos, Editorial Dos Soles.
DEDIEU, Jean Pierre (1992): "El reflujo del Islam español”. En Louis Cardaillac: Toledo siglos XII-XIII. Musulmanes, cristianos y judíos: la sabiduría y la tolerancia. Madrid, Alianza Editorial, pp. 4I-55.

DIAGO HERNANDO, Máximo ( 1992):"Alfonso VIII y el concejo de Soria". En Jaime Nuño González: Seminario Alfonso VIII y su época. II Curso de Cultura Medieval. Aguilar de Campoo. I-6 octubre 1990. [Madrid], Centros de Estudios del Románico, pp. 355-360.

ESCRIBANOVELASCO, Consuelo y SAN MIGUEL MATÉ, Luis Carlos (2002): "La cerca vieja de Valladolid. Nuevos datos arqueológicos". En Pedro Luis Huerta Huerta (coord.): IV Curso de Cultura Medieval. Seminario, la fortificación medieval en la Península Ibérica. Aguilar de Campoo, Fundación Santa María La Real, Centro de Estudios del Románico, pp. 285-295.

ESTEPA DÍEZ, Carlos (1977): Estructura social de la ciudad de León (siglos XI-XII). León, Centro de Estudios e Investigación "San Isidoro", Caja de Ahorros y Monte de Piedad de León.

FEDUCHI, Pedro (2003):"La construcción de las murallas: análisis morfológico y propuesta cronológica”. En Ángel Barrios García: La Muralla de Ávila. Madrid. Fundación Caja Madrid, pp. 57-113.

FERNÁNDEZ DURO, Cesáreo ( I 883): Memorias Históricas de la ciudad de Zamora, su provincia y obispado. Madrid. Disponible en: <http://www.ih.csic.es/departamentos/ medieval/fmh/l.htm> [consulta: | 3-4-2007].

FERNÁNDEZ OCHOA, Carmen y MORILLO, Ángel (2006):" "Las puertas de las murallas urbanas en la Hispania tardorromana". En Thomas G. Schattner y Fernando Valdés Fernández (eds.): Puertas de ciudades. Tipo arquitectónico y forma artística. Actas del coloquio en Toledo del 25 al 27 de septiembre 2003. Satz, Taravilla, Madrid, Deutsches Archaologisches Institut, Diputación Provincial de Toledo y Real Fundación de Toledo, pp. 253-273.

FRAILE DELGADO, Miguel (2005): Materiales de construcción en los castillos de Castilla y León. Madrid, Universidad Politécnica de Madrid. Tesis Doctoral Inédita.

GARCÍA FITZ, Francisco (1998a): Castilla y León frente al Islam. Estrategias de expansión y tácticas militares (siglos XI-XIII). Sevilla, Universidad de Sevilla.

GARCÍA FITZ, Francisco (1998b):"Fortificaciones, fronteras y sistemas defensivos en al-Andalus, siglos XI al XIII". En I Congreso Internacional de Fortificaciones en Al-Andalus. Cádiz, Fundación Municipal de Cultura José Luis Cano, pp. 269-280.

GARCÍA FITZ, Francisco (200 I): "Una frontera caliente. La guerra en las fronteras castellano-musulmanas (siglos XIXIII)". En Carlos de Ayala Martínez, Pascal Buresi y Philippe losserand: Identidad y representación de la frontera en el España medieval (siglos XI-XIV). Seminario celebrado en la Casa de Velázquez y la Universidad Autónoma de Madrid (1 4-1 5 de diciembre de 1998). Madrid, Casa de Velásquez, UAM, pp. I59-180.

GARCÍA FITZ, Francisco (2002): Relaciones políticas y guerra. La experiencia castellano-leonesa frente al Islam. Siglos XI-XIII. Sevilla, Universidad de Sevilla. 
GARCÍA FITZ, Francisco (2004): "Guerra y fortificaciones en la Plena Edad Media peninsular: una reflexión en torno a la existencia y funcionalidad bélica de los «sistemas defensivos»". En Francisco Toro Ceballos y José Rodríguez Molina (coords.): V Estudios de Frontera. Funciones en la red castral fronteriza. Homenaje a Don Juan Torres Fontes. Jaén, Diputación Provincial, pp. 223-242.

GAUTIER DALCHÉ, Jean (1979): Historia urbana de León y Castilla en la Edad Media (Siglos IX-XIII), Madrid.

GAUTIER DALCHÉ, Jean (198I): "Les péages dans les pays de la Couronne de Castille. Etat de la question, réflexions, perspectives de recherches". En Les Communications dans la Péninsule Ibérique au Moyen Age. Actes du colloque de Pau, 28-29 mars 1980. Bordeaux, pp. 73-78.

GAUTIER-DALCHÉ, Jean (1988): "Reconquète et structures de l'habitat en Castille". En André Bazzana (ed.): Castrum 3. Guerre, fortification et habitat dans le monde méditerranéen au Moyen Âge. Madrid, Casa de Velazquez, pp. $199-206$.

GÓMEZ IGLESIAS, Agustín (I95I): "Las puertas vieja y nueva de Guadalajara y otros datos sobre la muralla madrileña", Revista de la Biblioteca, Archivo y Museo del Ayuntamiento de Madrid. Vol. XX, No 61-62. Madrid, pp. 321-390.

GÓMEZ IGLESIAS, Agustín (1963):"Aspectos del Madrid medieval. La torre y puerta vieja de Guadalajara". En Cátedra de Madrid (curso segundo). Madrid, Sección de Cultura.

GONZÁLEZ, Julio (1942): "Fuero de Benavente de II67", Hispania. Vol. II, No 9. Madrid, pp. 619-626.

GONZÁLEZ, Julio (1943): "Repoblación de la «Extremadura» leonesa", Hispania. Vol. 3, No II. Madrid, pp. 195-273.

GONZÁLEZ, Julio (1944): Alfonso IX. Madrid. CSIC, Instituto Jerónimo Zurita.

GONZÁLEZ, Julio (1960): El reino de Castilla en la época de Alfonso VIII. Madrid, Escuela de Estudios Medievales.

GONZÁLEZ, Julio (1974): "La Extremadura Castellana al mediar el siglo XIII", Hispania. Vol. 34, N I27. Madrid, pp. 265-424.

GONZÁLEZ, Julio (1975): Repoblación de Castilla la Nueva. Madrid, Universidad Complutense de Madrid, Facultad de Filosofía y Letras.

GONZÁLEZ, Nazario (1958): Burgos. La ciudad marginada de Castilla. Estudios de Geografía Urbana. Burgos, [s.n.].

GONZÁLEZ GARCÍA, Manuel (1988): Salamanca: la repoblación y ciudad en la Baja Edad Media. Salamanca.

GONZÁLEZ RODRÍGUEZ, Rafael (1997a): "Origen y formación de una villa de repoblación. Benavente durante los reinados de Fernando II y Alfonso IX". Studia Historica. Historia Medieval, I5. Salamanca, pp. I05-I 38.

GONZÁLEZ RODRÍGUEZ, Rafael (1997b):"Infraestructura urbana y hacienda concejil. La cerca medieval de Benavente", Brigecio. Estudios de Benavente y sus tierras. No 7. Benavente, pp. |5|-|84.
GROSS, Georg (1987):" El Fuero de Madrid antes de I | 4 |", BRAH.T. CLXXXIV, cuaderno I. Madrid, pp. I05-I38.

GUTIÉRREZ CUADRADO, Juan (1975): Fuero de Bejar. Salamanca.

GUTIÉRREZ GONZÁLEZ, José Avelino (1988): "Sistemas defensivos y de repoblación en el Reino de León". En III Congreso de Arqueología Medieval Española. I. Ponencias. Oviedo, Asociación Española de Arqueología Medieval, Universidad de Oviedo, pp. |69-191.

GUTIÉRREZ GONZÁLEZ, José Avelino (1989): “Arquitectura militar y sistemas de fortificaciones en el reino de León". En Miguel Ángel Ladero Quesada et al.: Castillos medievales del reino de León. [Madrid, s.n.], pp. 157-I75.

GUTIÉRREZ GONZÁLEZ, José Avelino (1990): Las fortificaciones de la ciudad de Zamora. Estudio arqueológico e histórico. Zamora, Instituto de Estudios Zamorano Florián de Campo, Diputación Provincial.

GUTIÉRREZ GONZÁLEZ, José Avelino (1994): “La ciudad de Zamora entre el mundo antiguo y el feudalismo: morfología urbana". En Rafael Azuar y Javier Martí Oltra (coords.): IV Congreso de Arqueología Medieval Española. Sociedades en Transición. Alicante, Asociación Española de Arqueología Medieval, Diputación de Alicante, 1994, t. II, pp. 243-250.

GUTIÉRREZ GONZÁLEZ, José Avelino (1995): Fortificaciones y feudalismo en el origen de la formación del reino leonés (siglos IX-XIII). [Valladolid].

GUTIÉRREZ ROBLEDO, José Luis (2000):"Las murallas de Ávila". En Ángel Barrios García (coord.): Historia de Ávila. II. Edad Media (siglos VIII-XIII). Ávila, Institución Gran Duque de Alba, Diputación Provincial, Caja de Ahorros de Ávila, pp. 479-5 15.

GUTIÉRREZ ROBLEDO, José Luis (2002):'Las murallas de Ávila". En Miguel Ángel García Guinea y José Ma Pérez González (dirs) y José Luis Gutiérrez Robledo (coord.). Enciclopedia del Románico en Castilla y León. Ávila. Aguilar de Campoo, Fundación Santa María La Real, Cetro de Estudios del Románico, pp. 63-104.

GUTIÉRREZ ROBLEDO, José Luis (2007): "Las murallas de Ávila". Congreso Internacional Ciudades Amuralladas. Pamplona, 24-26 noviembre 2005. Pamplona, Gobierno de Navarra, pp. I 17-150.

HUICI MIRANDA, Ambrosio (1956): Las grandes batallas de la Reconquista durante las invasiones africanas (Almorávides, Almohades y Benimerines). Madrid, CSIC.

IBN ABI ZAR', Ali b. Abd Allan (1964): Rawd al-qirtas. Traducido y anotado por Ambrosio Huici Miranda. Valencia, [s.n.].

IBN AL-KARDABUS, Abd al-Malik (1993): Historia de alAndalus (Kitab al-iktifa'). Estudio, traducción y notas por Felipe Salgado Maillo. Madrid, Akal.

IBN 'IDARI AL-MARRAKUSI (I953): Al-Bayan al- mugrib fi ijtisar ajbar muluk al-Andalus wa al-Magrib. Los almohades. Traducción Ambrosio Huici Miranda. Tetuán, Editora Marroquí. 
IBN 'IDARI AL-MARRAKUSI (1963): Al Bayan al mugrib. Nuevos fragmentos almorávides y almohades. Traducido y anotado por Ambrosio Huici Miranda. Valencia, [s.n.].

IZQUIERDO BENITO, Ricardo (199|): Privilegios reales otorgados a Toledo durante la Edad Media (I l 0 I- | 494), Toledo, IPIET.

IZQUIERDO BENITO, Ricardo et al. (2006): "Las villas nuevas medievales del Tajo al Guadiana (Castilla-La Mancha y Extremadura) y Murcia (siglos XII y XIV)". En Pascual Martínez Sopena y Metxe Urteaga: Las villas nuevas medievales del suroeste europeo. De la fundación medieval al siglo XXI.Análisis histórico y lectura contemporánea. Actas de las Jornadas Interregionales de Hondarribia ( 16 - 18 noviembre 2005). Boletín Arkeolan, I4. Irún, pp. 267-308.

JUAN GARCÍA, Antonio de, CABALLERO KLINK, Alfonso y FERNÁNDEZ RODRÍGUEZ, Macarena (1995):"Alarcos medieval: La batalla de Alarcos". En Juan Zozaya: Alarcos. E fiel de la balanza. [Toledo], Servicio de Publicaciones de la Junta de Comunidades de Castilla-La Macha, pp. 4I-59

JIMÉNEZ ESTEBAN, Jorge (1973): "Puertas flanqueadas por dos cubos cilíndricos", Castillos de España. № 79 Madrid, pp. 22-29.

LACARRA, José Ma (1963): "Les villes frontiére dans l'Espagne des Xle et Xlle siécles", Le Moyen Age. Vol. LXIX. Paris, pp. 205-222.

LACARRA, José María (|98|): "Las ciudades fronterizas en la España de los siglos XI y XII". En José María Lacarra: Colonización, parías, repoblación y otros estudios. Zaragoza, Anubar Ediciones, pp. 95-। I0.

LARRÉN IZQUIERDO, Hortensia y GUTIÉRREZ-GONZÁLEZ, José Avelino (1999): "Recintos amurallados de Ciudad Rodrigo (Salamanca). Cronotipología". En Rodrigo de Balbín Behrmann y Primitiva Bueno Ramírez eds.: "I Congreso de Arqueología Peninsular. Tomo IV Arqueología Romana y Medieval. [Madrid], Universidad de Alcalá, Fundación Rei Afonso Henriques, pp. 497-506.

LEMA PUEYO, José Ángel (2008): Alfonso I el Batallador rey de Aragón y Pamplona (I l 04- I I 34). [Gijón], Ediciones Trea.

LEÓN TELLO, Pilar (1979): Judíos de Toledo. Madrid, CSIC.

LLORENTE, Juan Antonio ( 1806 - 1808): Noticias históricas de las tres provincias vascongadas... de Álava, Guipúzcoa y Vizcaya y el origen de sus fueros. Madrid.

M. DE V., E (I 883): "Monumentos históricos de España «Solar del Cid», en Burgos", La llustración Española y Americana. Año XXVII, No . XI. Madrid, p. 182.

MAJADA NEILA, José (1983): Fuero de Zamora. Introducción, transcripción, vocabulario. Salamanca. Librería Cervantes.

MALALANA UREÑA, Antonio (1987): Escalona Medieval. Madrid, AC Al-Mudayna.

MALALANA UREÑA,Antonio (1990):" "Puentes-fortaleza en el Tajo: el tramo Zorita de los Canes (Guadalajara)Castros (Cáceres)", Boletín de Arqueología Medieval. № 4 Madrid, pp. 195-222.
MALALANA UREÑA, Antonio (2009):"El contexto de los recintos amurallados románicos en los enclaves de frontera durante los siglos XII-XIII". En Alejandro Rodríguez de la Peña (dir.): Hacedores de Frontera. Estudios sobre el contexto social de la frontera en la España medieval. Madrid, CEU Ediciones, pp. 205-264.

MALALANA UREÑA, Antonio y PÉREZ-JUANA DEL CASAL, Irene (1999): "Los recintos defensivos del Madrid medieval a raíz de las excavaciones de la Plaza de Oriente", Revista de Arqueología. Año 20, №. 215. Madrid, pp. I0-19.

MANSILLA REOYO, Demetrio ( 1955$)$ : La documentación pontificia hasta Inocencio III (965-1216). Roma-(Burgos), Instituto Español de Estudios Eclesiásticos-Aldecoa.

MANZANO MORENO, Eduardo (|99|): La frontera de al-Andalus en época Omeya. Madrid, CSIC.

MAÑARES PÉREZ,Tomas,VALBUENA, Felipe y ALONSO PONGA, José Luis (1980a): "La arquitectura militar en la frontera del Reino de León con el de Castilla, en los siglos XII y XIII (I)", Tierras de León. Revista de la Diputación Provincial. Vol. 20, nº 40. León, pp. 89- I I 4.

MAÑARES PÉREZ,Tomas,VALBUENA, Felipe y ALONSO PONGA, José Luis (1980b): "La arquitectura militar en la frontera del Reino de León con el de Castilla, en los siglos XII y XIII (II)", Tierras de León. Revista de la Diputación Provincial. Vol. 20, n 4l. León, pp. 59-88.

MÁRQUEZ MUÑOZ, José Ángel (1987): "Una comunidad de villa y tierra de la Extremadura castellana: Almazán hasta el siglo XIII", Celtiberia. Vol. XXXVII, No. 73. Soria, pp. $21-27$

MARTÍN, José Luis y COCA, Javier (1987): Fuero de Salamanca. Salamanca, Diputación Provincial.

MARTÍN AYMERICH, Ma Dolores, TARDÍO DOVAO, Teresa y ZAMORA CANELLADA, Alonso (1990): Las murallas de Sepúlveda, (Segovia). Un ensayo de aproximación con métodos arqueológicos, a un ejemplo de pervivencia arquitectónica. Segovia, Diputación Provincia.

MARTÍN AYMERICH, Ma Dolores, TARDÍO DOVAO, Teresa y ZAMORA CANELLADA, Alonso (1992): "Las murallas de Sepúlveda". En III Congreso de Arqueología Medieval Española, Oviedo 27 de marzo - I de abril 1989. II Comunicaciones. Oviedo, AEAM, pp. 425-432.

MARTÍN MARTÍN, José Luis ( 1979): “La repoblación de la Transierra (siglos XII y XIII)". En Estudios dedicados a Carlos Callejo Serrano. Cáceres, Diputación Provincial, Servicios Culturales, pp. 477-497.

MARTÍN VISO, Iñaki (2000): "Castillos, poder feudal y reorganización espacial en la Transierra madrileña (siglos XII-XIII)", Espacio, Tiempo y Forma. Historia Medieval. Nº |3. Madrid, pp. 177-213

MARTíNVISO, Iñaki (200 I): "Riflessioni sull'incastellamento nella peninsola iberica: la Castiglia dell'Ebro e la Transierra di Madrid", Arqueología Medievale. № XXVIII. Roma, pp. $83-110$

MARTÍNVISO, Iñaki (2002):"Espacio y poder en los territorios serranos de la Región de Madrid (siglos X-XIII)". Arqueología y territorio medieval. № 9. Jaén, pp. 53-84. 
MARTíN VISO, Iñaki (2008): "Territorio y sociedad en la región de Madrid en la época del románico", En Miguel Ángel García Guinea y José María Pérez González (eds.) y Jaime Nuño González (coord.): Enciclopedia del Románico en Madrid. Madrid. Aguilar de Campoo, Fundación Santa María La Real, Centro de Estudios del Románico, pp. 2 I-49.

MARTÍNEZ DÍEZ, Gonzalo (1994): "La ciudad de Burgos en la Plena Edad Media". Burgos en la Plena Edad Media. III Jornadas Burgalesas de Historia. Burgos, Asociación Provincial de Libreros, pp. 75- 105.

MARTÍNEZ DÍEZ, Gonzalo (2002): "El románico en la provincia de Burgos. Marco histórico". En Miguel Ángel García Guinea y José María Pérez González (eds.) y Jaime José Manuel Rodríguez Montañés (coord.): Enciclopedia del Románico en Castilla y León. Burgos. Volumen I. Aguilar de Campoo, Fundación Santa María La Real, Centro de Estudios del Románico, pp. 23-38.

MARTÍNEZ LILLO, Sergio (1998): Arquitectura militar andalusí en la Marca Media. El caso de Talabira. Toledo, Ayuntamiento de Talavera.

MARTÍNEZ LILLO, Sergio, MORALEDA OLIVARES, Alberto y SÁNCHEZ SANZ, Sergio (2005): "El yacimiento arqueológico de «Entretorres» (Talavera de la Reina). Últimas aportaciones del período andalusí". En Congreso Espacio fortificados en la provincia de Toledo. Toledo, Diputación de Toledo, pp. I17-154.

MARTÍNEZ LILLO, Sergio y MURILLO FRAGERO, José Ignacio (2003): "Últimas actuaciones arqueológicas en las murallas". En Ángel Barrios García: La Muralla de Ávila. Madrid. Fundación Caja Madrid, pp. 269-29I.

MARTÍNEZ SOPENA, Pascual (1989): “Las pueblas reales de León y la defensa del reino en los siglos XII y XIII". En Miguel Ángel Ladero Quesada et al.: Castillos medievales del reino de León. [Madrid, s.n.], pp. II3-I37.

MARTÍNEZ SOPENA, Pascual (1985): LaTierra de Campos occidental. Poblamiento, poder y comunidad del siglo $X$ al XIII. Valladolid, Institución Cultural Simancas, Diputación de Valladolid.

MARTÍNEZ SOPENA, Pascual (2002): "Espacio y sociedad en Valladolid durante los siglos XI y XII". En Miguel Ángel García Guinea y José María Pérez González (dirs.) y José Manuel Rodríguez Montañés (coord.): Enciclopedia del Románico en Castilla y León. Valladolid. Aguilar de Campoo, Fundación Santa María La Real, Centro de Estudios del Románico, pp. 19-4|.

MARTÍNEZ SOPENA, Pascual; AGUADO SEISDEDOS, Vidal; GONZÁLEZ RODRÍGUEZ. Rafael (1996): Privilegios Reales de la villa de Benavente (siglos XII-XIV). Benavente.

MIGUEL RODRÍGUEZ, Juan Carlos de (1989): La comunidad mudéjar de Madrid. Un modelo de análisis de aljamas mudéjares castellanas. Madrid, Asociación Cultural Al-Mudayna.

MIGUEL RODRÍGUEZ, Juan Carlos de (1990): La población mudéjar madrileña entre la conquista y el siglo XIII". En Madrid del siglo IX al XI. Madrid, Comunidad de Madrid, pp. 309-318.
MíNGUEZ, José Ma (1994): Las sociedades feudales. I. Antecedentes, formación y expansión (siglos VI al XIII). Madrid, Nerea.

MÍNGUEZ, José Ma (2000): Alfonso VI. Poder, expansión y reorganización interior. Madrid, Editorial Nerea.

MOLÉNAT, Jean-Pierre (1988): "Villes et forteresses musulmanes de la región tolédane disparues après l'ocupation chrétienne". En André Bazzana (ed.): Castrum 3. Guerre, fortification et habitat dans le monde méditerranéen au Moyen Âge. Madrid, Casa de Velázquez, pp. 21 5-224.

MOLÉNAT, Jean-Pierre (1992): "Mudéjars et mozárabes à Tolède du Xlle au XVe siècles". Revue dus mondes musulman et de la Méditerranée, vol. 63, núm. I. Aix-enProvence, pp. 143- 153.

MOLÉNAT, Jean-Pierre (1998): "Tolède fin Xle-début XII siècle. Le probleme de la permanence ou de l'émigration des musulmans". En Carlos Laliena Corbera y Juan F. Utrilla (eds.): De Toledo a Huesca. Sociedades medievales en transición a finales del siglo XI ( I 080- I I 00). Zaragoza, Instituto Fernando El Católico, pp. | 01 - | | |.

MONSALVO ANTÓN, José Ma (2002): "Los espacios de poder en la ciudad medieval. Impresiones a partir de cuatro casos: León, Burgos, Ávila y Salamanca". En José Ignacio de la Iglesia Duarte (coord.): Los espacios de poder en la España Medieval. XII Semana de Estudios Medievales. Nájera 2001. Logroño, IER, pp. 97-147.

MONSALVO ANTÓN, José Ma (2003): "Frontera pionera, monarquía en expansión y formación de los concejos de villa y tierra. Relaciones de poder en el realengo concejil entre el Duero y el Tajo (c. 1072 - c. I 222)", Arqueología y Territorio Medieval. Vol. I0, n. 2. Jaén, pp. 45- 126.

MONTAÑA CONCHIÑA, Juan Luis de la (1997): "Sistemas defensivos y repoblación en Extremadura (siglos XII-XIII)", Castillos de España. N I08. Madrid, pp. 23-34.

MONTEVERDE, José Luis (1949): "La puerta de San Esteban y su estructura", Boletín de la Comisión Provincial de Monumentos y de la Institución Fernán-González de la ciudad de Burgos. Año XXVII, No I0. Burgos, pp. 31-33.

MORALEDA OLIVARES, Alberto, SÁNCHEZ SANZ, Sergio, MARTÍNEZ LILLO, Sergio (2004): "El yacimiento de «Entretorres» (Talavera de la Reina)". En Alfonso Caballero Klink y José Luis Ruiz Rodríguez (coords.): Investigaciones arqueológicas en Castilla-La Mancha. 1996-2002. Toledo, Junta de Comunidades de Castilla-La Mancha, pp. 409-421.

MORALEDA OLIVARES, Alberto, MARTÍNEZ LILLO, Sergio y SÁNCHEZ SANZ, Sergio (1999-2000):" Primeros resultados de los trabajos arqueológicos en Entretorres. Primer recinto de la muralla islámica de Talavera de la Reina", Cuaderna. Revista de estudios humanísticos de Talavera y su antigua tierra, № 7-8. Talavera, pp. 54-70.

MOXÓ, Salvador de (1979): Repoblación y sociedad en la España cristiana medieval. Madrid, Rialp.

MUÑOZ, José María (1953): "Las murallas salmantinas y sus puertas. El postigo Ciego", Zephyrus. N IV. Salamanca, p. 30. 
MUÑOZ GARCÍA, Miguel Ángel y SERRANO-PIEDECASAS, Luis (2000): "La arqueología de las villas de repoblación al sur del río Tormes, como revisión de la Historia Local". En V Congreso de Arqueología Medieval Española. Valladolid, Junta de Castilla y León, 2000, vol. I, pp. 383-392.

NIETO, José A. (2006): Artesanos y mercaderes. Una historia social y económica de Madrid (I 450- I 850). Madrid.

NOVOA PORTELA, Feliciano y VILLALBA RUIZ DE TOLEDO, F. Javier (2003): "A propósito de los «sistemas defensivos» de fortificaciones en la Edad Media", Espacio Tiempo y Forma, Serie III, Historia Medieval, núm. I 6. Madrid, pp. 215-228.

NUÑO GONZÁLEZ, Jaime (2002a): "Villalpando. Murallas". En Miguel Ángel García Guinea y José Ma Pérez González (dirs.) y José Manuel Rodríguez Montañés (coord.): Enciclopedia del Románico en Castilla y León. Zamora. Aguilar de Campoo, Fundación Santa María La Real, Centro de Estudios del Románico, pp. 272-275.

NUÑO GONZÁLEZ, Jaime (2002b): "Zamora. Murallas". En Miguel Ángel García Guinea y José Ma Pérez González (dirs) y losé Manuel Rodríguez Montañés (coord.): Enciclopedia del Románico en Castilla y León. Zamora. Aguilar de Campoo, Fundación Santa María La Real, Centro de Estudios del Románico, pp. 357-366.

NUÑO GONZÁLEZ, Jaime (2002c): "Almazán. Murallas”. En Miguel Ángel García Guinea y José Mª Pérez González (dirs.) y José Manuel Rodríguez Montañés (coord.): Enciclopedia del Románico en Castilla y León. Soria. Volumen 1. Aguilar de Campoo, Fundación Santa María La Real, Centro de Estudios del Románico, pp. |3|-133.

NUÑO GONZÁLEZ, Jaime (2002d):"Berlanga de Duero. Murallas". En Miguel Ángel García Guinea y José Ma Pérez González (dirs.) y José Manuel Rodríguez Montañés (coord.): Enciclopedia del Románico en Castilla y León. Soria. Volumen I. Aguilar de Campoo, Fundación Santa María La Real, Centro de Estudios del Románico, pp. 226-227.

O'CALLAGHAN, Joseph F. (1996): El rey sabio. El reinado de Alfonso X de Castilla. Sevilla, Universidad de Sevilla.

OSABA Y RUIZ DE ERECHÚN, Basilio (1976): "El arte árabe y sus huellas". Arte burgalés. Quince mil años de expresión artística. Vitoria, Caja de Ahorros Municipal de Burgos, pp. 68-83.

PALACIOS MARTÍN, Bonifacio (1989): "Alfonso VIII y su política en Extremadura", Anuario de Estudios Medievales. Vol. 19. Barcelona, pp. I55-168.

PALACIOS MARTÍN, Bonifacio (1992): "Alfonso VIII y su política de frontera en Extremadura. La creación de la diócesis de Plasencia", En la España Medieval. № 15. Madrid. pp. 77-96.

PALACIOS ONTALVA, J. Santiago (2005): Las fortalezas del Reino de Toledo y la consolidación política del reino castellano (1085-1 252). Madrid, Ediciones de la UAM.

PAVÓN MALDONADO, Basilio (1988): Arte toledano: islámico y mudéjar. Madrid, Instituto Hispano-Árabe de Cultura.
PAVÓN MALDONADO, Basilio (1992): Alcalá de Henares medieval. Arte islámico y mudéjar. Madrid, CSIC.

PAVÓN MALDONADO, Basilio (1999): Tratado de arquitectura hispano-musulmana. II. Ciudades y Fortalezas. Madrid, CSIC.

PELAYO, OBISPO DE OVIEDO (1913): Chronicon Regum Legionensium. En Ambrosio Huici Miranda: Crónicas Latinas de la Reconquista. Valencia, Hijos de F.Vives Mora.

PELAYO, OBISPO DE OVIEDO (1924): Crónica del Obispo don Pelayo. Ed. B. Sánchez Alonso, Madrid.

PÉREZ DETUDELA, Ma Isabel (2005):" "El Madrid medieval en su contexto geográfico". En M ${ }^{a}$ Isabel Pérez de Tudela (coord.): Ciclo de conferencias Fuero de Madrid en su octavo centenario. Madrid, Ayuntamiento, Ateneo, pp. 29-52.

PEREZ GONZÁLEZ, Maurilio (ed.) (1997): Crónica del Emperador Alfonso VII. León, Universidad de León.

PONCE DE LEÓN, Pedro (2004): "Las puertas del Vado y Vieja de Bisagra o de Alfonso VI. Análisis comparativo". En Jesús Carrobles Santos (dir.): Las Murallas de Toledo. Madrid: Fundación Caja Madrid, pp. 27I-28I.

PONCE DE LEÓN, Pedro y CARROBLES SANTOS, Jesús (2004): "Memoria de la intervención en las murallas de Toledo". En Jesús Carrobles Santos (dir.): Las Murallas de Toledo. Madrid: Fundación Caja Madrid, pp. 166-223.

PORRES MARTÍN-CLETO, Julio (1993): Los Anales Toledanos I y |I. Toledo, IPIET, Diputación Provincial.

POSTIGO ALDEAMIL, Ma Josefa (1984): "El Fuero de Plasencia", Revista de Filología Románica. № 2. Madrid, pp. $|75-2| 4$.

POSTIGO ALDEAMIL, Ma Josefa (1985): "El Fuero de Plasencia", Revista de Filología Románica. № 3. Madrid, pp. 169-224.

RAMOS DE CASTRO, Guadalupe (1978): Las murallas de Zamora. Valladolid, Ministerio de Cultura.

RECUERO ASTRAY, Manuel (1979): Alfonso VII, emperador. El Imperio Hispánico en el siglo XII. León, Centro de Estudios e Investigación San Isidoro, Caja de Ahorros y Monte de Piedad, Archivo Histórico Diocesano.

REILLY, Bernard F. (1992): Cristianos y musulmanes 103 II I 57. En Historia de España, dirigida por Johes Lynch, t. VI. Barcelona, Ed. Crítica.

RISCO, Manuel (1792): Historia de la ciudad y corte de León y de sus reyes. [Madrid].

RIU, Manuel (1992):"Lectura arqueológica de la documentación de Alfonso VIII ( I I 58-I2| 4)". En Jaime Nuño González: Seminario Alfonso VIII y su época. II Curso de Cultura Medieval. Aguilar de Campoo. I-6 octubre 1990. [Madrid], Fundación Santa María La Real, Centro de Estudios del Románico, pp. 205-216.

RODRÍGUEZ ALMEIDA, Emilio (1981): Ávila romana. Ávila, Caja de Ahorros de Ávila. 
RODRÍGUEZ FERNÁNDEZ, Justiniano ( 1981 ): Los Fueros del Reino de León. II. Documentos. León.

RODRÍGUEZ-PICAVEA, Enrique (1999) "Aproximación a la geografía de la frontera meridional de Castilla (I I 571212 )", Cuadernos de Historia Medieval. Sección Miscelánea, No 2. Madrid, pp. 29-42.

ROJAS RODRÍGUEZ-MALO, Juan Manuel y VILLA GONZÁLEZ, J. Ramón (1999): "Origen y evolución del «aparejo segoviano» entre los siglos X y XVI". En Rodrigo de Balbín Behrmann y Primitiva Bueno Ramírez eds.: II Congreso de Arqueología Peninsular. Tomo IV Arqueología Romana y Medieval. [Madrid], Universidad de Alcalá, Fundación Rei Afonso Henriques, pp. 583-588.

RUCQUOI, Adeline (1997): Valladolid en la Edad Media. I. Génesis de un poder. [Valladolid], Consejería de Educación y Cultura.

RUIZTABOADA, Arturo (2002): "Aproximación al estudio del recinto amurallado de Toledo: El descubrimiento de la Puerta del Vado", Tulaytula. Revista de la Asociación de Amigos del Toledo Islámico. Nª 9. Toledo, pp. 55-82.

RUIZ TABOADA, Arturo (2004): "La muralla de los arrabales de San Isidoro, Santiago y La Granja (Toledo)". En Jesús Carrobles Santos (dir,): Las Murallas de Toledo. Madrid: Fundación Caja Madrid, pp. 251-269.

RUIZ TABOADA, Arturo (2005): "La reforma cristiana del segundo recinto amurallado de la ciudad de Toledo". En Congreso Espacios fortificados de la provincia de Toledo. Toledo, Diputación Provincial, pp. 231-254.

RUIZ TABOADA, Arturo y CARROBLES SANTOS, Jesús (2006): "Una puerta entre dos mundos. La Puerta del Vado en el segundo recinto amurallado de la ciudad de Toledo". En Thomas G. Schattner y Fernando Valdés Fernández (eds.): Puertas de ciudades. Tipo arquitectónico y forma artística. Actas del coloquio en Toledo del 25 al 27 de septiembre 2003. Satz, Taravilla, Madrid, Deutsches Archaologisches Institut, Diputación Provincial de Toledo y Real Fundación de Toledo, pp. 39|-403.

SÁEZ LARA, Fernando (1993): "Catálogo de castillos, fortificaciones y recintos amurallados de la Comunidad de Madrid". En Alicia Cámara Muñoz y Javier Gutiérrez Marcos (coords.): Castillos, fortificaciones y recintos amurallados de la Comunidad de Madrid. Madrid, Comunidad de Madrid, pp. 75-277.

SÁEZ LARA, Fernando; MARTíNEZ LILLO, Sergio y MALALANA UREÑA, Antonio (1999): "Poblamiento y red viaria en la Marca Media. Un comienzo de aproximación (ss. VIII-X)". En Rodrigo de Balbín Behrmann y Primitiva Bueno Ramírez eds.: /I Congreso de Arqueología Peninsular.Tomo IV Arqueología Romana y Medieval. [Madrid], Universidad de Alcalá, Fundación Rei Afonso Henriques, pp. 537-554.

SAGREDO FERNÁNDEZ, Félix (1979): Briviesca antigua y medieval. [S.I.].

SANTOS CANALEJO, Elisa Carolina de (1986): La historia medieval de Plasencia y su entorno geo-histórico: la Sierra de Béjar y la Sierra de Gredos. Cáceres.

SAYÁNS, Francisco (2005): Plasencia en el siglo XII. [Madrid, s.n.].
SERRANO-PIEDECASAS, Luis y MUÑOZ GARCÍA, Miguel Ángel (1994): "San Felices de los Gallegos (Salamanca). Análisis estratigráfico de la cerca vieja", Studia Historica. Historia Medieval. № I2. Salamanca, pp. I05-I 3 I.

SERRANO-PIEDECASAS, Luis y MUÑOZ GARCÍA, Miguel Ángel (1996): "San Felices de los Gallegos (Salamanca). Análisis estratigráfico de la cerca vieja", Castillos de España. No 106. Madrid, pp. 21-33.

SERRANO-PIEDECASAS, Luis y MUÑOZ GARCÍA, Miguel Ángel (2000): "Aproximación arqueológica a las cercas medievales de la ciudad de Salamanca". V Congreso de Arqueología Medieval Española. Valladolid, 22 a 27 de marzo de 1999. [Valladolid], Junta de Castilla y León, Consejería de Educación y Cultura, 2000, pp. 407-4I4.

SOUSA CARDOSO, Mario de (200 I): As muralhas de Santarém. Interpretação e enquadramento histórico-arqueológico. Santarém, Câmara Municipal de Santarém.

SUÁREZ ÁLVAREZ, Ma Jesús (1982): La villa de Talavera y su tierra en la Edad Media (I 369-1 504). Oviedo, Universidad de Oviedo, Diputación Provincial de Toledo.

TERRASSE, Michel (1970): "Talavera hispano-musulmane (notes historico-archéologiques)", Mélanges de la Casa de Velázquez. Vol. VI. Madrid, pp. 79-I 12.

TORRES BALBÁS, Leopoldo (1949): Arte Almohade. Arte Nazarí. Arte Mudéjar. En Ars Hispaniae. T. IV. Madrid, Plus-Ultra.

TORRES BALBÁS, Leopoldo (1952): "Soria: interpretación de sus orígenes y evolución urbana", Celtiberia. $N^{\circ}$ 3. Soria, pp. 7-31.

TORRES BALBÁS, Leopoldo: ( 1987): "La Edad Media". En A.García y Bellido et al:: Resumen histórico del urbanismo en España. Madrid, Instituto de Estudios de Administración Local, pp. 65-170.

UREÑA Y SMENJAUD, Rafael de (1935): Fuero de Cuenca. (Formas primitivas y sistemática. Texto latino. Texto castellano y adaptación del fuero de Iznatorzaf). Madrid.

VALDEÓN BARUQUE, Julio (199|): "Reflexiones sobre las murallas urbanas de la Castilla medieval", En Cesare de Seta y Jacques Le Goff (eds.): La ciudad y las murallas. Madrid, Ediciones Cátedra, pp. 67-87.

VALDEÓN BARUQUE, Julio (1993): "La frontera y el sistema de defensa en la Edad Media. Fortalezas y núcleos urbanos". En Alicia Cámara Muñoz y Javier Gutiérrez Marcos (coords.): Castillos, fortificaciones y recintos amurallados de la Comunidad de Madrid. Madrid, DG Patrimonio Cultural, Comunidad de Madrid, pp. 13-20.

VALDÉS FERNÁNDEZ, Fernando (1987): “La Puerta Vieja de Bisagra. Notas para una cronología de la muraIla de Toledo". En II Congreso de Arqueología Medieval Española. Madrid, Comunidad Autónoma, AEAM, vol. II, pp. 28I-294.

VALDÉS FERNÁNDEZ, Fernando (2004): "La fortificación de los estados latinos de Oriente y su influjo en la Península Ibérica: el recinto de la ciudad de Toledo". En Jesús Carrobles Santos (dir): Las Murallas de Toledo. Madrid: Fundación Caja Madrid, pp. 47-73. 
VALDÉS FERNÁNDEZ, Fernando (2006): "Puertas de recintos urbanos y cambio político. Los casos de la muralla urbana de Toledo y de las alcazabas de Mérida y Badajoz". En Thomas G. Schattner y Fernando Valdés Fernández (eds.): Puertas de ciudades. Tipo arquitectónico y forma artística. Actas del coloquio en Toledo del 25 al 27 de septiembre 2003. Satz, Taravilla, Madrid, Deutsches Archaologisches Institut, Diputación Provincial de Toledo y Real Fundación de Toledo, pp. 407-423.

VARGAS AGUILAR, Joaquín de (1974): Dibujos salmantinos. Salamanca, CSIC, SES.

VILLANUEVA ZUBIZARRETA, Olatz, SEQUERO MARTíN, Belén y SERRANO GUTIÉRREZ, José Manuel (I99|): "Restos arqueológicos de la cerca vieja de Valladolid. Contribución al desarrollo urbano de la ciudad". En Germán Delibes de Castro et al. (corrds.): Arqueología urbana en Valladolid. Valladolid, Junta de Castilla y León, Consejería de Cultura y Bienestar Social, pp. 189-214.

VILLAR GARCÍA, Luis Miguel (1986): La Extremadura castellano-leonesa. Guerreros, clérigos y campesinos (711. 1252).Valladolid, Junta de Castilla y León. Consejería de Educación y Cultura.

XIMÉNEZ DE RADA, Rodericus ( 1 985): Opera. Zaragoza, Anubar Ediciones.

ZAMORA CANELLADA, Alonso (1993): "El castillo de Ayllón (Segovia). Estudio arqueológico e histórico", Estudios segovianos. Vol. XXXIV, No 90. Segovia, pp. I-522.
ZAMORA CANELLADA, Alonso (1994): "Un particular sistema de construcción militar, en los albores del siglo Xl". En Actas del I Congreso de Castellología Ibérica. Palencia, Diputación Provincial, 76I-782.

ZAMORA CANELLADA, Alonso (2008): "Fortificaciones en la provincia de Segovia. Hacia un inventario", Oppidum. Cuadernos de investigación. Nº extra I. Segovia, pp. I39-176.

ZAMORA CANELLADA, Alonso y VELA COSSío, Fernando (2005): "Paramentos de fortificaciones en la Segovia prerrománicas. (Siglos VII-XI)". En IV Congreso Nacional de Historia de la Construcción. Cádiz, Instituto Juan de Herrera, Sociedad Española de Historia de la Construcción, Colegio Oficial de Arquitectos de Cádiz, vol. II, pp. I | 37- I 54.

ZOZAYA, Juan (2004): "Asentamientos islámicos en la región de Madrid". En Araceli Turina Gómez, Salvador Quero Castro y Amalia Pérez Navarro (coords.): Testimonios del Madrid medieval. El Madrid musulmán. Madrid, Museo de San Isidro, pp. 43-79.

ZOZAYA, Juan (2008): “iPoblado?, ¿ciudades?, ¿campamentos?, jrecintos castrales? En la Marca Media: hacia una tipología". Al-Andalus país de ciudades. Actas del Congreso celebrado en Oropesa (Toledo), del 12 al 14 de marzo de 2005. [Madrid], Diputación Provincial de Toledo, pp. 23-63. 


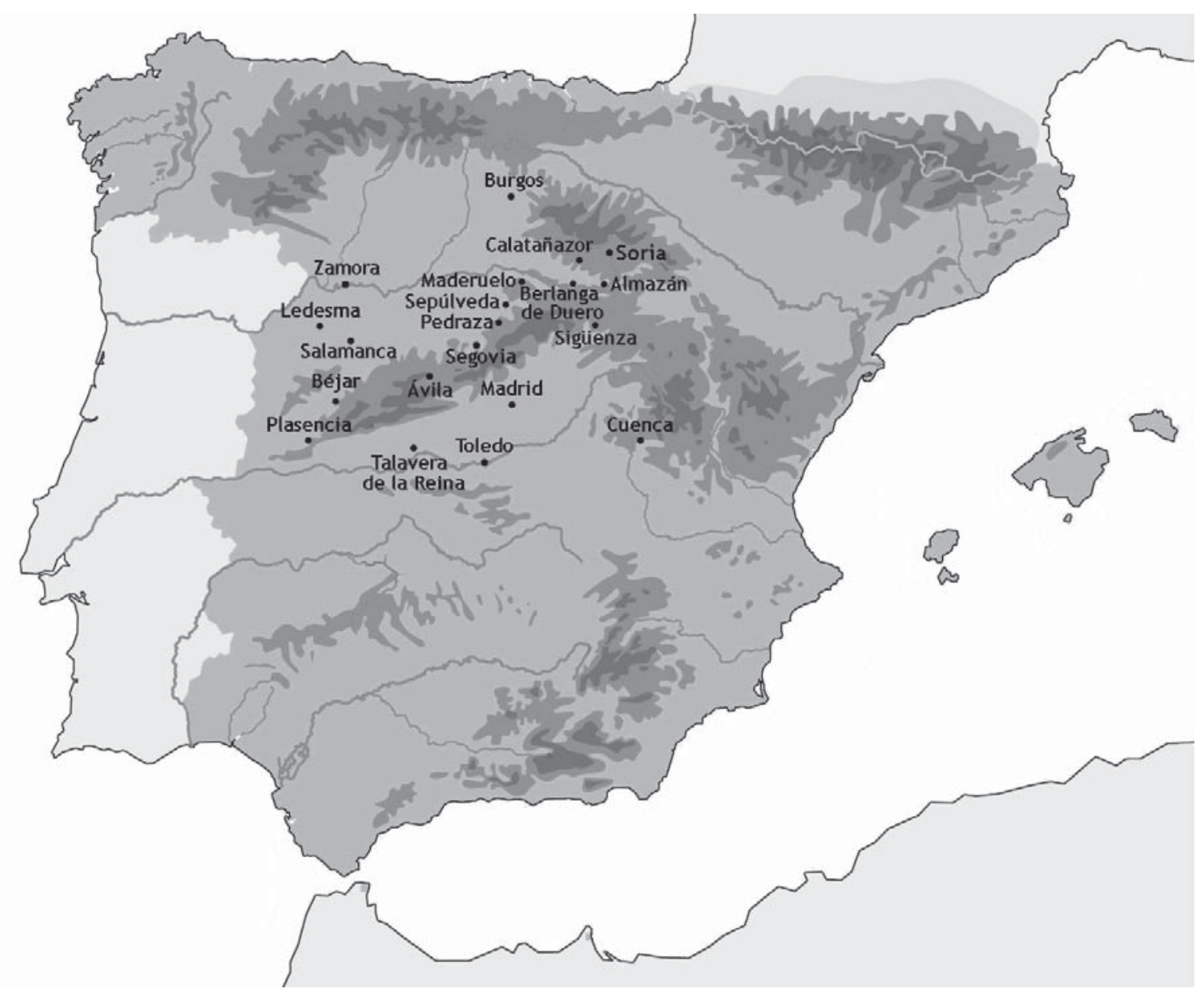

Figura I. Mapa con la localización de algunas de las ciudades fortaleza erigidas a lo largo del siglo XII. 

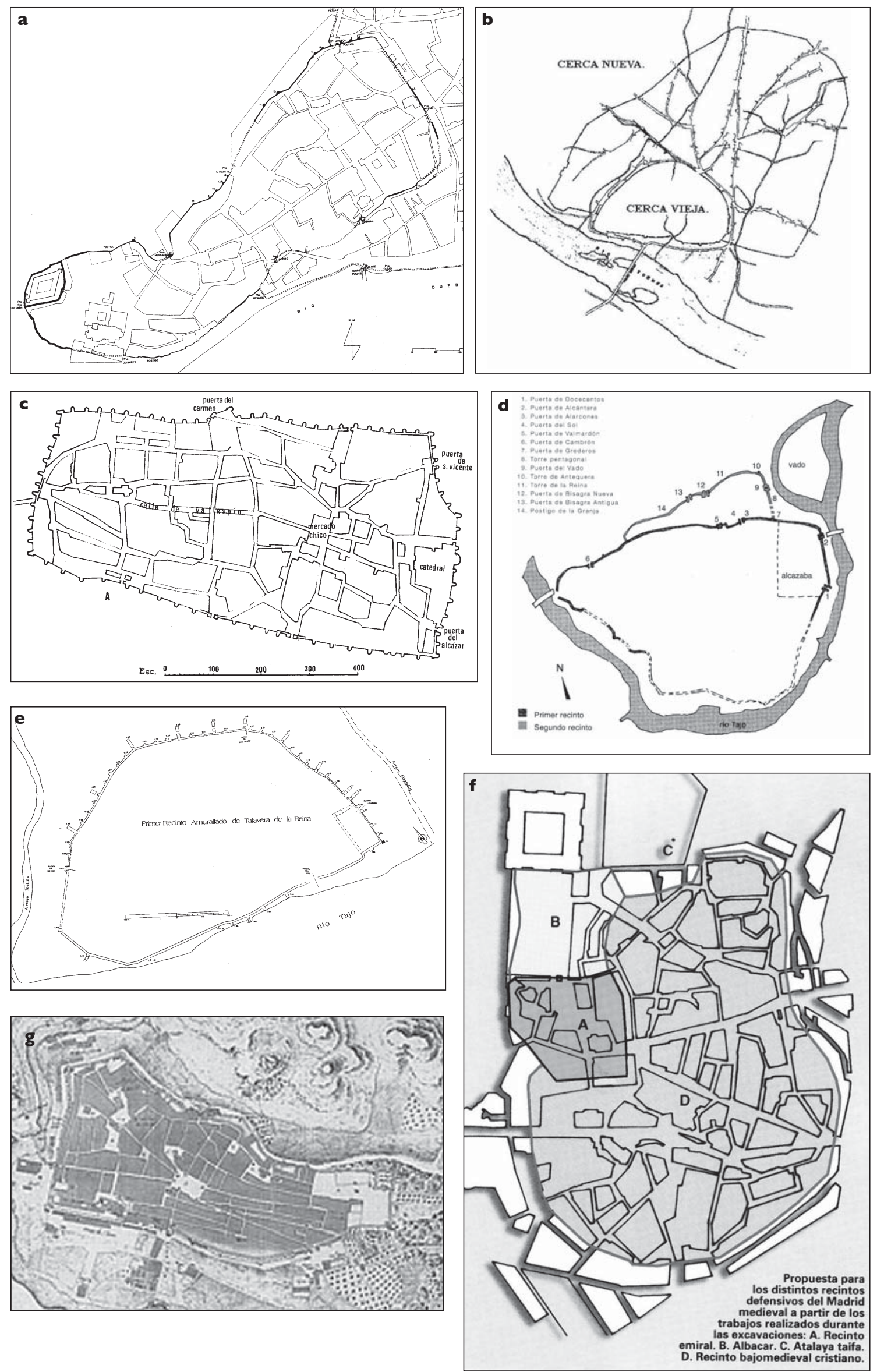
Figura 2. Ejemplo de plantas de ciudades amuralladas en la Extremadura y en la Transierra: a) Zamora (GUTIÉRREZ, 1990); b) Salamanca, modelo de recinto de extraordinarias dimensiones, que crece a parir de otro recinto formado en torno a un primitivo enclave fosilizado (SERRANO-PIEDECASAS y MUÑOZ GARCÍA, 2000: p. 407); c) Ávila, ejemplo de planta regular (RODRÍGUEZ ALMEIDA, 198I: p. 24); d) Toledo es el mejor prototipo de aplicación de todos los estilos y técnicas arquitectónicas ejecutadas a lo largo de los siglos XII y XIII (RUIZ TABOADA, 2004: p. 253); e) Talavera, ciudad andalusí asimilada sin cambios, salvo la incorporación de las torres albarranas (MARTíNEZ LILLO, 1998); f) Madrid, a partir de los recintos andalusíes, A y B, se añade el nuevo espacio cristiano, D (MALALANA y PÉREZ-JUANA, 1999: p. 18); g) Plasencia, ciudad de nueva planta. Plano de Iznardo, 1839 (BARRAGÁN, 2007: p. 63).

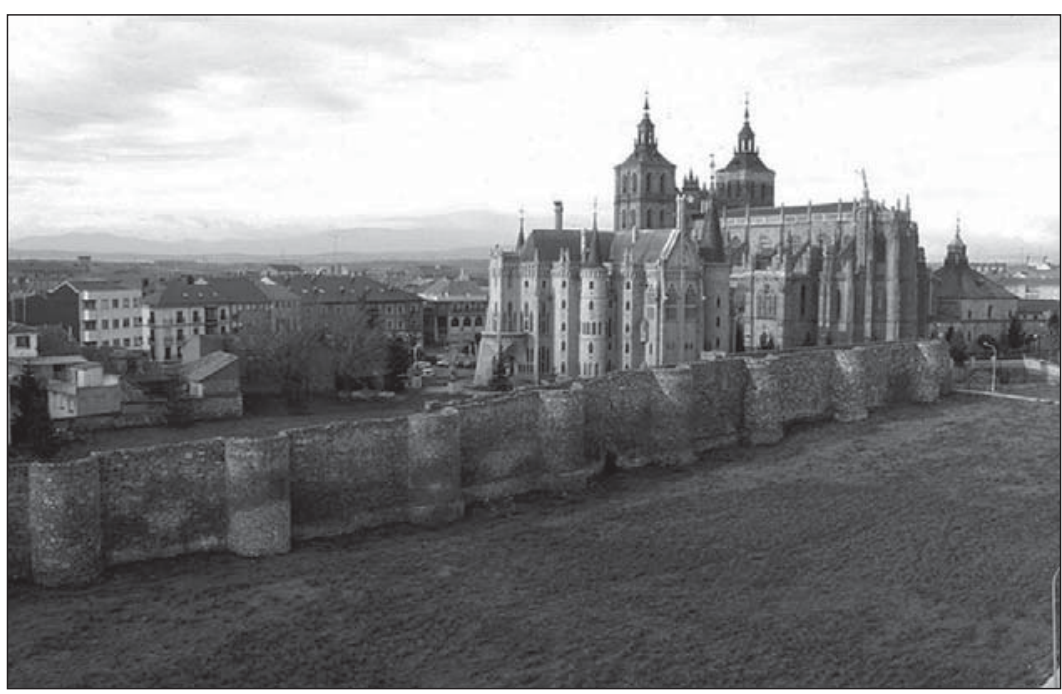

Figura 3. Astorga. Murallas tardorromanas. Este recinto, junto al de León son los modelos seguidos para levantar las grandes ciudades fortaleza castellano leonesas del siglo XII. Fotografía cortesía de Ángel Morillo Cerdán.

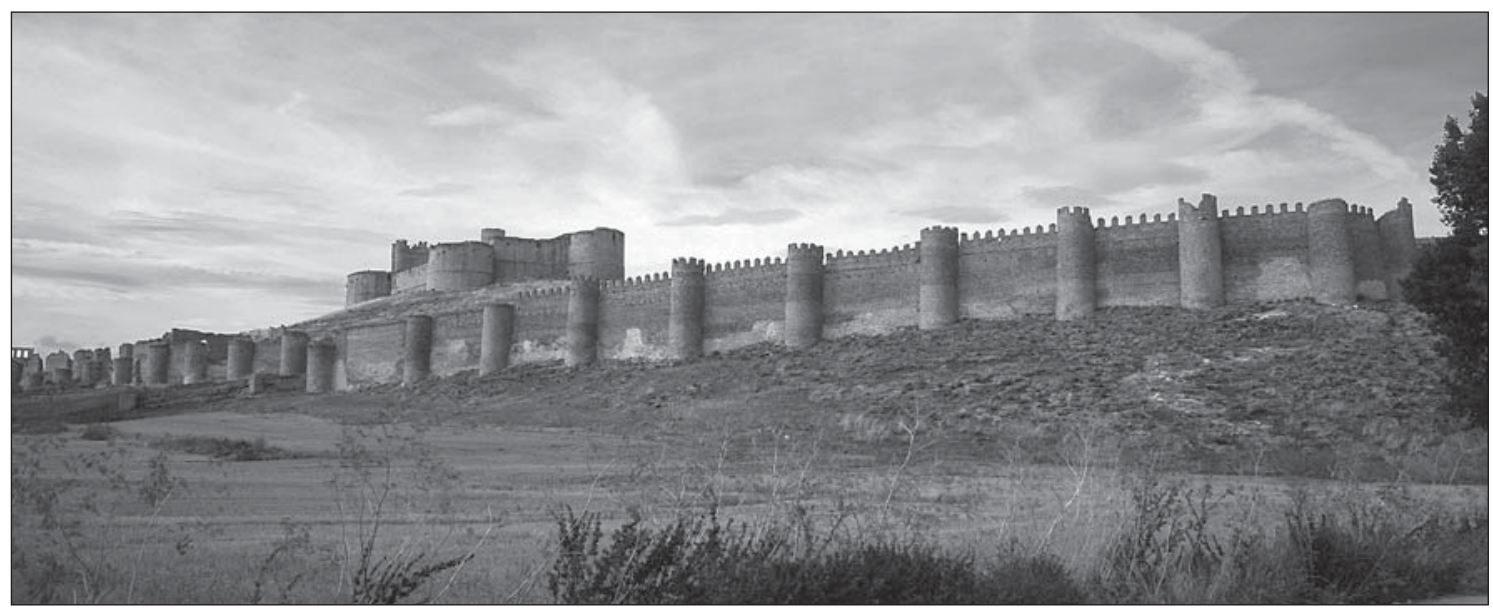

Figura 4. Berlanga de Duero (Soria). El único tramo que se conserva de la "cerca vieja" está constituido por una veintena de torres semicirculares dispuestas en serie. La puerta, rota y tapiada, está protegida por dos torres con la misma planta. La fábrica es de mampostería concertada. 


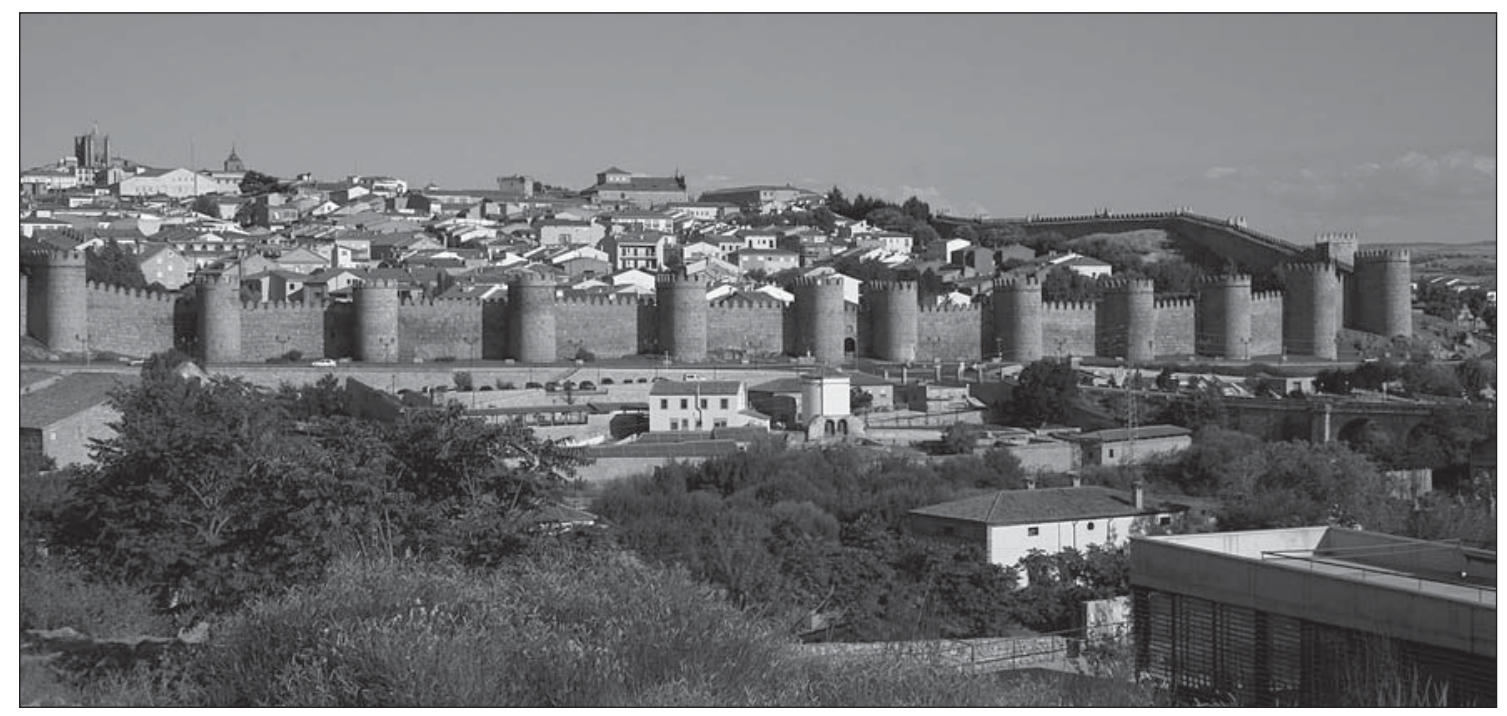

Figura 5a. Ávila. Frente y puerta del Río. Las torres son de planta ultrasemicircular y el acceso a la ciudad es directo. Observamos como todo el tramo se adapta a la topografía, tanto es así, que las dos torres de flanqueo de la puerta no están niveladas.

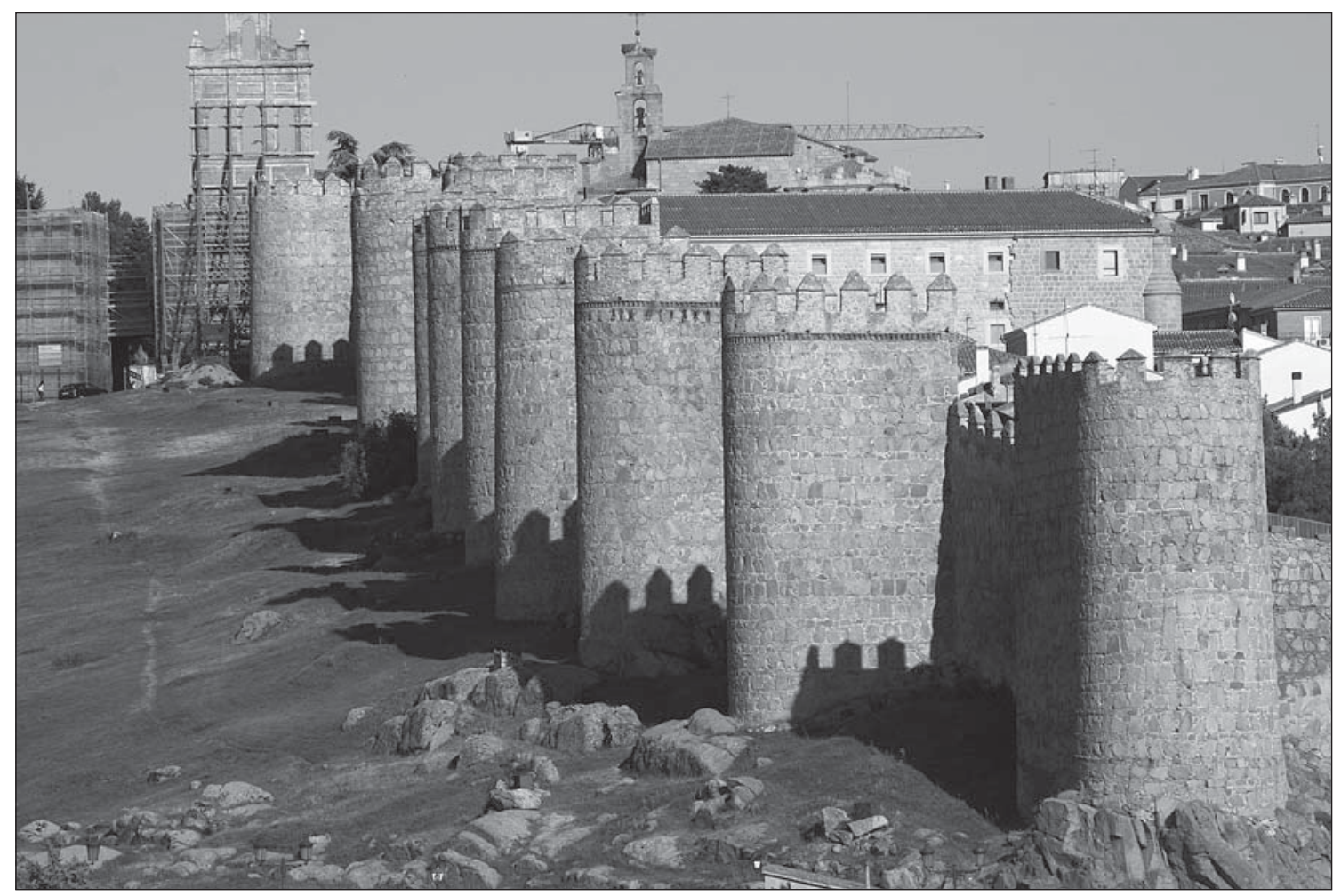

Figura 5b. Ávila. Sector Cubo de las Mulas a de San Segundo. En esta vista se puede comprobar cómo la planta de las torres, ultrasemicircular, en una disposición avanzada, permite flanquear los paños desde mejores posiciones. 


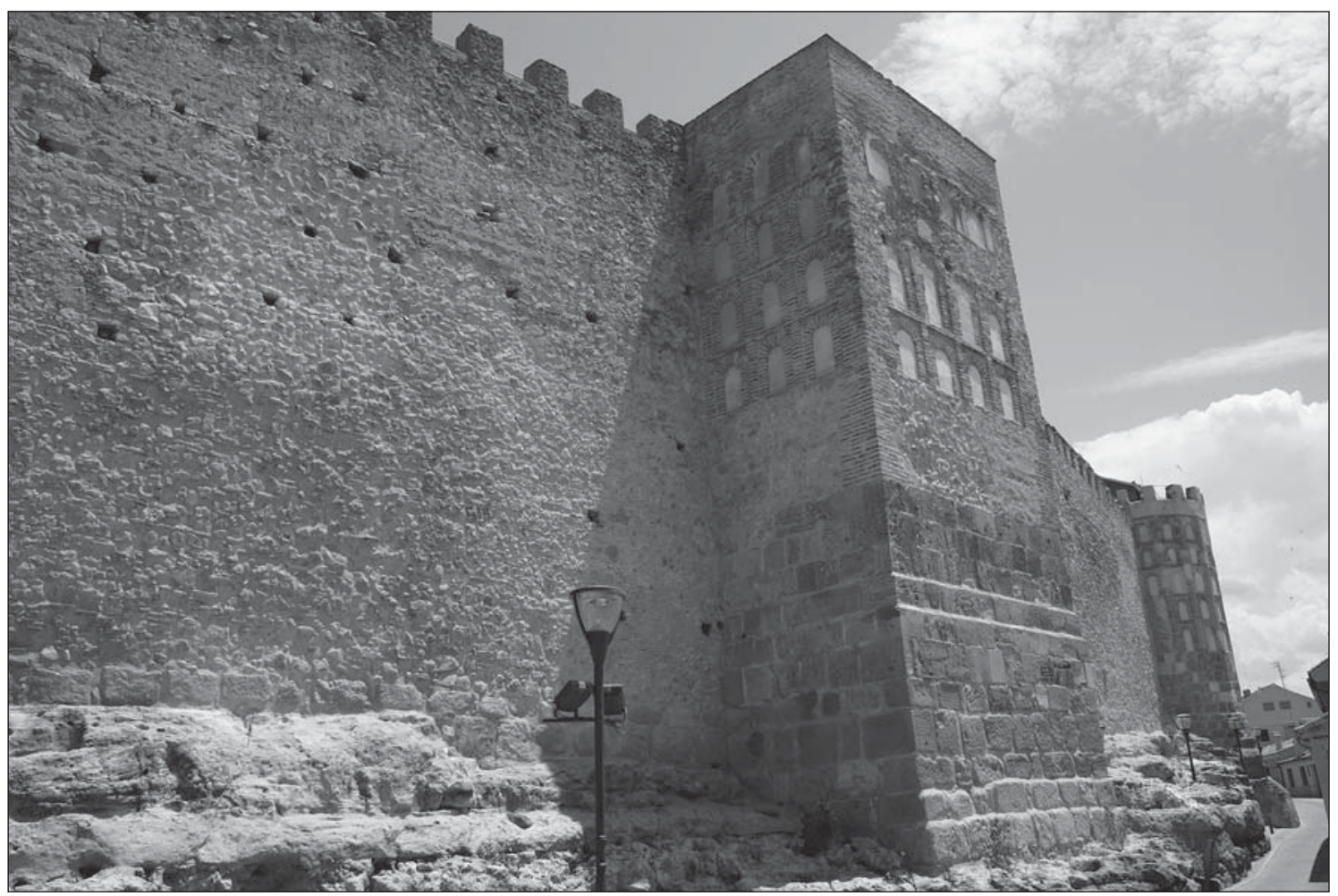

Figura 6a. Segovia. Frente del Paseo del Salón de Isabel II. Alguna de las torres utiliza como zócalo una estructura cuadrangular, zarpa que Juan Zozaya ha interpretado como perteneciente a una fortificación anterior andalusí (ZOZAYA, 2008: 27).

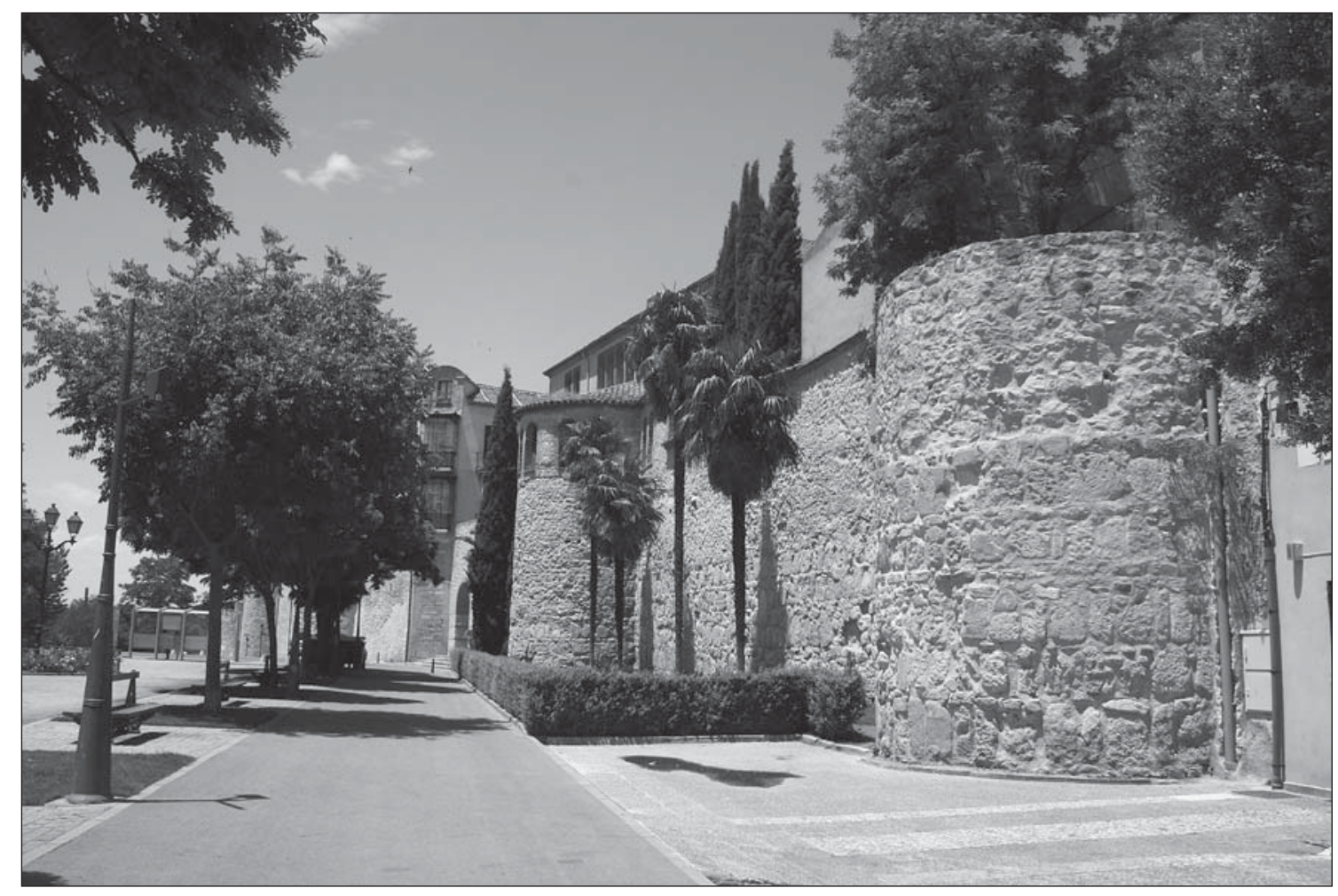

Figura 6b. Segovia. Tramo puerta de San Andrés Calle Arturo Merino. En la primera de las torres, la fabrica muestra como los mampuestos, regularmente trabajados, se disponen a espejo; estilo similar al utilizado en Ávila y Sigüenza. 


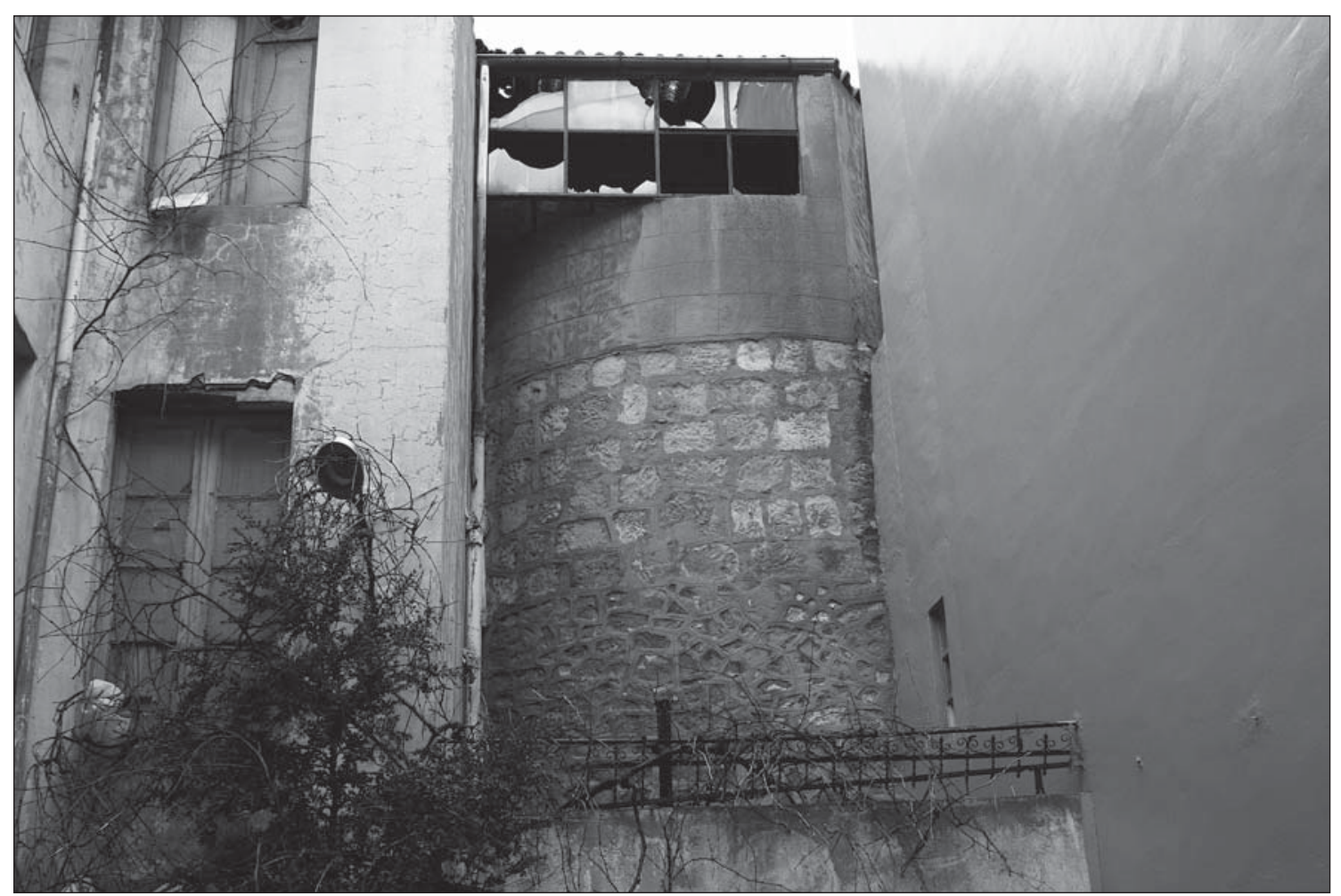

Figura 7. Soria. Cubo semicircular parcialmente oculto entre los edificios.

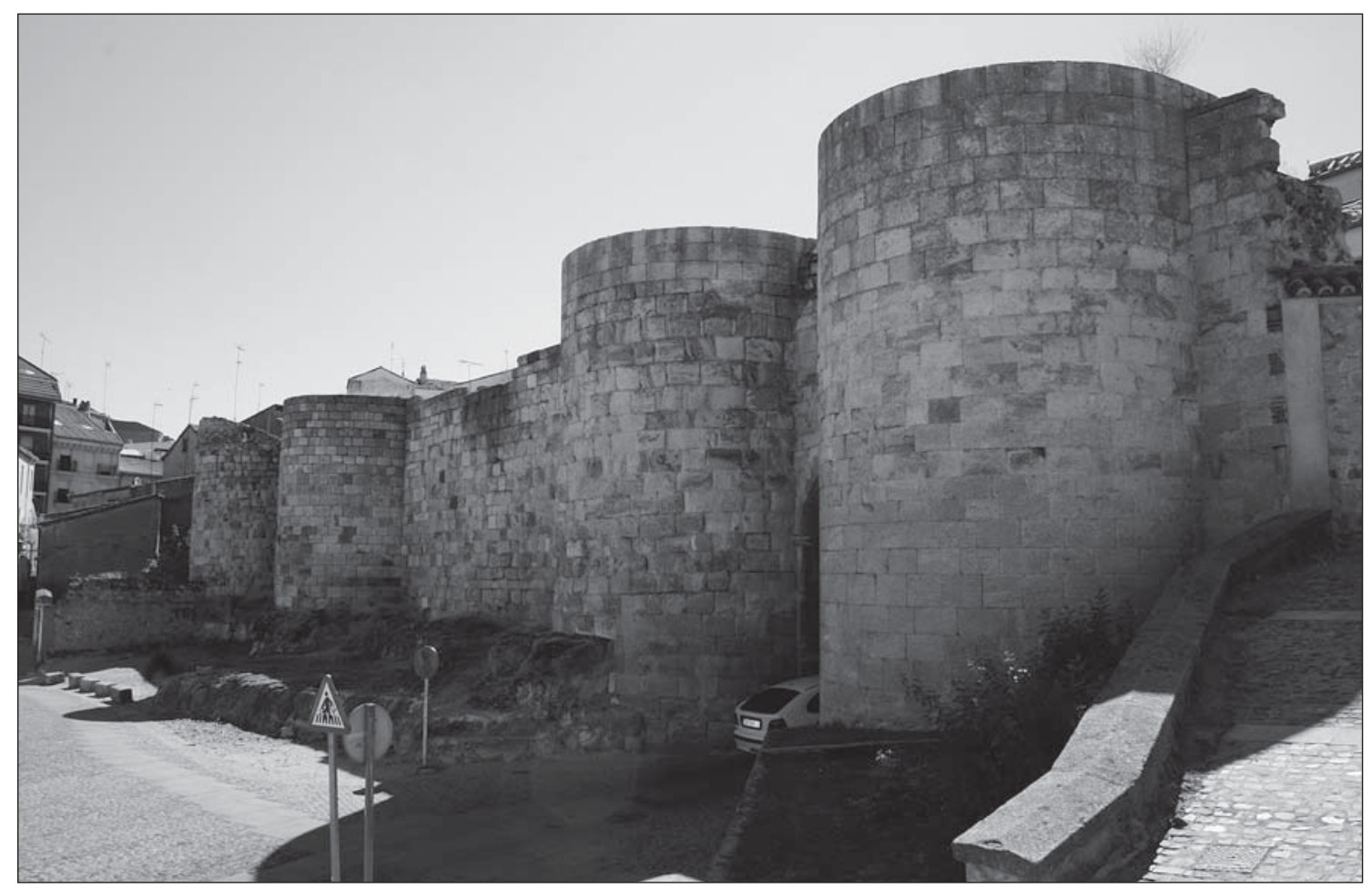

Figura 8. Zamora. Frente de la puerta de Doña Urraca. El estrecho acceso está protegido por dos torres cilíndricas. El sector está defendido por otras dos torres. La fábrica es regular. Entre otros detalles es la presencia de pequeñas aberturas o desagües en la parte inferior de los muros. 


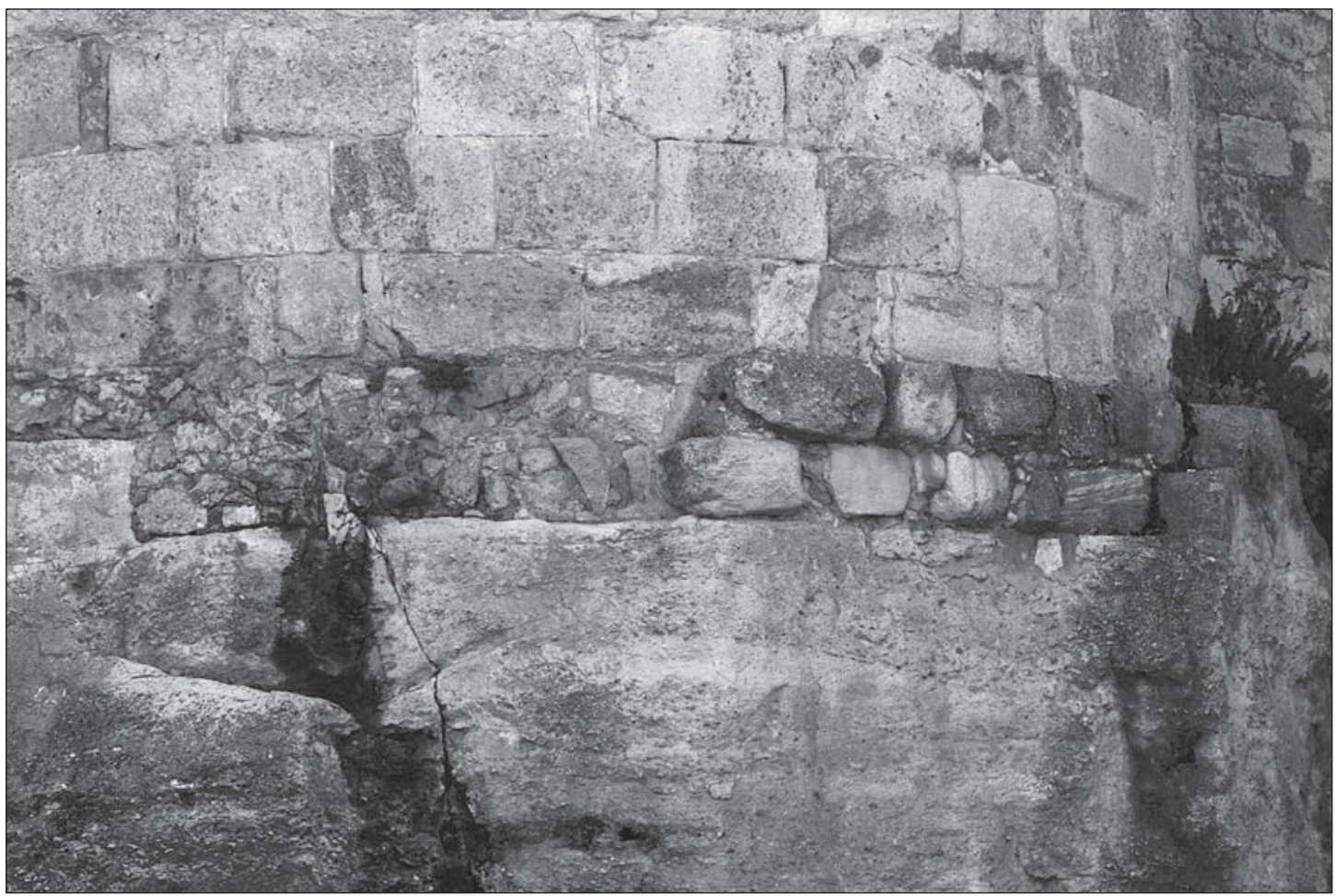

Figura 9. Zamora. Cimentación excavada en la roca y parte del alzado regular de una de las torres.

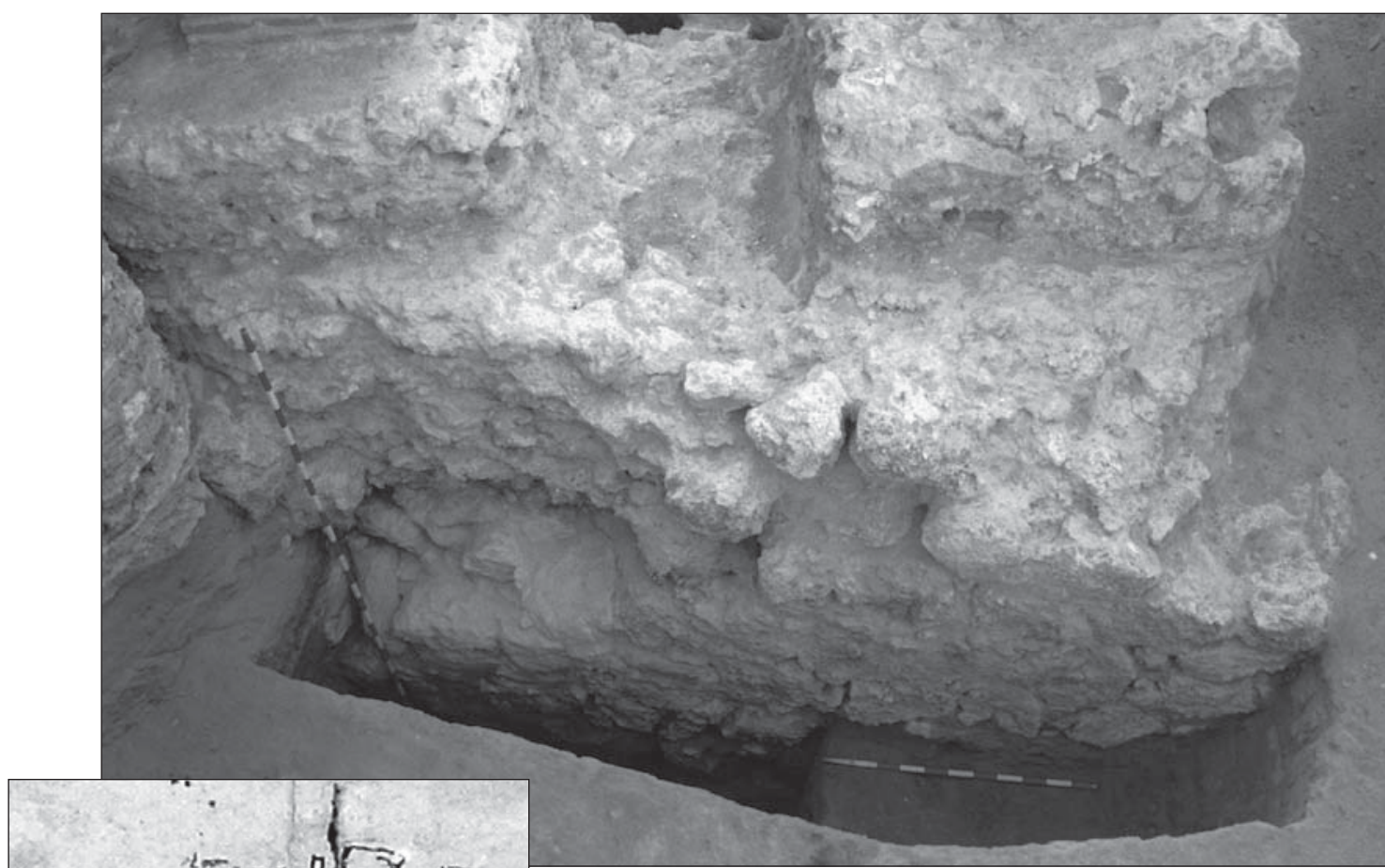

Figura IOa. Madrid. Intervención arqueológica de la Almería. Detalle de la cimentación escalonada del frente del albacar sobre el río Manzanares. Fotografía cortesía de Arqueomedia.

Figura IOb. Madrid. La cimentación escalonada de la imagen anterior se traslada, manteniendo el mismo perfil escalonado, al lienzo. Vista de Anton van Wyngaerde. 

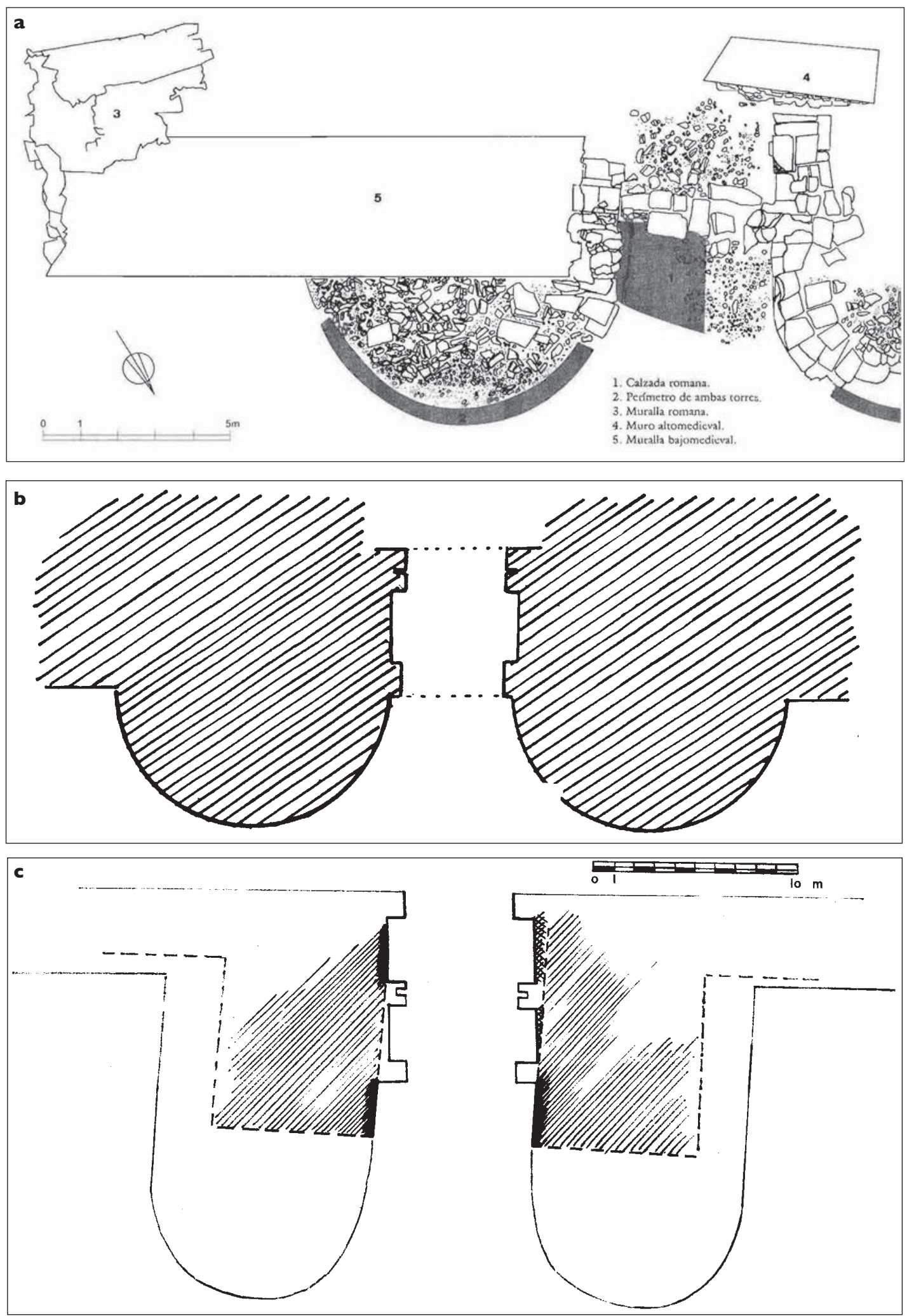

Figura I I. Plantas de puertas de acceso simple flanqueadas por torres semicirculares: a) Puerta de Hierro del recinto de Asturica Augusta (FERNÁNDEZ OCHOA y MORILLO, 2006: p. 268). Sin duda, el modelo de puerta bajoimperial fue el aplicado en los accesos abiertos en las murallas de las ciudades fortaleza de la segunda mitad del siglo XIl; b) Zamora, Puerta de Doña Urraca (RAMOS DE CASTRO, 1978); c) Ávila, Puerta de San Vicente. En este caso, la puerta absorbe otra anterior, también cristiana, edificada a principios del XII. Sobresale la planta de las torres de flanqueo, que aquí son ultrasemicirculares (RODRÍGUEZ ALMEIDA, 198I: p. 28). 


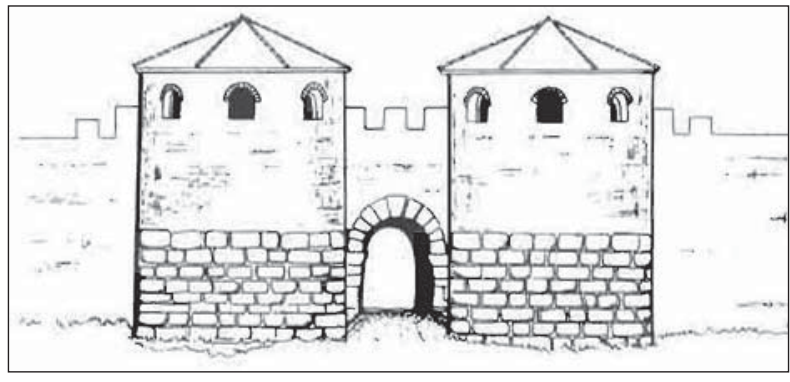

Figura I 2. Asturica Ausgusta. Reconstrucción de la Puerta de Hierro, en donde destacan las torres semicirculares de flanqueo (FERNÁNDEZ OCHOA y MORILLO, 2006: p. 268).

Figura I3. Zamora. Puerta de Doña Urraca.
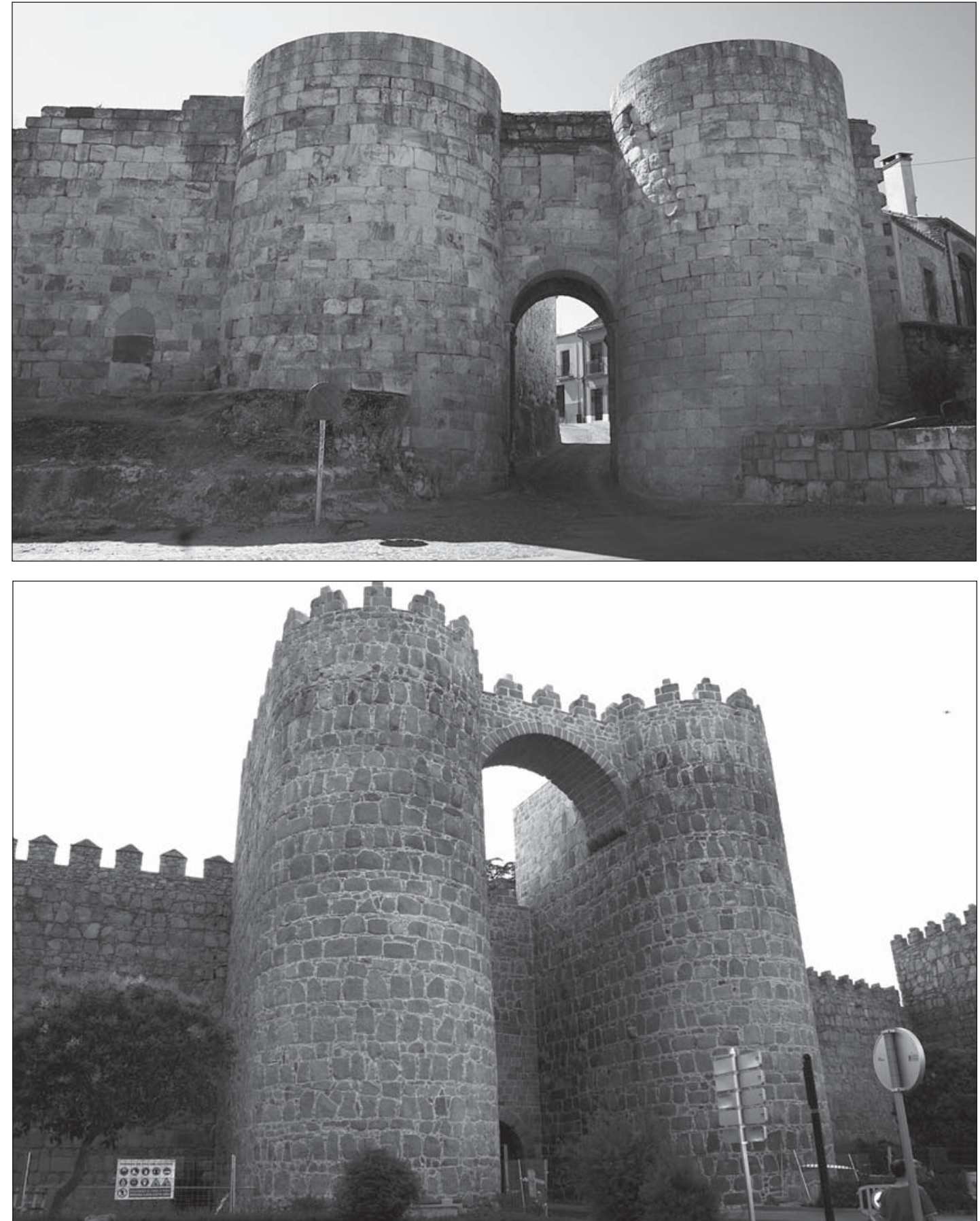

Figura I4. Ávila. Puerta de San Vicente. Acceso directo protegido por dos torres ultrasemicirculares de flanqueo. En una de las torres puede observarse como ha quedado integrada otra cuadrangular que pertenece a otra fase anterior, posiblemente de finales del XI o principios del XII. La fábrica es a espejo. 


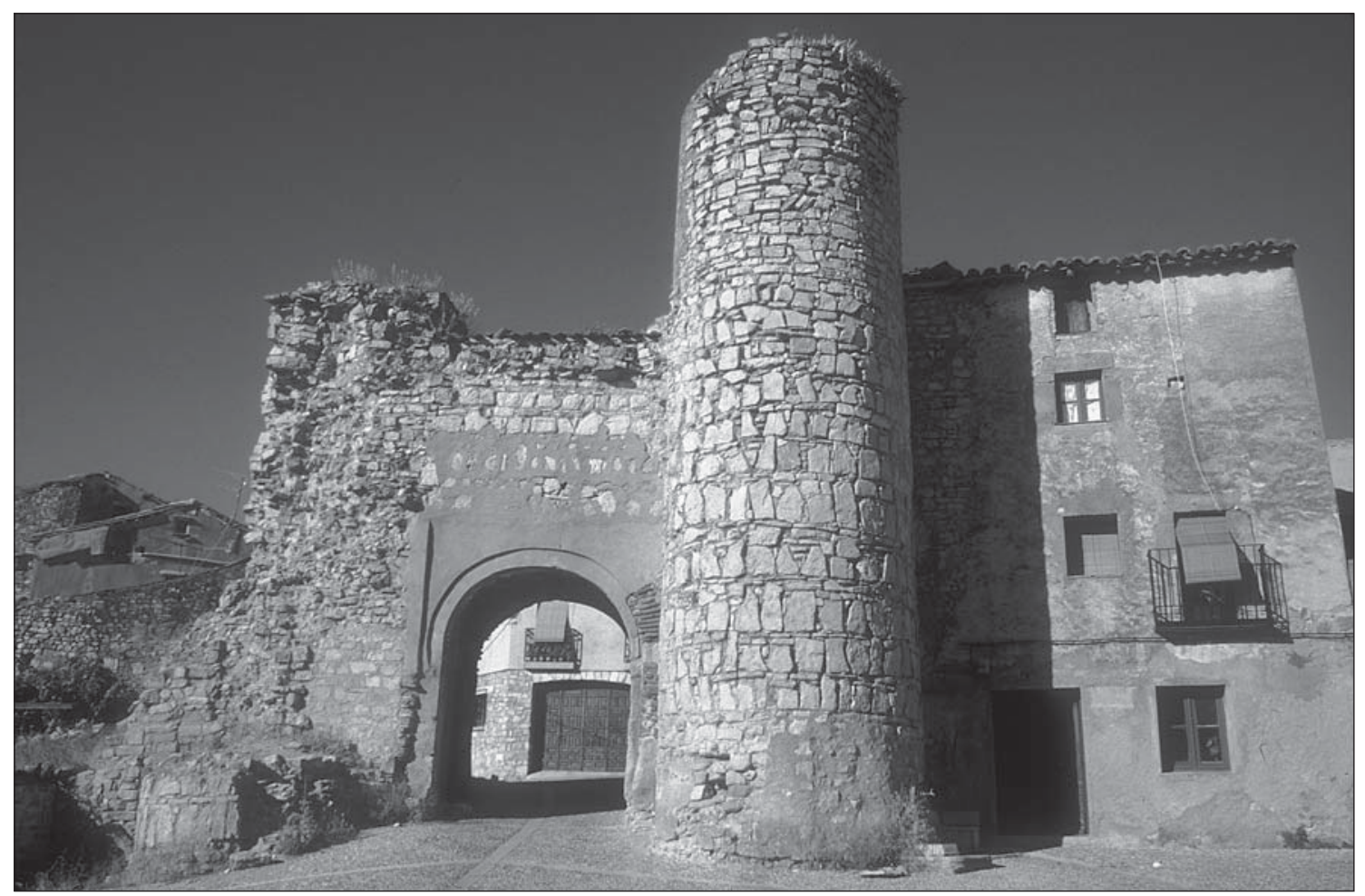

Figura I 5. Sigüenza (Guadalajara). Puerta de Hierro. La fábrica es a espejo similar a la utilizada en Ávila.

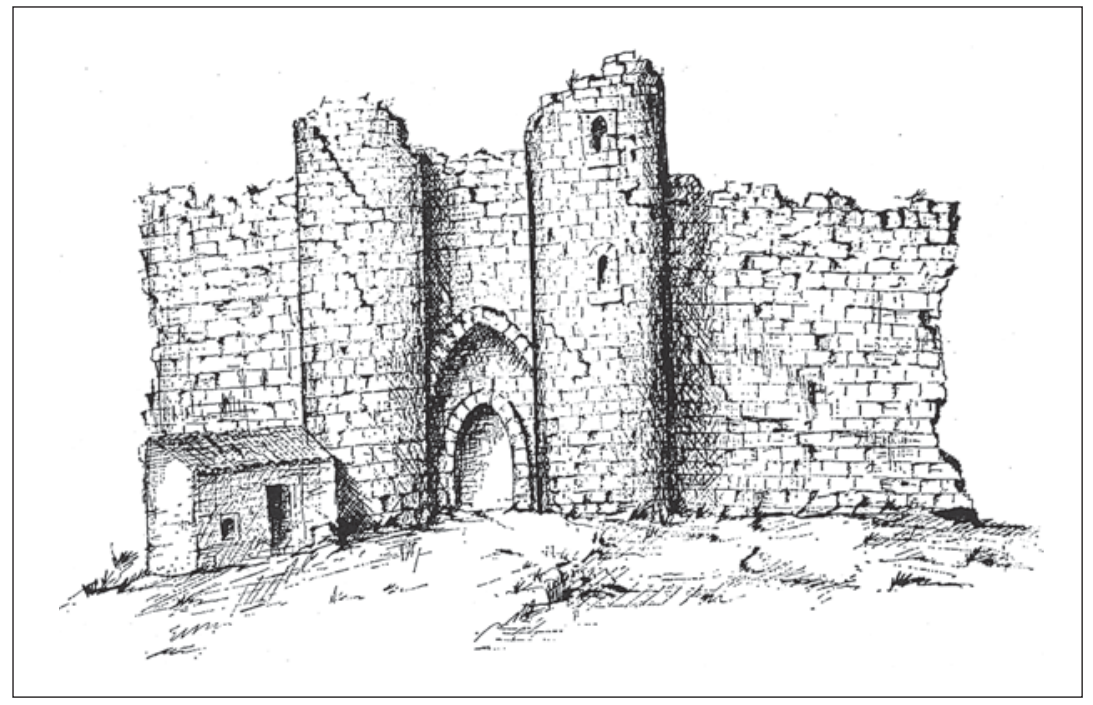

Figura I6. Salamanca. Puerta de Villamayor (VARGAS AGUILAR, 1974: 14). 


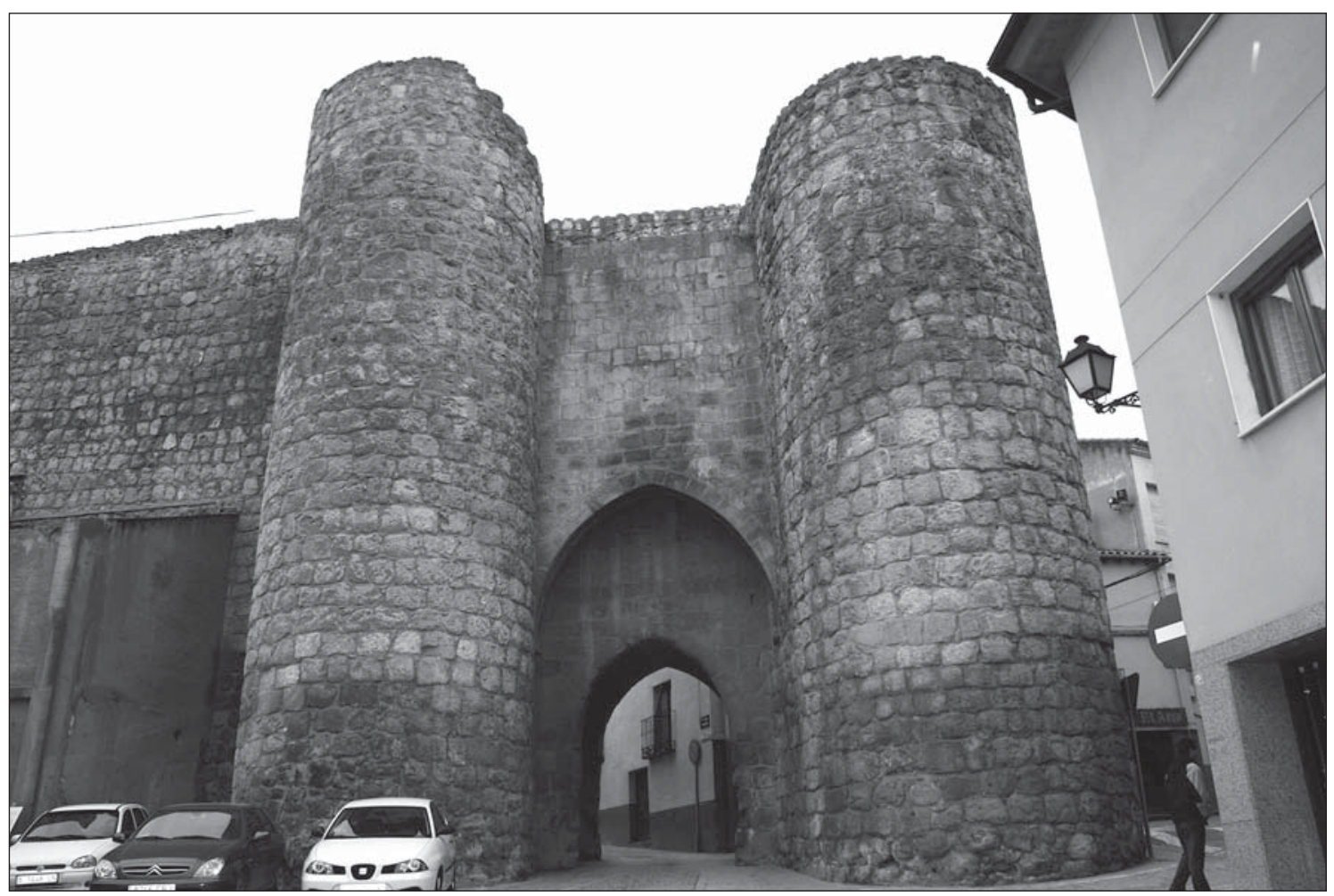

Figura I7. Almazán (Soria). Puerta de Herreros.

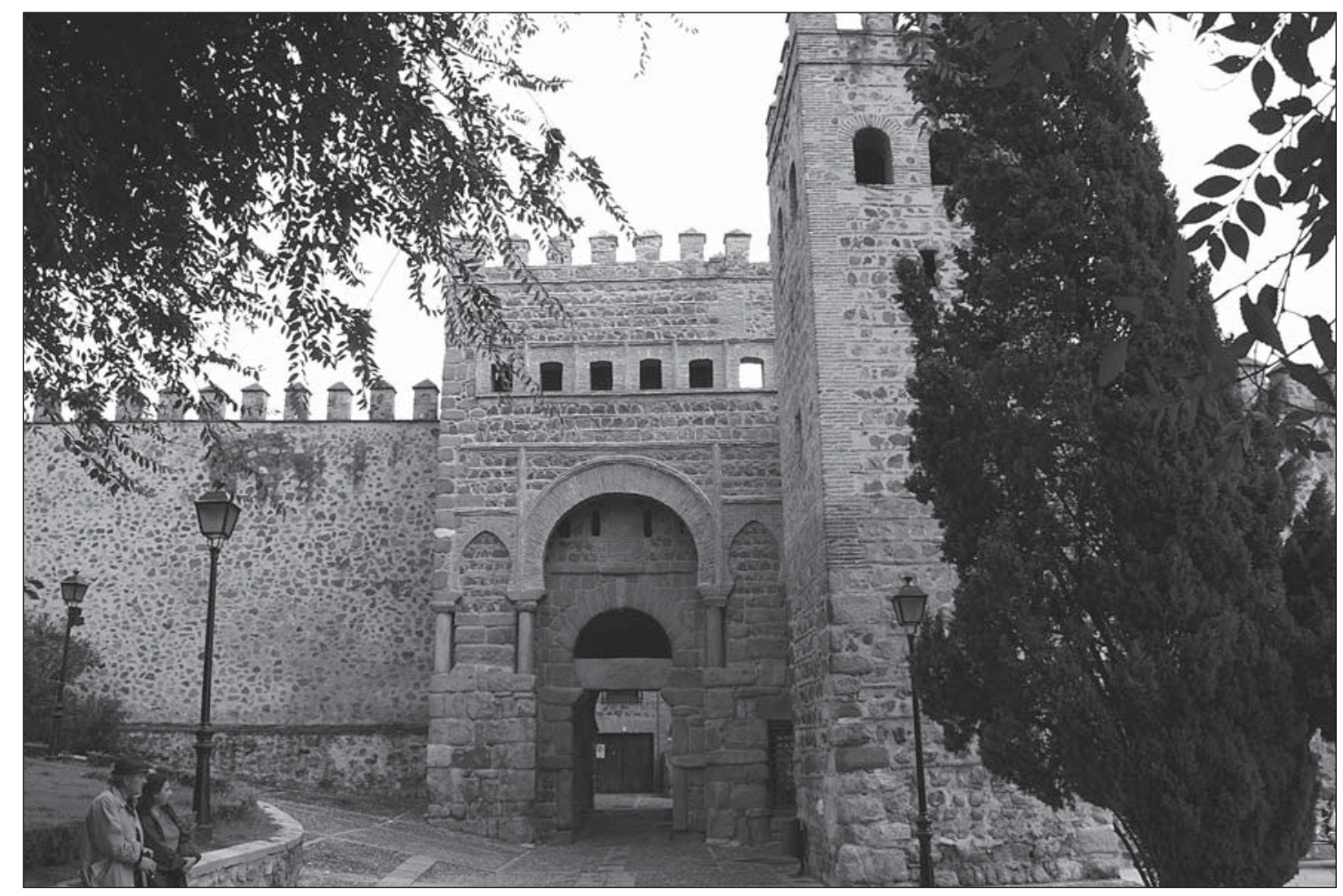

Figura I8. Toledo. Puerta de Bisagra Vieja. Fachada exterior. El estilo evoluciona dejando atrás el románico, ahora se adopta el mudéjar. 


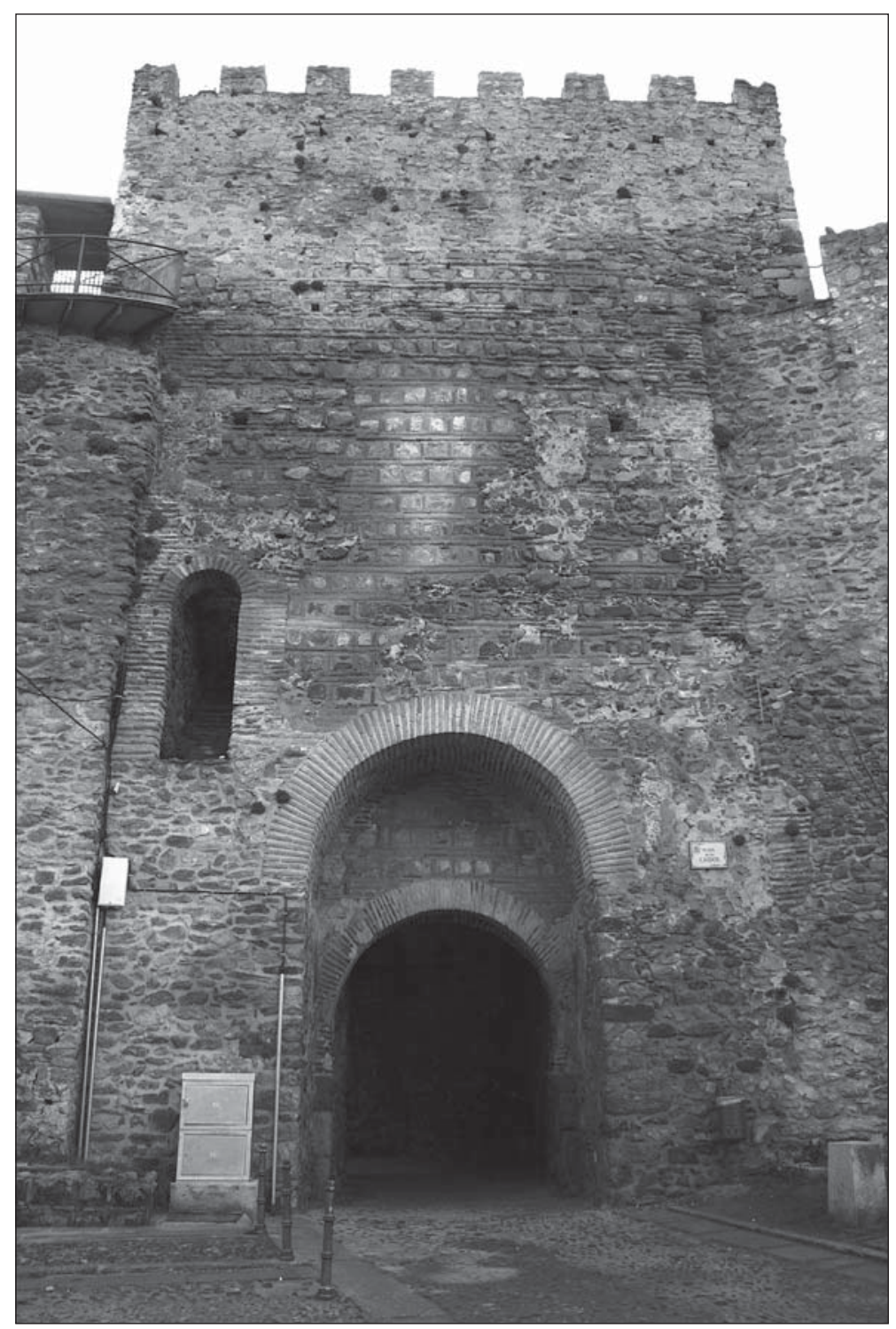

Figura 19. Buitrago (Madrid). Puerta del Reloj. Fachada interior. Estructura de factura mudéjar y cuya fábrica es el aparejo toledano. Destaca la puerta en altura para acceder a las plantas superiores.

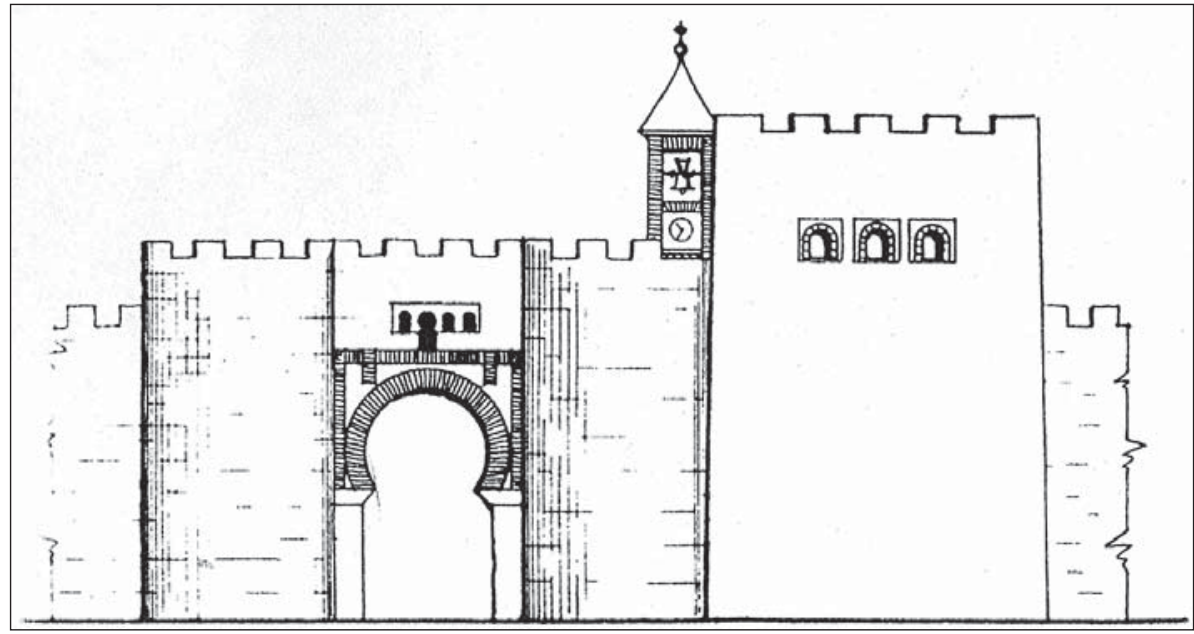

Figura 20. Madrid. Puerta de Guadalajara (GÓMEZ IGLESIAS, I95I). 


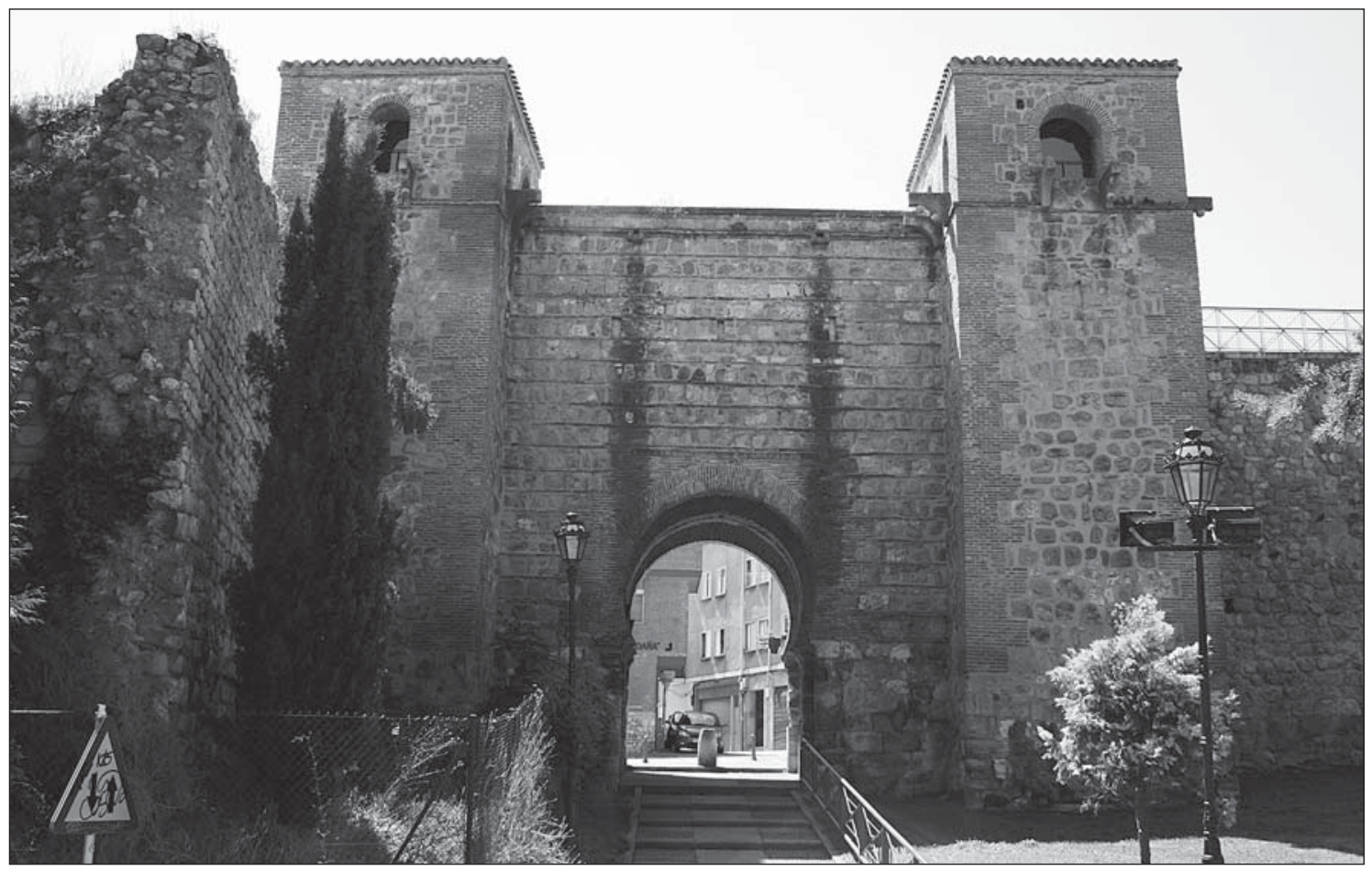

Figura 2 I. Burgos. Puerta de San Esteban. Fachada exterior.

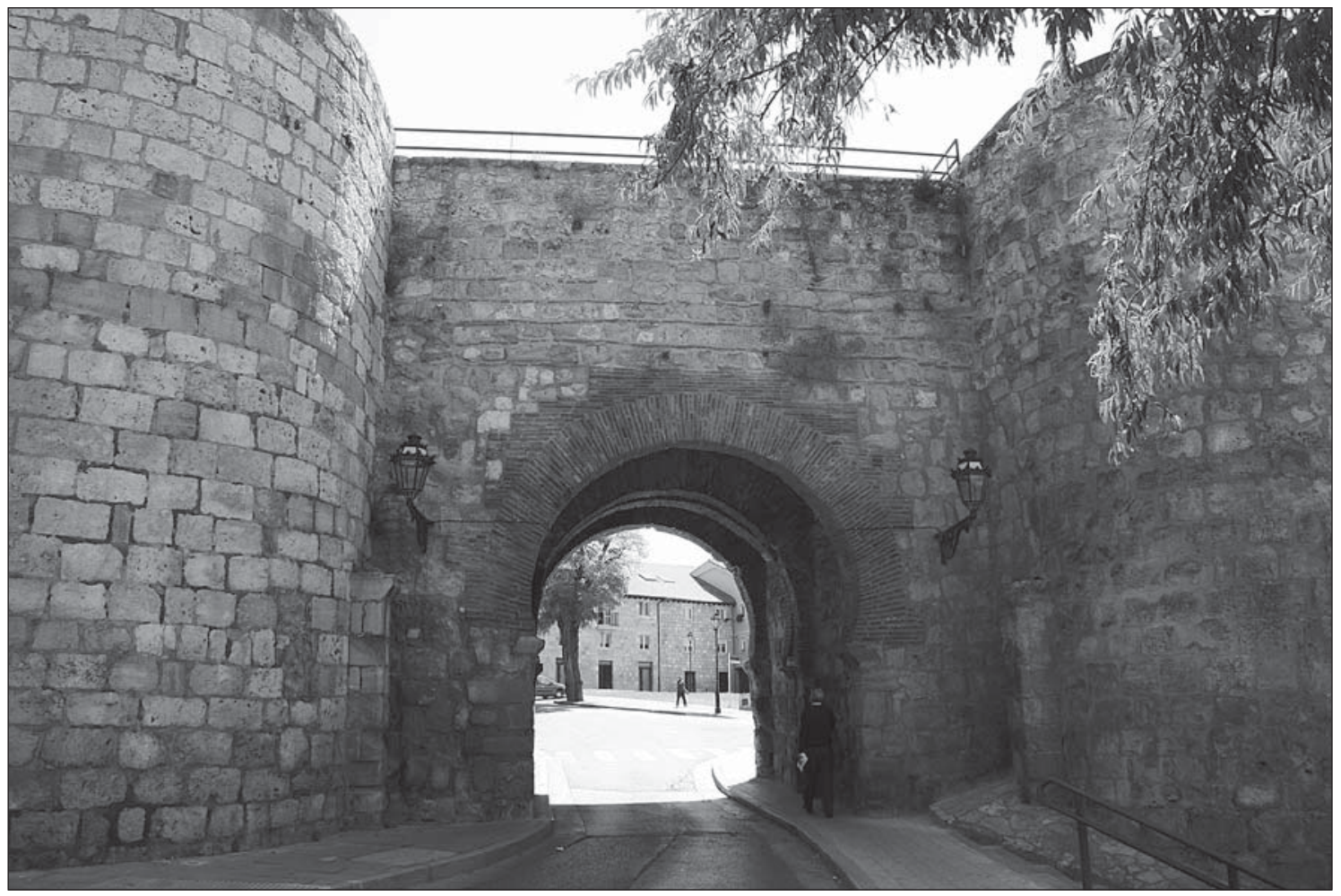

Figura 22. Burgos. Puerta de San Martín. Fachada exterior. La puerta ha sido edificada entre dos torres de flanqueo semicirculares, estructuras que debieron pertenecer a una fase anterior de la muralla burgalesa. 


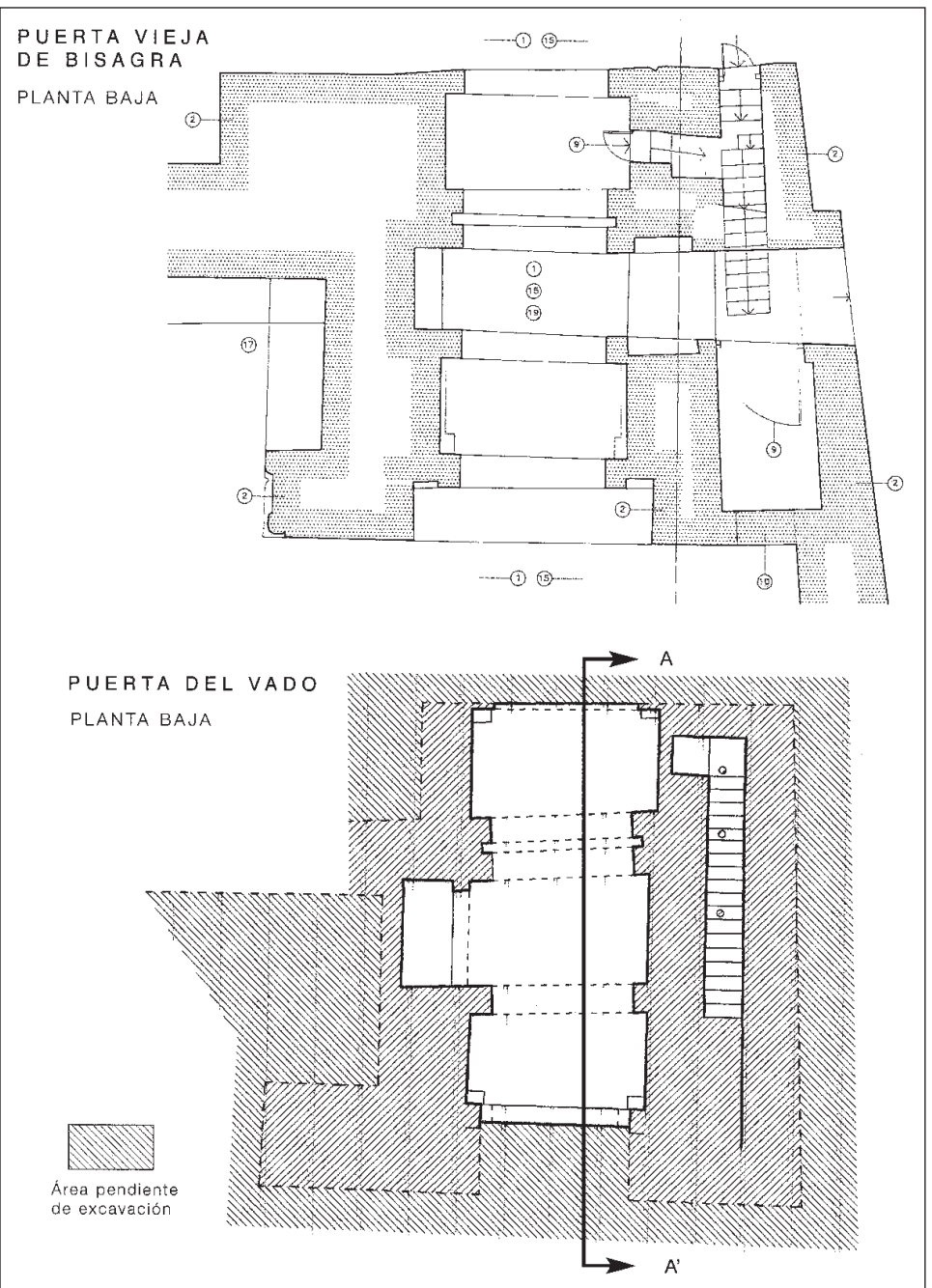

Figura 23. Planta baja de las puertas de Bisagra Vieja y del Vado de Toledo (PONCE DE LEON, 2004: p. 278).

Figura 24. Toledo. Puerta de Bisagra Vieja. Fachada intramuros.

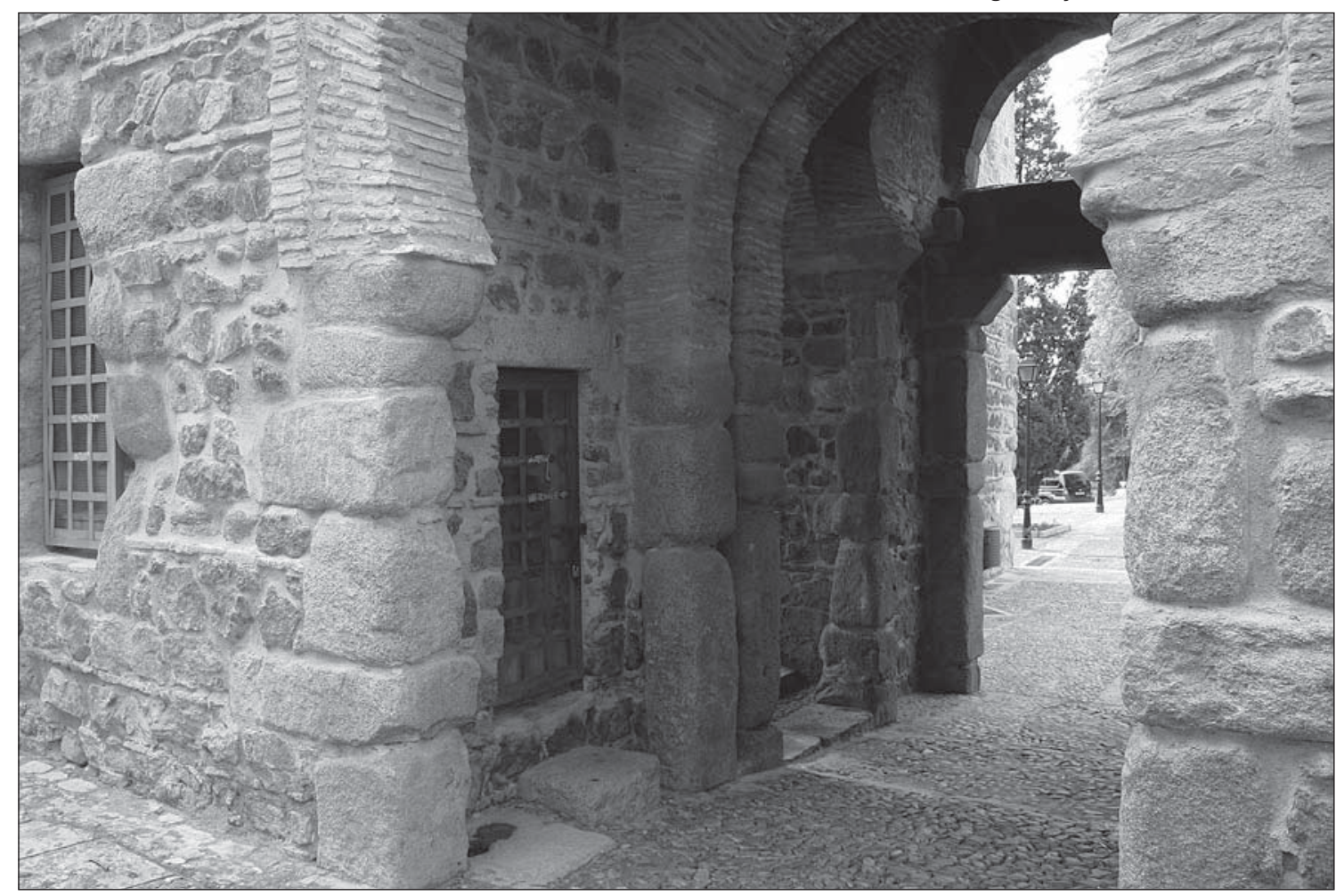




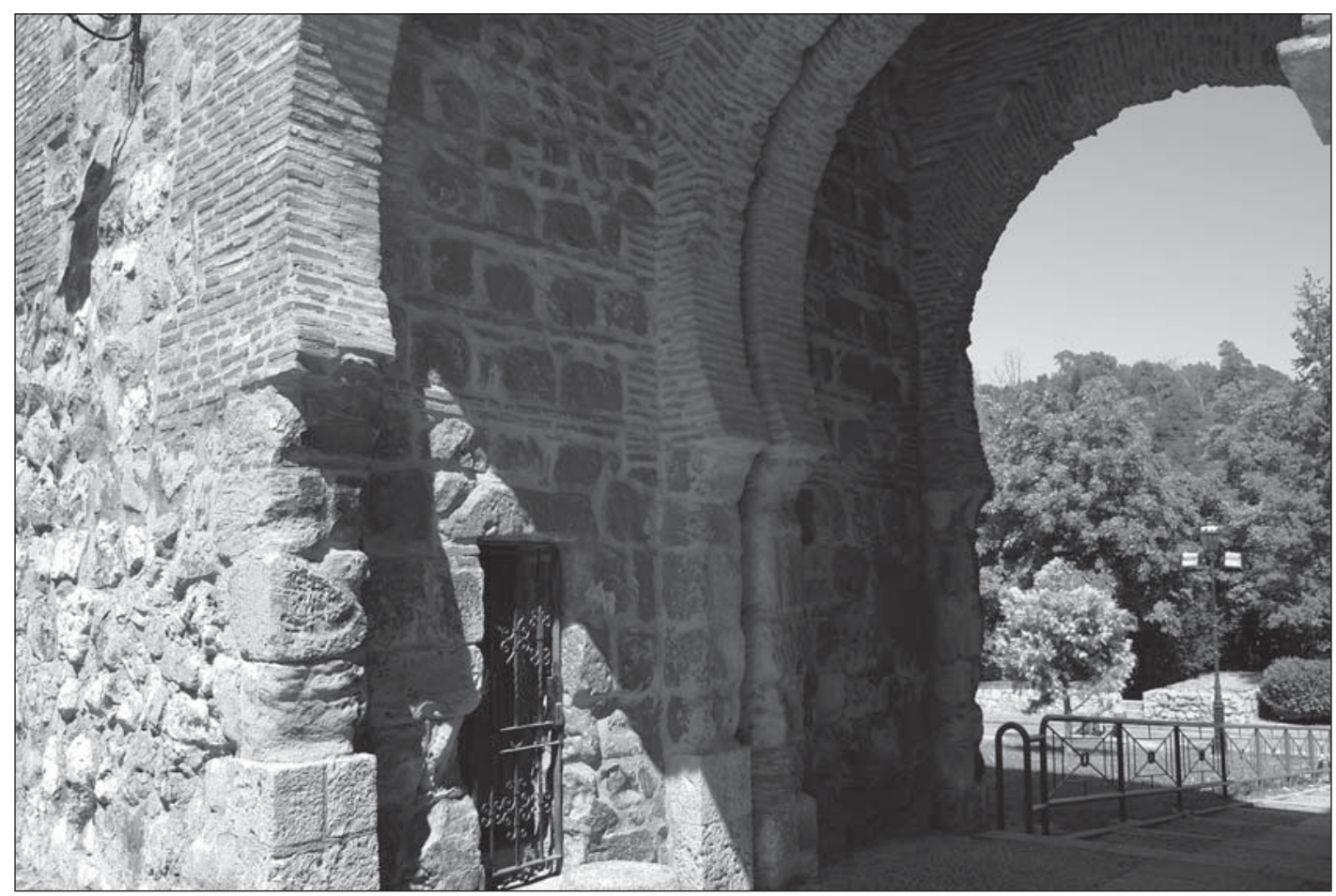

Figura 25. Burgos. Puerta de San Esteban. Fachada intramuros. Casi gemela de la anterior, observamos varias de sus características: La compartimentación de los tres espacios interiores en el pasillo; las jambas de los arcos son de sillares y las roscas de ladrillo; entre los arcos gemelos intermedios se desliza el rastrillo; el portillo que permite el acceso a las plantas superiores tiene la misma ubicación; o el aparejo tipo Al toledano.

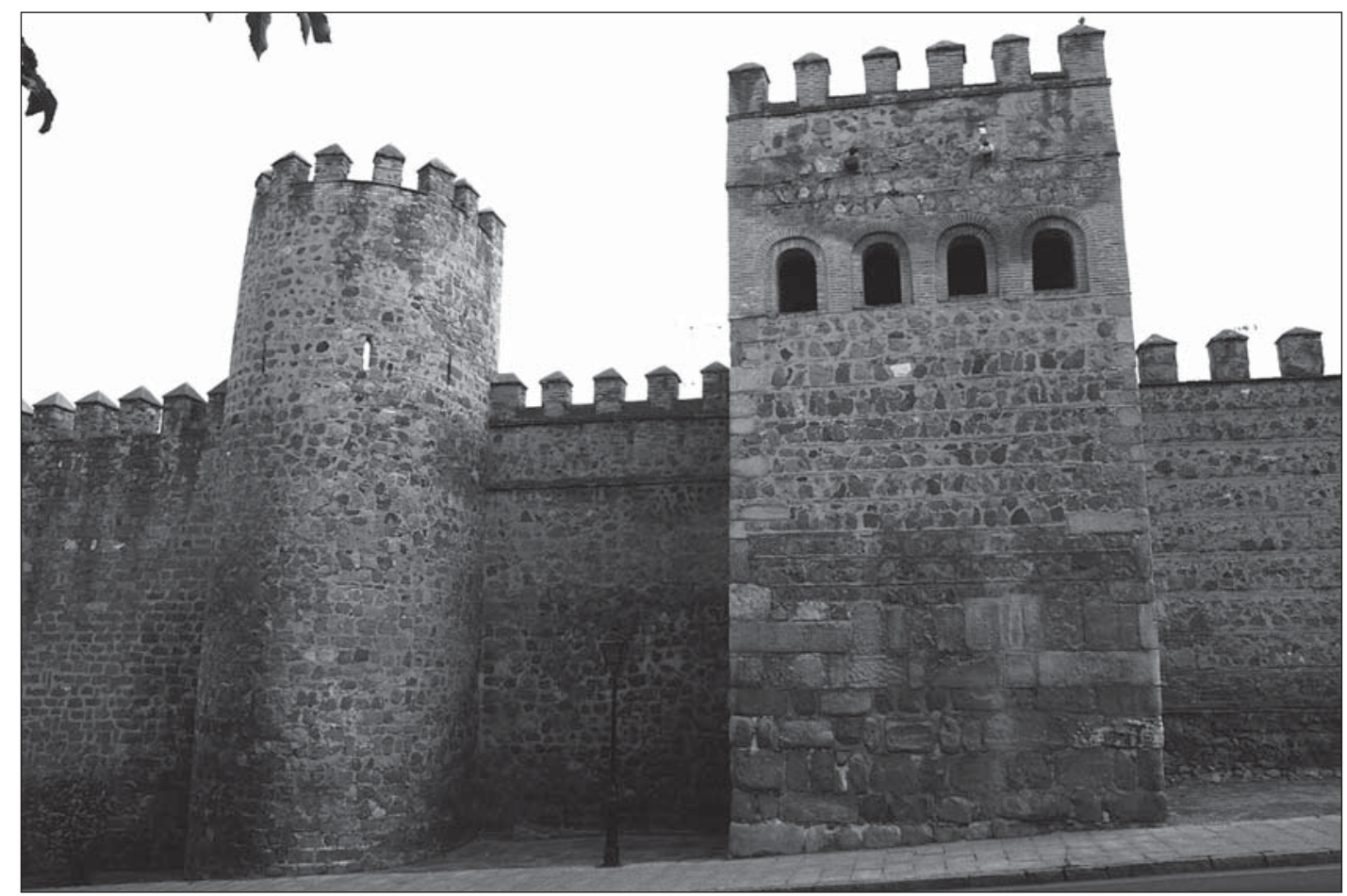

Figura 26. Toledo. Entorno de la Torre de la Reina, en donde se comprueba la sucesión de fases constructivas, torres semicirculares y torres cuadrangulares. En estas últimas la fábrica se caracteriza por disponer de un fuerte y alto zócalo de sillares, mientras que el resto de la construcción es de aparejo toledano tipo Al, similar al empleado en las puertas del Vado, Bisagra y Bisagra Vieja. 


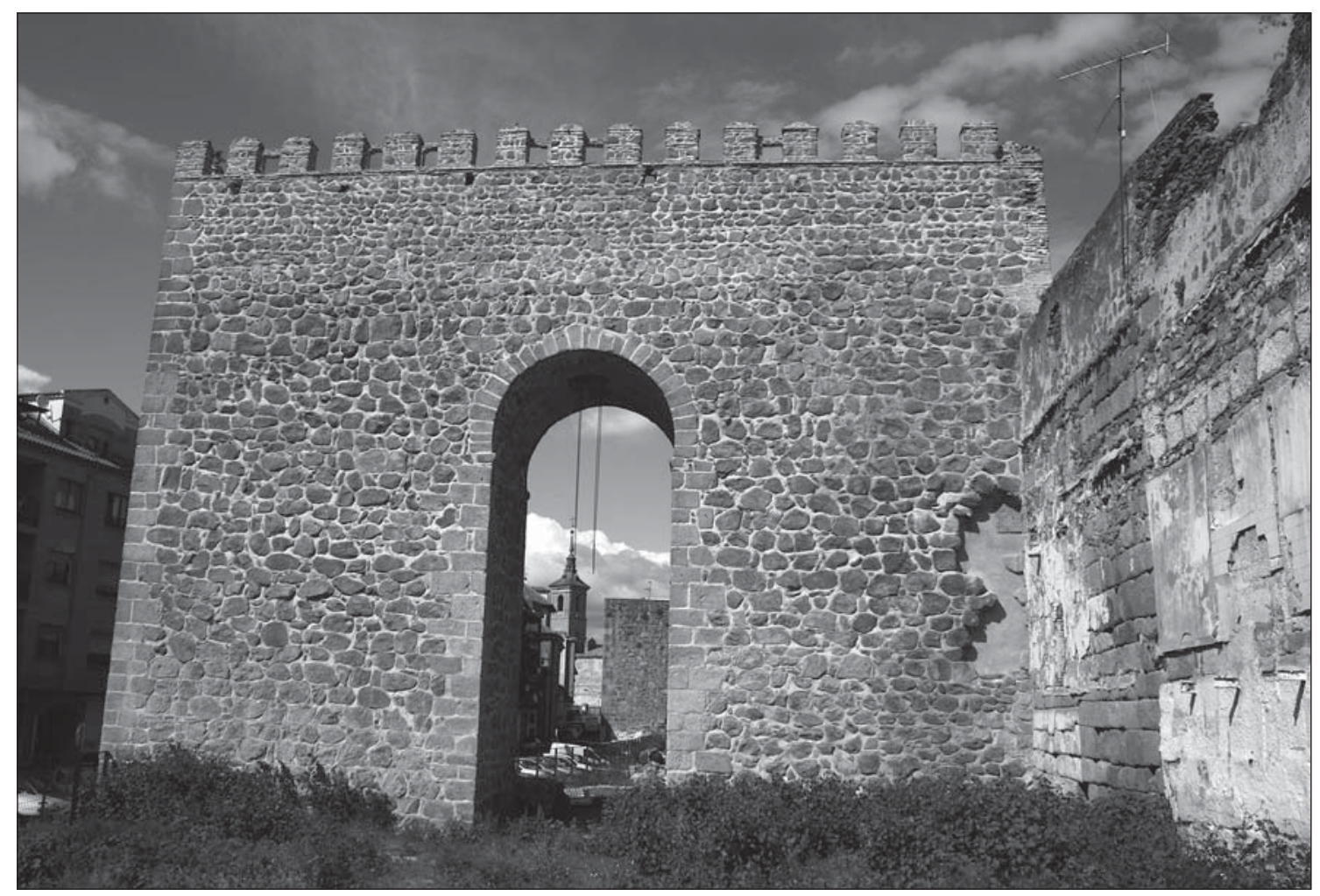

Figura 27. Talavera (Toledo). Ejemplo de torre albarrana dispuesta en serie. Una de las principales característica es su fábrica, de mampostería concertada, frente al aparejo utilizado en el resto de las albarranas cristianas que es el mudéjar. Este detalle, sitúa a Talavera como uno de los primeros lugares en levantar torres de éste tipo. Asimismo, podemos comprobar cómo ésta gran estructura fue construida embutiendo una de las torres cuadrangulares de los recintos andalusíes.

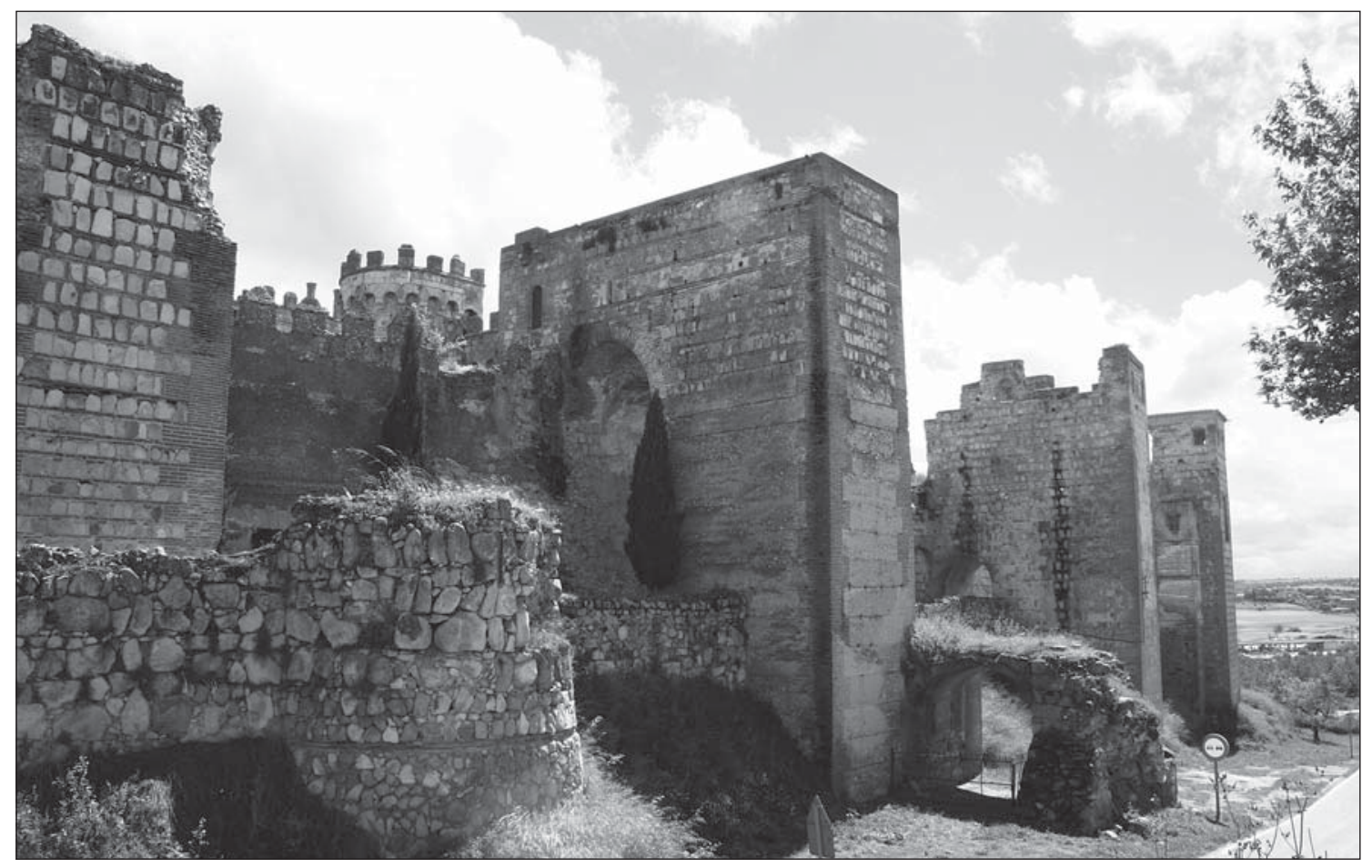

Figura 28. Escalona (Toledo). Línea de albarranas de la fortaleza dispuestas en serie en el frente que se defiende hacia el interior de la ciudad. 